\title{
The burden of disease and injury in the United States 1996
}

Catherine M Michaud*1, Matthew T McKenna22, Stephen Begg3, Niels Tomijima ${ }^{4}$, Meghna Majmudar' ${ }^{5}$, Maria T Bulzacchelli6, Shahul Ebrahim ${ }^{2}$, Majid Ezzati ${ }^{1}$, Joshua A Salomon ${ }^{1}$, Jessica Gaber Kreiser, Mollie Hogan ${ }^{3}$ and Christopher JL Murray ${ }^{1}$

Address: ${ }^{1}$ Harvard Initiative for Global Health, Harvard University, $104 \mathrm{Mt}$ Auburn Street, Cambridge, MA 02138, USA, ${ }^{2}$ Centers for Disease Control and Prevention, 1600 Clifton Road MS E-47, Atlanta, Georgia 30333, USA, ${ }^{3}$ School of Population Health, The University of Queensland, Brisbane, Australia, ${ }^{4}$ Columbia University in the City of New York, 2960 Broadway, New York, NY 10027-6902, USA, ${ }^{5}$ Haas School of Business, 545 Student Services \#1900, University of California, Berkeley, CA 94720-1900, USA and 'Bloomberg School of Public Health, Johns Hopkins University, 615 N. Wolfe Street, Baltimore, MD 21205, USA

Email: Catherine M Michaud* - cmichaud@hsph.harvard.edu; Matthew T McKenna - mtm1@cdc.gov; Stephen Begg - s.begg@sph.uq.edu.au; Niels Tomijima -nmt2102@columbia.edu; Meghna Majmudar - mmajmud@yahoo.com; Maria T Bulzacchelli - mbulzacc@jhsph.edu; Shahul Ebrahim - sbe2@cdc.gov; Majid Ezzati - mezzati@hsph.harvard.edu; Joshua A Salomon - jsalomon@hsph.harvard.edu; Jessica Gaber Kreiser - jessicakreiser@hotmail.com; Mollie Hogan - m.hogan@sph.uq.edu.au; Christopher JL Murray - christopher_murray@harvard.edu

* Corresponding author

Published: 18 October 2006

Population Health Metrics 2006, 4:1I doi:10.1 I86/1478-7954-4-1I
Received: 14 November 2005

Accepted: 18 October 2006

This article is available from: http://www.pophealthmetrics.com/content/4/I/I I

(C) 2006 Michaud et al; licensee BioMed Central Ltd.

This is an Open Access article distributed under the terms of the Creative Commons Attribution License (http://creativecommons.org/licenses/by/2.0), which permits unrestricted use, distribution, and reproduction in any medium, provided the original work is properly cited.

\begin{abstract}
Background: Burden of disease studies have been implemented in many countries using the DisabilityAdjusted Life Year (DALY) to assess major health problems. Important objectives of the study were to quantify intra-country differentials in health outcomes and to place the United States situation in the international context.
\end{abstract}

Methods: We applied methods developed for the Global Burden of Disease (GBD) to data specific to the United States to compute Disability-Adjusted Life Years. Estimates are provided by age and gender for the general population of the United States and for each of the four official race groups: White; Black; American Indian or Alaskan Native; and Asian or Pacific Islander. Several adjustments of GBD methods were made: the inclusion of race; a revised list of causes; and a revised algorithm to allocate cardiovascular disease garbage codes to ischaemic heart disease. We compared the results of this analysis to international estimates published by the World Health Organization for developed and developing regions of the world.

Results: In the mid-1990s the leading sources of premature death and disability in the United States, as measured by DALYs, were: cardiovascular conditions, breast and lung cancers, depression, osteoarthritis, diabetes mellitus, and alcohol use and abuse. In addition, motor vehicle-related injuries and the HIV epidemic exacted a substantial toll on the health status of the US population, particularly among racial minorities. The major sources of death and disability in these latter populations were more similar to patterns of burden in developing rather than developed countries.

Conclusion: Estimating DALYs specifically for the United States provides a comprehensive assessment of health problems for this country compared to what is available using mortality data alone. 


\section{Background}

This paper presents the results of a study conducted cooperatively by scientists from the Centers for Disease Control and Prevention (CDC) and the Harvard School of Public Health. The study essentially applied the methods used in the Global Burden of Disease analysis to data specific to the United States in order to calculate DisabilityAdjusted Life Year (DALY) values for major health conditions and risk factors [1].

The genesis of the US Burden of Disease and Injury study (USBODI) was the release of the 1993 World Development Report: Investing in Health published by the World Bank. This landmark report in international health policy introduced a new summary measure of population health - the Disability-Adjusted Life Year (DALY) [2]. In contrast to the traditional reliance on death counts and rates to assess the burden of health events, the DALY attempted to combine the impact of non-fatal health outcomes with mortality. Though originally developed for comparative analyses of disease burden in different regions of the world, this perspective seemed particularly appropriate to inform policy in a country such as the United States. In industrialized country settings, where death rates are low relative to developing countries, the majority of deaths occur after the age of 75 years. Yet too many deaths still occur at younger ages and many could be prevented. Therefore, information for health policy deliberations needs to emphasize the burden of premature mortality as well as disability. As stated in a recent Institute of Medicine report on summary health measures, "Mortality measures, although important, provide decision makers incomplete and insensitive information about overall population health." [3].

From the outset, this study had three major goals. The first goal was to incorporate non-fatal conditions into assessments of health status in the United States. So far most discussions about the relative importance of various health conditions centered on the number of deaths attributed to specific diseases, injuries or risk factors [4]. The focus on deaths has important implications for policy and great influence on resource allocation. As the average life expectancy continues to rise in economically developed countries, more and more deaths are attributed to chronic conditions that are recalcitrant to treatment and may have limited preventability [5]. Prioritization of research and health care expenditures based on such data tends to result in a focus on rescue-oriented, life-saving, and technologically advanced approaches rather than adequate consideration of interventions that promote healthy life-styles and improve overall physical and emotional function [6]. The DALY offers a rational methodology for weighing the relative importance of fatal and nonfatal health events. Hence, a much broader range of health conditions that are rarely identified as causes of death, such as mental health disorders and musculoskeletal diseases, can be introduced into data-based deliberations on health policy.

The second major goal was to develop a comprehensive set of internally consistent and scientifically credible epidemiological estimates for the major health conditions in the United States. This is greatly facilitated by a plethora of population-based surveys, registries and administrative data systems that attempt to capture information on a wide range of health events [7]. The major challenge is to impose a consistent and conceptually rigorous analytic approach so that the estimates are internally consistent. Reviews of cost-effectiveness ratios that depend on epidemiologic data and statistical modeling have demonstrated that it is very difficult to compare results from one study to the next because of major variations in methods, underlying assumptions, data sources and conceptual frameworks [8]. A major source of these inconsistencies is that most such models are developed on a case by case, disease by disease basis, with little attention to conceptual consistency and integration of data from multiple sources [9]. Estimates developed with an adherence to conceptual consistency for the United States can serve not only as a useful source of epidemiologic information, but can also stimulate further analyses and refinements by other investigators.

The third and final goal of the US Burden of Disease and Injury study was to provide a set of internationally comparable health statistics that place the United States public health situation in a global context. World population growth and technological developments over the last few decades in telecommunications, industrial pollution and transportation have effectively made the earth a much smaller planet [10]. This dynamic has major implications for the importation and exportation of health related vectors that include infectious diseases, manufactured products (e.g. energy rich foods, tobacco), and health system organization and practices [11-13]. Given the emergence of this global public health "village," and the growing importance of the DALY as a metric for assessing population health, it seems critical to provide an analysis of the public health situation in the United States that uses methods being adopted by international organizations and health ministries throughout the world.

The Global Burden of Disease (GBD) study developed health statistics for 8 large regions of the world. It includes the United States, which possesses substantial intranational racial, ethnic and cultural variability. Generating a set of estimates specific to the United States not only provides an opportunity to frame the major health problems in this country in a global context, but also facilitates 
explication of intra-national disparities. For example, a previously published monograph that resulted from this project identified differences between race, sex and county-specific life expectancies that rivaled differences seen between the nations with the highest (Japan) and lowest (Sierra Leone) life expectancy values in the world [14].

The overall purpose of this study is to expand the understanding of the major determinants of ill and good health in the United States. The ultimate goal of such understanding should be policies and programs that decrease the overall impact and disparities in disease, disability and premature death.

\section{Methods}

The study was patterned after the GBD and applied methods used in the GBD analysis to compute years of life lost due to premature mortality (YLL), years of life lost due to disability (YLD), and disability-adjusted life years (DALYs). The conceptual and computational details of how these parameters were estimated for individual conditions have been presented in the GBD. A summary overview of GBD methods is provided [see Additional file 1].

The detailed mortality data file for 1996 provided deaths by age, sex and race to compute YLL [15]. The National Health Interview Survey (NHIS), National Health and Nutrition Examination Survey (NHANES), National Longitudinal Alcohol Epidemiologic Survey (NLAES), the National Hospital Discharge Database, disease registers, and epidemiological studies provided the epidemiological parameters needed to compute YLD for 72 conditions that account for at least 90 per cent of the DALY total in the United States. If data on race and gender specific subgroups were too sparse to derive reasonable epidemiological parameters for particular conditions, YLD were estimated for these subgroups using YLD to YLL ratios for the overall population. For the remaining 26 conditions, YLD were calculated using YLD to YLL ratios from Established Market Economies (EME) countries in the GBD, applied to US specific estimates of YLL. A detailed presentation of analytic methods, data sources, and data sets used to develop estimates for major causes of diseases and injuries is provided [see Additional file 2].

Below we describe adjustments that were made to GBD methods in the context of the United States. These were 1) the inclusion of race; 2) a revised list of causes; and 3) a revised algorithm to allocate cardiovascular disease garbage codes to ischaemic heart disease (IHD).

\section{Selection of population groups}

Estimates of the burden of disease and injury were done by gender and seven age groups $(0-4 ; 5-14 ; 15-24 ; 25-$
$44 ; 45-64 ; 65-74$ and $75+$ ) for the total US population, as well as for each of the four official race groups specified by the Office of Management and Budget (OMB): White; Black; American Indian or Alaskan Native; and Asian or Pacific Islander. Whites were the largest population group (82.8 per cent, or 219.7 million). Blacks represented 12.6 per cent of the population (33.5 million); American Indians - 0.9 per cent (2.3 million), and Asians - 3.7 per cent (9.7 million). Estimates by ethnicity were not included in this report because reliable estimates were only available for a subset of the Hispanic population.

The inclusion of race in the analysis posed particular challenges for minority populations because of race misclassification. Two independent data sets were combined to calculate death rates: the number of deaths in the numerator comes from the detailed mortality file, and population numbers in the denominator are from the census. There was no discrepancy in reporting of race in both data sets for Whites and Blacks, but race misclassification was found to be problematic for Asians and American Indians. Self-reporting of race in the census tended to be higher, particularly for American Indians, than was the attribution of race (by a third party) on death certificates - which will yield an underestimate of death rates [16]. However, we did not correct for race misclassification in American Indians and Asians because evaluations showed that discrepancies in race reporting varied from year to year and thus provided supportive evidence that there may be no systematic bias. Therefore race differentials expressed as rates may have been slightly overestimated. Death and DALY rates were age-standardized to the general population.

There were also important gaps in the available epidemiological data for Asians and American Indians. In order to fill information gaps, we assumed that ratios of YLL to YLD by cause, gender and age were similar to that of the total population. Such assumptions introduce a certain level of uncertainty in the estimates, and call for caution in the interpretation of rankings for causes that have small differences in the number of DALYs. For simplicity, American Indians or Alaskan Natives are referred to as "American Indians, " and Asians or Pacific Islanders as "Asians" in the text, tables and figures below.

\section{USBODI cause list}

Even though essentially all deaths in the United States are registered and medically certified, a detailed assessment of mortality data was conducted as part of the USBODI. This was done to further explore and refine the utility of the adjustment procedures for misclassification that were used in the GBD, and to provide a contrast to the overall results using the DALY. 
The International Statistical Classification of Disease and Related Health Problems, Version 9, (ICD-9) [17] code listed as the underlying cause for each death recorded in the United States in 1996 was attributed to corresponding disease categories listed in the GBD. The GBD classification scheme was developed as a tool to better inform the health policy debate (Table 1). The list of causes selected for the USBODI was amended based on the distribution of causes of deaths in the United States. All ICD-9 reported codes accounting for more than 0.1 per cent of total deaths were examined. This process identified modifications that were needed from the GBD cause list. Several causes of little relevance to the United States were dropped, i.e. malaria and other tropical diseases. Other causes were added, i.e. Sudden Infant Death Syndrome (SIDS), and septicemia. For those codes accounting for more than 0.1 per cent of deaths that were not included in the GBD list the choice was made in consultation with CDC based on two major criteria. If the code represented a true cause of death with significance for health policy, it was added to the cause list. If the code more likely represented a "garbage category," then after consultation with

Table I: Global burden of disease classification system - main categories

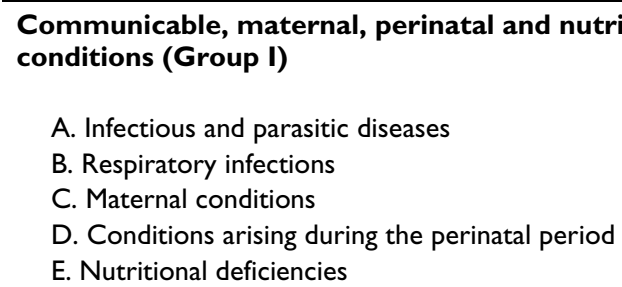

\section{Noncommunicable diseases (Group II)}
A. Malignant neoplasms
B. Other neoplasms
C. Diabetes mellitus
D. Endocrine disorders
E. Neuro-psychiatric conditions
F. Sense organ diseases
G. Cardiovascular diseases
H. Respiratory diseases
I. Digestive diseases
J. Genito-urinary diseases
K. Skin diseases
L. Musculo-skeletal diseases
M. Congenital anomalies
N. Oral conditions

Injuries (Group III)

A. Unintentional injuries

B. Intentional injuries

Source: Global Burden of Disease and Injury 1990 experts in that disease and a review of published autopsy studies on this subject, a redistribution algorithm was proposed and applied. For example, careful consideration was given to the nearly 10.9 per cent of cancer deaths assigned to "unknown primary." There were another $4 \%$ of cancers that did not have a code that corresponded to the GBD classification system. The race and sex specific age distribution of cancers attributed to an ill-defined primary source were compared to all other cancer deaths. These distributions were generally similar. Therefore, cancers attributed to an ill-defined primary source were redistributed proportionally to all defined primary sources based on age, race and sex specific distributions. The detailed list of causes selected for the USBODI is provided [see Additional file 3].

\section{Redistribution algorithm for cardiovascular garbage codes} The most problematic aspect of cause of death coding pertains to coding of ischaemic heart disease (IHD) (ICD-9 codes 410-414), which is one of the leading causes of premature mortality. The wide cross-national variations that exist in IHD reported mortality rates were explored in the context of the GBD and were convincingly attributed to variations across countries in coding practices. Physicians may use several ICD-9 codes that are actually due to IHD when they assign the cause of death. These include heart failure (428), ventricular dysrhythmias (427.1, 427.4, 427.5), general atherosclerosis (440.9), and ill-defined descriptions and complications of heart disease (429.0, 429.1, 429.2 and 429.9). IHD deaths may be assigned to these ill-defined cardiovascular codes, or "garbage codes" because of insufficient clinical information at the time of death, local medical diagnostic practices or simply by error. The statistical approach developed to correct for likely undercoding resulting from different coding practices in the GBD included a two-step procedure comprising an ordinary least squares (OLS) regression equation predicting the proportion of cardiovascular death for each age group assigned to ill-defined codes as a function of the proportion of deaths assigned to IHD, and the correction of proportions for each country within set constraints, based on the assumption that the cluster of countries where ill-defined coding was low defined the standard coding practices.

An exploration of cardiovascular death coding in the United States showed important differences in coding practices between states. Indeed, the proportion of all cardiovascular deaths (minus stroke) coded to cardiovascular "garbage" codes ranged from $14 \%$ in New Mexico to $37 \%$ in Alabama and New Jersey (Table 2). Figure 1 illustrates the enormous variation across US states in coding practices with respect to these ill-defined cardiovascular codes. For each state, the fraction of cardiovascular deaths (excluding stroke) that are assigned to ICD-9 codes 410- 
Table 2: Proportion of all cardiovascular deaths (except stroke) coded to cardiovascular "garbage codes" by state - United States 1996

\begin{tabular}{llllll}
\hline State name & \% CV garbage & State name & $\%$ CV garbage & State name & $\%$ CV garbage \\
\hline Alabama & 37 & Kentucky & 25 & North Dakota & 19 \\
Alaska & 22 & Louisiana & 23 & Ohio & 25 \\
Arizona & 22 & Maine & 24 & Oklahoma & 18 \\
Arkansas & 21 & Maryland & 24 & Oregon & 23 \\
California & 18 & Massachusetts & 22 & Pennsylvania & 15 \\
Colorado & 26 & Michigan & 19 & Rhode Island & 20 \\
Connecticut & 29 & Minnesota & 35 & South Carolina & 21 \\
Delaware & 29 & Mississippi & 17 & South Dakota & 19 \\
DC & 28 & Missouri & 29 & Tennessee & 21 \\
Florida & 16 & Montana & 31 & Texas & 24 \\
Georgia & 30 & Nebraska & 34 & Utah & 24 \\
Hawaii & 28 & Nevada & 20 & Vermont & 26 \\
Idaho & 17 & New Hampshire & 17 & Washington & 24 \\
Illinois & 19 & New Jersey & 37 & West Virginia & 26 \\
Indiana & 18 & New Mexico & 14 & Wisconsin & 17 \\
lowa & 20 & New York & 19 & Wyoming & 21 \\
Kansas & 24 & North Carolina & 21 & 19 \\
\hline
\end{tabular}

414 is shown on the $\mathrm{y}$-axis. On the $\mathrm{x}$-axis the fraction of cardiovascular deaths (excluding stroke) that are assigned to the ill-defined cardiovascular codes is measured. The strong negative relation between IHD mortality and that from ill-defined cardiovascular codes supports the suggestion that the quality of IHD death certification varies substantially across states, as it does across countries in the world.

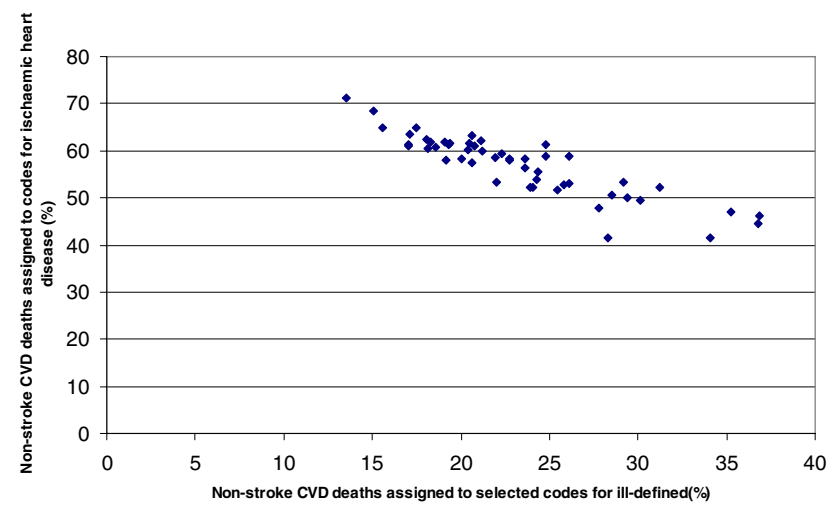

\section{Figure I}

Proportion of cardiovascular disease deaths (excluding stroke) assigned to selected codes for ill-defined causes and directly assigned to ischemic heart disease in the United States.
This preliminary analysis confirmed the need to correct for under-registration of IHD in the US. To estimate the fraction of IHD deaths assigned to ill-defined cardiovasular codes, the regression equation applied in the GBD was revised. Age and sex specific lung cancer death rates were added to the model. Lung cancer mortality rates measure the cumulative effects of tobacco exposure as a risk factor for IHD [18].

The regression model for the US included age and sex specific lung cancer death rates, and ill-defined cardiovascular disease (CVD) rates for Blacks and Whites. These regression equations predicted the proportion of illdefined CVD deaths by age and sex for Whites and Blacks. We applied results of regression equations for Whites to American Indians and Asians, which were not included in the regressions due their small population size.

The finding that the extent of miscoding increased in older age groups is consistent with GBD regression results: R-square increases with increasing age, which provides further evidence that ill-defined codes are indeed being used for IHD which is more common in older ages. Differences in coding practices observed by race as well as gender are not fully explained (Table 3 ). A recent study concluded that "the greater presence of medical knowledge at the time of death, reflected by place of death and cardiologist per capita, reduces the use of ill-defined cardiovascular clusters. Racial and gender effects on coronary heart disease (CHD) assignment may reflect disparities in access to care and quality of care." [19] 
Table 3: R-squared values applied to the redistribution of cardiovascular garbage codes

\begin{tabular}{|c|c|c|c|c|c|}
\hline \multicolumn{6}{|c|}{ WHITES } \\
\hline \multirow[t]{2}{*}{ Male } & \multicolumn{2}{|l|}{ Lung Cancer } & \multicolumn{2}{|c|}{ CVGarbageCodes } & \multirow[t]{2}{*}{ R-squared } \\
\hline & Coefficient & Pvalue & Coefficient & Pvalue & \\
\hline 15 & -0.499 & 0.273 & 0.557 & .000 & $26.17 \%$ \\
\hline 30 & 2.396 & .000 & -0.193 & 0.424 & $52.10 \%$ \\
\hline 45 & 1.495 & .000 & -0.741 & .000 & $77.77 \%$ \\
\hline 65 & 1.235 & .000 & -0.833 & .000 & $69.02 \%$ \\
\hline 75 & 2.73 & .000 & -1.122 & .000 & $47.64 \%$ \\
\hline \multicolumn{6}{|c|}{ Female } \\
\hline 15 & 0.348 & 0.0324 & 0.097 & 0.395 & $3.53 \%$ \\
\hline 30 & 0.727 & .000 & 0.539 & 0.008 & $37.82 \%$ \\
\hline 45 & 0.869 & .000 & -0.315 & 0.283 & $31.41 \%$ \\
\hline 65 & -0.459 & 0.206 & 0.752 & 0.018 & $11.47 \%$ \\
\hline 75 & 2.011 & 0.123 & -0.679 & 0.021 & $12.25 \%$ \\
\hline \multicolumn{6}{|c|}{ BLACKS } \\
\hline \multirow[t]{2}{*}{ Male } & \multicolumn{2}{|l|}{ Lung Cancer } & \multicolumn{2}{|c|}{ CV GarbageCodes } & R-squared \\
\hline & Coefficient & Pvalue & Coefficient & Pvalue & \\
\hline 15 & 0.592 & 0.314 & -0.0393 & 0.792 & $4.13 \%$ \\
\hline 30 & 1.575 & 0.013 & 0.0735 & 0.785 & $23.40 \%$ \\
\hline 45 & 1.211 & .000 & -0.403 & 0.025 & $47.27 \%$ \\
\hline 65 & 0.435 & 0.082 & -0.551 & .000 & $40.73 \%$ \\
\hline 75 & 0.183 & 0.769 & -0.7207 & 0.005 & $26.34 \%$ \\
\hline \multicolumn{6}{|c|}{ Female } \\
\hline 15 & -0.829 & 0.042 & 0.256 & 0.047 & $16.06 \%$ \\
\hline 30 & -0.846 & 0.0127 & 0.532 & 0.03 & $12.85 \%$ \\
\hline 45 & 0.02 & 0.942 & -0.11 & 0.634 & $8.30 \%$ \\
\hline 65 & 0.695 & 0.42 & -1.369 & 0.059 & $13.60 \%$ \\
\hline 75 & 1.015 & 0.524 & -0.772 & 0.013 & $16.67 \%$ \\
\hline
\end{tabular}

\section{International comparisons}

Ten countries with comparable levels of development and a population greater than 10 million: Australia, Canada, France, Germany, Greece, Italy, Japan, Netherlands, Spain and the United Kingdom, were selected for international comparisons. YLL by cause were obtained directly from the World Health Organization (WHO). YLD and DALY estimates were only available at the regional level, with the exception of Australia, where a national burden of disease study applying the GBD methodology had been conducted [21].

International comparisons may address two sets of issues - the difference in the magnitude of YLL (expressed as YLL rates), or differences in the distribution of major causes of YLL. We examined differences in rankings of major causes of YLL and YLL rates between the United States and other comparable countries.
Rankings for the twenty leading causes of mortality burden in the United States were compared to rankings for these conditions in the ten selected countries. We made one change in the list of conditions adopted for the United States to ensure comparability among countries, which was to combine mortality burden due to lymphomas and multiple myelomas. These two conditions are different forms of reticuloendothelial malignancies. Estimates were not available for these conditions separately in several of the selected countries. This change slightly altered rankings in the United States for several conditions, as the two conditions combined had a higher mortality burden than lymphomas alone. Lymphomas and multiple myelomas ranked $14^{\text {th }}$ for males and $13^{\text {th }}$ for females, and the mortality burden for lymphomas ranked $19^{\text {th }}$ and $17^{\text {th }}$ respectively. We plotted the rankings for each of the twenty leading causes of mortality burden in the United States (horizontal bars) against the range of 
rankings observed for each of these conditions in the selected countries (vertical bars), for each sex. The lowest and highest rankings observed in the countries other than the US define the bounds of vertical bars for each condition. Rankings, from one to twenty, are inversely related to the magnitude of mortality burden. Thus, IHD, which caused the largest number of YLL in the United States, ranked $1^{\text {st }}$. We also compared YLL rankings for the twenty leading causes of YLL for each race and sex against the ranges observed in the ten selected countries.

\section{Results}

Detailed tabulations of deaths, YLL, YLD and DALYs for the 73 causes included in the USBODI by age, gender and race are provided [see Additional file 4]. Epidemiological parameters (incidence, prevalence, age at onset, duration, remission rates) and disability weights for each condition are provided [see Additional file 5].

Below we report key findings for the burden of disease and injury (DALYs); the mortality burden due to premature deaths (YLL); and the disability burden due to nonfatal health outcomes (YLD).

\section{Burden of disease and injury Leading causes of DALYs}

The burden of disease and injury resulting from premature deaths and disability was an estimated 33 million DALYs in 1996. Premature mortality contributed 55 per cent of the total (18 million YLL), and disability - 45 per cent (15 million YLD). Noncommunicable diseases (Group II) caused 80 per cent of total DALYs, the balance being almost equally divided between communicable diseases, maternal, perinatal and nutritional causes (Group I) and injuries (Group III). Cardiovascular diseases, neuropsychiatric conditions, cancers and injuries caused approximately two thirds of the total DALYs (Figure 2). Ischaemic heart disease (IHD) was the leading and single largest cause of deaths and DALYs causing almost 10 per cent of DALYs. The three other causes ranking in the top five-cerebrovascular diseases, motor vehicle accidents, unipolar major depression - contributed almost equally to the total burden, with shares ranging between 4.1 and 4.6 per cent (Table 6).

\section{Sex and age patterns}

The total disease burden for males (17.9 million DALYs) exceeded that for females (15 million DALYs). The excess disease burden for males was mostly due to the much larger number of premature deaths in young adult males. IHD resulted in twice the number of DALYs for males as it did for females, and was equal to the combined disease burden due to the three major causes of injuries that took a high toll in young adult males - motor vehicle accidents, homicide and violence, and self-inflicted injuries. Unipo- lar major depression caused almost the same disease burden for females that did motor vehicle accidents for males (Table 7).

Half of the total disease burden in the United States occurred in adults between the ages of 25 and 64 years, the other half being almost evenly split between younger and older age groups: 23 per cent under the age of 25 years, and 27 per cent for ages 65 years and above. In sharp contrast, the number of deaths gradually increased with age. More than half of all deaths occurred in adults aged 75 years and older (Table 8 ).

The share of total DALYs was very similar for both sexes up to the age of 14 years, but increased in adult males between 15 and 64 years. In older adults, the share of total DALYs for females exceeded that for males (Table 9). Differentials in DALY rates between males and females were greatest between 25 and 44 years, when motor vehicle accidents, alcohol use and abuse, HIV/AIDS and major unipolar depression took the highest toll.

\section{Patterns by race}

Blacks and American Indians suffered disproportionate shares of total burden relative to their population size: DALY rates per thousand were 165.7 for Blacks; 128.7 for American Indians; 120.6 for Whites, and 75.3 for Asians. The proportional distribution of Groups I, II, and III varied between races, pointing to important differences in prevailing patterns of burden of disease. Group I and III combined caused one fifth of total DALYs for Whites and Asians, and one third of total DALYs for Blacks and American Indians. The excess was due to Group I (17 per cent of total DALYs) for Blacks and Group III for American Indians (19 per cent of total DALYs) (Figure 3).

IHD was among the three leading causes of DALYs for all races. The two other causes were cerebrovascular diseases and lung cancer for Whites; HIV/AIDS and homicide and violence for Blacks; alcohol use and motor vehicle accidents for American Indians; and unipolar major depression and cerebrovascular diseases for Asians (Table 10).

Sex differentials in total burden by race increased with higher DALY rates. Male to female DALY ratios were 1.23 for Blacks, 1.21 for American Indians, 1.10 for Whites, 1.05 for Asians, and 1.17 overall. Although patterns of disease burden differed between races, leading causes were common to both sexes. Premature deaths contributed the largest share of total burden for males in all races, with the exception of Asian males. Non-fatal health outcomes contributed the largest share for females in all races, with the exception of Black females (Figure 4). 

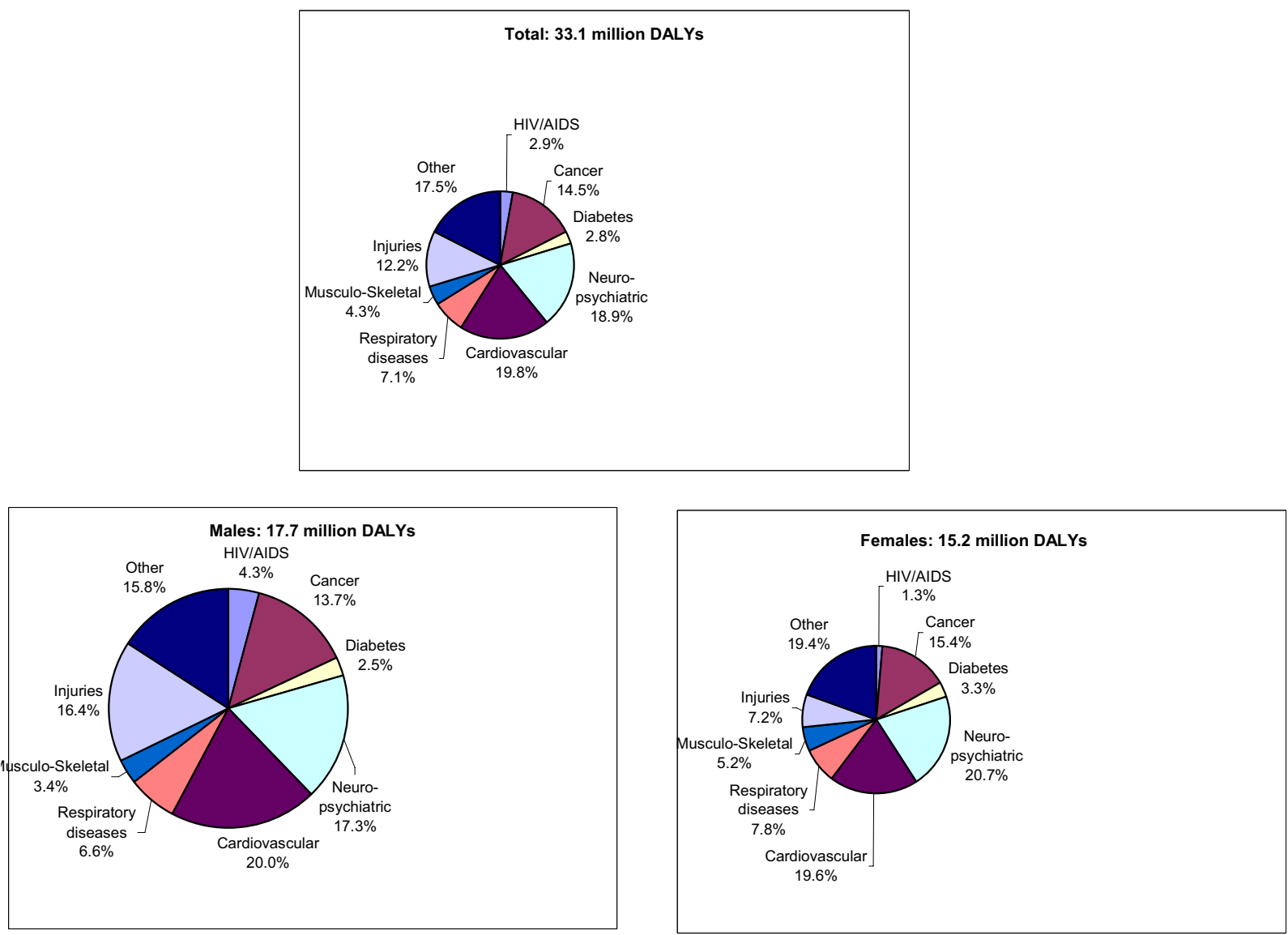

\section{Figure 2}

Burden of Disease (DALYs) by sex and major disease groups, US, 1996.

DALY rates by age, sex, and race for HIV/AIDS, IHD and cerebrovascular diseases; hypertension and hypertensive heart disease, inflammatory cardiac diseases; and major causes of injuries capture changes in DALY rates over the lifespan as well as differences by race and sex in these important causes of disease burden (Figures 5, 6, 7, 8). DALY rates peaked in young adults for HIV/AIDS and injuries, and increased with age for cardiovascular diseases. DALY rates for Black males and females exceeded rates for the other race groups for HIV/AIDS, hypertension, cerebrovascular diseases, inflammatory cardiac diseases, motor vehicle accidents, homicide and violence, and self-inflicted injuries. Differentials between Blacks and the other races were always greater for males than for females, and were greatest in young adult males for HIV/ AIDS, homicide and violence, hypertension and inflammatory cardiac diseases. Asian males and females had the lowest DALY rates for all major causes of burden. Differentials between races were least pronounced for IHD for both sexes.

\section{Mortality burden}

Leading causes of YLL

In 1996, 2.3 million people died in the United States, causing the loss of 18.1 million YLL ( 55 per cent of total DALYs). Age patterns of deaths and YLL differ: the number of deaths increased with age, the resulting number of YLL was greater for children and young adults than it was for older ages (Figure 9). The number of deaths and resulting number of YLL from any cause are not equivalent (Figure $10)$.

IHD was the unequivocal lead cause of death and YLL, causing almost one of every four deaths and 16 per cent of 
Table 4: Disability weights from person trade-off exercise conducted in Atlanta compared to composite scores from other exercises conducted at various international sites

\begin{tabular}{|c|c|c|c|c|c|c|c|c|}
\hline \multirow[t]{2}{*}{ Indicator Condition } & \multicolumn{4}{|c|}{ Atlanta PTO $(\mathrm{N}=35)$} & \multicolumn{4}{|c|}{ Composite scores $(N=192)$} \\
\hline & Median & Mean & S.D.* & C.V. ${ }^{+}$ & Median & Mean & S.D.* & C.V. ${ }^{+}$ \\
\hline Vitiligo on Face & 0 & 0.04 & 0.11 & 2.75 & 0 & 0.04 & 0.1 & 2.5 \\
\hline Watery Diarrhea & 0.02 & 0.06 & 0.08 & 1.33 & 0.05 & 0.1 & 0.16 & 1.60 \\
\hline Fracture of Radius & 0.06 & 0.1 & 0.11 & 1.10 & 0.09 & 0.13 & 0.16 & 1.23 \\
\hline Infertility & 0.03 & 0.11 & 0.16 & 1.45 & 0.09 & 0.16 & 0.19 & 1.19 \\
\hline Erectile Dysfunction & 0.09 & 0.19 & 0.22 & 1.16 & 0.17 & 0.22 & 0.23 & 1.05 \\
\hline Severe Sore Throat & 0.13 & 0.19 & 0.18 & 0.95 & 0.13 & 0.23 & 0.26 & 1.13 \\
\hline Rheumatoid Arthritis & 0.17 & 0.26 & 0.24 & 0.92 & 0.29 & 0.32 & 0.22 & 0.69 \\
\hline Below Knee Amputation & 0.29 & 0.32 & 0.20 & 0.63 & 0.29 & 0.34 & 0.22 & 0.65 \\
\hline Deafness & 0.44 & 0.43 & 0.28 & 0.65 & 0.36 & 0.4 & 0.24 & 0.60 \\
\hline Recto-vaginal Fistula & 0.29 & 0.38 & 0.33 & 0.87 & 0.41 & 0.44 & 0.28 & 0.64 \\
\hline Angina & 0.38 & 0.39 & 0.23 & 0.59 & 0.43 & 0.46 & 0.26 & 0.57 \\
\hline Mental Retardation & 0.64 & 0.55 & 0.28 & 0.51 & 0.5 & 0.5 & 0.25 & 0.50 \\
\hline Blindness & 0.5 & 0.53 & 0.25 & 0.47 & 0.63 & 0.58 & 0.21 & 0.36 \\
\hline Paraplegia & 0.67 & 0.6 & 0.25 & 0.42 & 0.71 & 0.68 & 0.2 & 0.29 \\
\hline Major Depression & 0.89 & 0.79 & 0.23 & 0.29 & 0.81 & 0.75 & 0.2 & 0.27 \\
\hline Severe Migraine & 0.96 & 0.89 & 0.18 & 0.20 & 0.88 & 0.8 & 0.2 & 0.25 \\
\hline Dementia & 0.9 & 0.85 & 0.16 & 0.19 & 0.9 & 0.86 & 0.13 & 0.15 \\
\hline Active Psychosis & 0.95 & 0.9 & 0.12 & 0.13 & 0.91 & 0.87 & 0.14 & 0.16 \\
\hline Quadriplegia & 0.93 & 0.9 & 0.09 & 0.10 & 0.91 & 0.87 & 0.14 & 0.16 \\
\hline
\end{tabular}

* S.D. = standard deviation.

+ C.V. = Coefficient of Variation (standard deviation/mean)

total YLL. The mortality burden due to IHD was more than double the mortality burden due to lung cancer, and almost three times that due to motor vehicle accidents (Table 11). The share of YLL exceeded that of YLD for cardiovascular diseases, cancers, injuries, respiratory infections, and conditions arising during the perinatal period.

Sex and age patterns

The number of deaths and the age at death is driving differentials in mortality burden observed by age, sex and race. The mortality burden for males (10.5 million YLL) was 40 per cent greater than that for females ( 7.5 million YLL) (Table 12). The excess male mortality burden was largely due to the higher mortality burden resulting from IHD, injuries (motor vehicle accidents, homicide and violence, self-inflicted injuries), and HIV/AIDS. These causes combined resulted in 40 per cent of total YLL (4.1 million YLL) for males, but only in 24 per cent of total YLL for females (1.8 million YLL), and accounted for 80 per cent of the total sex differential. The female mortality burden exceeded that of males only for cerebrovascular diseases. Also noteworthy was the toll due to breast cancer (450 thousand YLL), which was almost equal to that of lung cancer (523 thousand YLL). YLL rates were higher for all leading causes for males than they were for females, with the exception of cerebrovascular diseases (Figure 11). The

Table 5: Pearson's correlation coefficients for median disability weights for each exercise based on 19 conditions common to all person trade-off exercises

\begin{tabular}{|c|c|c|c|c|c|c|c|c|c|}
\hline \multicolumn{10}{|l|}{ Group } \\
\hline International I & International I & & & & & & & & \\
\hline Netherlands & 0.96 & Netherlands & & & & & & & \\
\hline Maghreb-8 & 0.94 & 0.95 & Maghreb & & & & & & \\
\hline Japan & 0.90 & 0.82 & 0.85 & Japan & & & & & \\
\hline GBD & 0.97 & 0.95 & 0.97 & 0.88 & GBD & & & & \\
\hline International II & 0.99 & 0.97 & 0.94 & 0.89 & 0.97 & International II & & & \\
\hline CDC & 0.97 & 0.98 & 0.92 & 0.84 & 0.95 & 0.98 & CDC & & \\
\hline Brazil & 0.90 & 0.91 & 0.87 & 0.83 & 0.87 & 0.90 & 0.90 & Brazil & \\
\hline Mexico & 0.95 & 0.93 & 0.92 & 0.90 & 0.93 & 0.96 & 0.96 & 0.95 & Mexico \\
\hline Composite & 0.99 & 0.98 & 0.96 & 0.89 & 0.98 & 0.99 & 0.99 & 0.94 & 0.97 \\
\hline
\end{tabular}


Table 6: Twenty leading causes of DALYs and deaths, US 1996

\begin{tabular}{|c|c|c|c|c|c|}
\hline & DALY & $\%$ of total & & Deaths & $\%$ of total \\
\hline Total DALYs & $33,090,212$ & & Total Deaths & $2,314,689$ & \\
\hline Ischemic heart disease & $3,134,732$ & 9.5 & Ischemic heart disease & 536,314 & 23.17 \\
\hline Cerebrovascular Disease & $1,510,287$ & 4.6 & Lung trachea or bronchial cancer & 168,206 & 7.27 \\
\hline Motor vehicle accidents & $1,393,278$ & 4.2 & Cerebrovascular Disease & 161,678 & 6.98 \\
\hline Unipolar major depression & $\mathrm{I}, 370,285$ & 4.1 & COPD & 99,982 & 4.32 \\
\hline Lung trachea or bronchial cancer & $1,362,712$ & 4.1 & Lower respiratory infections & 84,319 & 3.64 \\
\hline COPD & $1,253,491$ & 3.8 & Diabetes mellitus & 62,452 & 2.70 \\
\hline Alcohol use & $1,141,193$ & 3.4 & Cancer colon or rectum & 61,189 & 2.64 \\
\hline HIV & 956,418 & 2.9 & Breast cancer & 46,649 & 2.02 \\
\hline Diabetes mellitus & 946,291 & 2.9 & Motor vehicle accidents & 43,735 & 1.89 \\
\hline Osteoarthritis & 942,682 & 2.8 & $\begin{array}{l}\text { Dementia and other degenerative and } \\
\text { hereditary CNS disorders }\end{array}$ & 43,190 & 1.87 \\
\hline $\begin{array}{l}\text { Dementia and other degenerative and } \\
\text { hereditary CNS disorders }\end{array}$ & 889,242 & 2.7 & $\begin{array}{l}\text { Hypertension and hypertensive heart } \\
\text { disease }\end{array}$ & 39,589 & 1.71 \\
\hline Congenital Abnomalities & 761,951 & 2.3 & Prostate cancer & 36,667 & 1.58 \\
\hline Homicide and Violence & $7 \mid 4,621$ & 2.2 & Self-inflicted & 31,725 & 1.37 \\
\hline Self-inflicted & 674,443 & 2.0 & HIV & 31,188 & 1.35 \\
\hline Asthma & 665,103 & 2.0 & Cancer pancreas & 29,494 & 1.27 \\
\hline Drug use & 543,841 & 1.6 & Inflammatory Cardiac & 29,066 & 1.26 \\
\hline Breast cancer & 514,786 & 1.6 & Lymphomas & 26,443 & 1.14 \\
\hline $\begin{array}{l}\text { Conditions arising during the perinatal } \\
\text { period }\end{array}$ & 493,958 & 1.5 & Cirrhosis of the liver & 25,488 & 1.10 \\
\hline Cancer colon or rectum & 483,931 & 1.5 & Nephritis or nephrosis & 24,569 & 1.06 \\
\hline Cirrhosis of the liver & 411,539 & 1.2 & Homicide and Violence & 22,351 & 0.01 \\
\hline
\end{tabular}

pattern of mortality burden shifted from a predominance of injuries between ages 5 and 44 years, to a gradual increase in chronic diseases (cancers and cardiovascular diseases) among older adults (Tables 13, 14, 15, 16, 17, 18).

\section{Patterns by race}

The share of YLL due to communicable diseases (which include HIV/AIDS), maternal causes, perinatal and nutritional conditions was twofold larger for Blacks (20 per cent) than it was for any of the other races. Injuries predominated among American Indians, causing one third of the total mortality burden, and one fifth or less in the other races.

The mortality burden was highest for Blacks and lowest for Asians, for both sexes and all ages. A few causes contributed about one third of total YLL in each race. These were IHD, lung cancer and motor vehicle accidents for Whites; IHD, HIV/AIDS and homicide and violence for Blacks; motor vehicle accidents, IHD and self-inflicted injuries for American Indians; and IHD, motor vehicle accidents, cerebrovascular diseases, and lung cancer for Asians (Tables 15, 16, 17, 18; Figures 12, 13).
Comparative rankings of mortality burden in the United States and selected industrialized countries

Relative YLL rankings observed in the United States and in ten selected industrialized countries (Australia, Canada, France, Germany, Greece, Italy, Japan, Netherlands, Spain and the United Kingdom) were similar for IHD, lung cancer and motor vehicle accidents for males, and IHD, breast cancer and cerebrovascular diseases for females, which ranked among the top five leading causes of YLL in all countries. In contrast, the range of rankings observed was widest for HIV/AIDS and inflammatory cardiac diseases (cardiomyopathy and endocarditis) for both sexes, appearing to cause a very high mortality burden in some countries, and a much lower mortality burden in others (Figures 14 and 15). The wide range observed for these two conditions may point to real differences in causes of death and their important risk factors, but may also indicate differences in cause of death reporting practices, particularly for inflammatory cardiac disease, which ultimately leads to congestive heart failure, and may not have been diagnosed as the underlying cause.

\section{US YLL rankings by race compared to selected industrialized} countries

The higher share of YLL due to homicide and violence in the general population in the United States was observed 
Table 7: Twenty leading causes of DALYs, by sex, US 1996

\begin{tabular}{|c|c|c|c|}
\hline & Males & & \\
\hline & Cause list & DALY & $\%$ total \\
\hline & Total DALY & $17,860,393$ & \\
\hline I & Ischaemic heart disease & $1,958,184$ & $11.0 \%$ \\
\hline 2 & Motor vehicle accidents & 933,798 & $5.2 \%$ \\
\hline 3 & Lung trachea or bronchial cancer & 812,804 & $4.6 \%$ \\
\hline 4 & HIV & 763,816 & $4.3 \%$ \\
\hline 5 & Alcohol use & 731,890 & $4.1 \%$ \\
\hline 6 & Cerebrovascular Disease & 673,928 & $3.8 \%$ \\
\hline 7 & COPD & 641,701 & $3.6 \%$ \\
\hline 8 & Homicide and Violence & 567,717 & $3.2 \%$ \\
\hline 9 & Self-inflicted & 541,399 & $3.0 \%$ \\
\hline 10 & Unipolar major depression & 469,929 & $2.6 \%$ \\
\hline 11 & Diabetes mellitus & 442,051 & $2.5 \%$ \\
\hline 12 & Osteoarthritis & 434,856 & $2.4 \%$ \\
\hline 13 & Drug use & 411,780 & $2.3 \%$ \\
\hline 14 & Congenital Abnomalities & 410,388 & $2.3 \%$ \\
\hline 15 & Dementia and other degenerative and hereditary CNS disorders & 382,392 & $2.1 \%$ \\
\hline 16 & Asthma & 303,088 & $1.7 \%$ \\
\hline 17 & Cirrhosis of the liver & 280,632 & $1.6 \%$ \\
\hline 18 & Conditions arising during the perinatal period & 273,577 & $1.5 \%$ \\
\hline 19 & Cancer colon or rectum & 249,462 & $1.4 \%$ \\
\hline \multirow[t]{5}{*}{20} & Prostate cancer & 238,889 & $1.3 \%$ \\
\hline & sub-total & $|1,522,28|$ & $64.5 \%$ \\
\hline & \multicolumn{3}{|l|}{ Females } \\
\hline & Cause list & DALY & $\%$ total \\
\hline & Total DALY & $15,229,819$ & \\
\hline I & Ischaemic heart disease & $1,176,548$ & $7.7 \%$ \\
\hline 2 & Unipolar major depression & 900,356 & $5.9 \%$ \\
\hline 3 & Cerebrovascular Disease & 836,359 & $5.5 \%$ \\
\hline 4 & COPD & 611,790 & $4.0 \%$ \\
\hline 5 & Lung trachea or bronchial cancer & 549,908 & $3.6 \%$ \\
\hline 6 & Breast cancer & 514,786 & $3.4 \%$ \\
\hline 7 & Osteoarthritis & 507,826 & $3.3 \%$ \\
\hline 8 & Dementia and other degenerative and hereditary CNS disorders & 506,849 & $3.3 \%$ \\
\hline 9 & Diabetes mellitus & 504,240 & $3.3 \%$ \\
\hline 10 & Motor vehicle accidents & 459,480 & $3.0 \%$ \\
\hline 11 & Alcohol use & 409,303 & $2.7 \%$ \\
\hline 12 & Asthma & 362,015 & $2.4 \%$ \\
\hline 13 & Congenital Abnomalities & 351,563 & $2.3 \%$ \\
\hline 14 & Cancer colon or rectum & 234,469 & $1.5 \%$ \\
\hline 15 & Conditions arising during the perinatal period & 220,382 & $1.4 \%$ \\
\hline 16 & Lower respiratory infections & 195,448 & $1.3 \%$ \\
\hline 17 & PTSD & 193,533 & $1.3 \%$ \\
\hline 18 & HIV & 192,602 & $1.3 \%$ \\
\hline 19 & Panic disorder & 182,218 & $1.2 \%$ \\
\hline 20 & Bipolar disorder & 165,236 & $1.1 \%$ \\
\hline
\end{tabular}

in all races and both sexes (Figures 16 and 17). YLL rankings for all races and both sexes fell outside those observed in other countries for inflammatory cardiac diseases, pointing to a higher burden in the United States.
Rankings for cerebrovascular diseases, on the other hand, pointed to a lower share of burden for males in all races. YLL rates exceeded rates for other countries for HIV/AIDS, homicide and violence, and inflammatory cardiac disease 
Table 8: Ten leading causes of DALYs by age, US 1996

\begin{tabular}{|c|c|c|c|c|c|c|}
\hline Rank & All ages & DALYs & $\%$ of total & $0-4$ & DALYs & $\%$ of total \\
\hline & Total & $33,090,212$ & & Total & $2,123,767$ & \\
\hline 1 & Ischaemic heart disease & $3,134,732$ & 9.5 & Congenital abnomalities & 679,542 & 32.0 \\
\hline 2 & Cerebrovascular disease & $1,510,287$ & 4.6 & Perinatal conditions & 492,486 & 23.2 \\
\hline 3 & Motor vehicle accidents & $1,393,278$ & 4.2 & Sudden infant death syndrome & 102,255 & 4.8 \\
\hline 4 & Unipolar major depression & $\mathrm{I}, 370,285$ & 4.1 & Asthma & 77,323 & 3.6 \\
\hline 5 & Lung, trachea or bronchial cancer & $1,362,712$ & 4.1 & Diarrhoeal diseases & 60,438 & 2.8 \\
\hline 6 & COPD & $|, 253,49|$ & 3.8 & Motor vehicle accidents & 48,630 & 2.3 \\
\hline 7 & Alcohol use & $1,141,193$ & 3.4 & Falls & 41,289 & 1.9 \\
\hline 8 & HIV & 956,418 & 2.9 & Homicide and violence & 35,055 & 1.7 \\
\hline 9 & Diabetes mellitus & 946,291 & 2.9 & Lower respiratory infections & 30,640 & 1.4 \\
\hline 10 & Osteoarthritis & 942,682 & 2.8 & Fires & 22,090 & 1.0 \\
\hline \multirow[t]{2}{*}{ Rank } & $5-14$ & DALYs & $\%$ of total & $15-24$ & DALYs & $\%$ of total \\
\hline & Total & $1,136,989$ & & Total & $3,884,235$ & \\
\hline 1 & Asthma & 236,494 & 20.8 & Motor vehicle accidents & 499,505 & 12.9 \\
\hline 2 & Motor vehicle accidents & 128,357 & 11.3 & Alcohol use & 433,515 & 11.2 \\
\hline 3 & Unipolar major depression & 61,622 & 5.4 & Drug use & 291,844 & 7.5 \\
\hline 4 & Epilepsy & 42,461 & 3.7 & Homicide and violence & 282,746 & 7.3 \\
\hline 5 & Schizophrenia & 41,254 & 3.6 & Schizophrenia & 237,967 & 6.1 \\
\hline 6 & Falls & 39,886 & 3.5 & Bipolar disorder & 221,134 & 5.7 \\
\hline 7 & Homicide and violence & 28,242 & 2.5 & Unipolar major depression & 197,309 & 5.1 \\
\hline 8 & Fires & 19,514 & 1.7 & Panic disorder & 158,379 & 4.1 \\
\hline 9 & Congenital abnomalities & 17,860 & 1.6 & Asthma & 157,997 & 4.1 \\
\hline 10 & Drowning & 16,472 & $\mathrm{I} .4$ & Self-inflicted & $157,28 \mid$ & 4.0 \\
\hline \multirow[t]{2}{*}{ Rank } & $25-44$ & DALYs & $\%$ of total & 45-64 & DALYs & $\%$ of total \\
\hline & Total & $8,364,608$ & & Total & $8,478,954$ & \\
\hline I & Unipolar major depression & 823,548 & 9.8 & Ischaemic heart disease & $1,154,002$ & 13.6 \\
\hline 2 & HIV & $75 I, 598$ & 9.0 & Lung, trachea or bronchial cancer & 630,224 & 7.4 \\
\hline 3 & Alcohol use & 549,949 & 6.6 & COPD & 504,418 & 5.9 \\
\hline 4 & Motor vehicle accidents & 523,203 & 6.3 & Cerebrovascular Disease & 492,918 & 5.8 \\
\hline 5 & Self-inflicted & 352,241 & 4.2 & Diabetes mellitus & 395,612 & 4.7 \\
\hline 6 & Homicide and violence & 308,550 & 3.7 & Osteoarthritis & 361,774 & 4.3 \\
\hline 7 & Ischaemic heart disease & 274,704 & 3.3 & Breast cancer & 250,963 & 3.0 \\
\hline 8 & Diabetes mellitus & 238,472 & 2.9 & Unipolar major depression & 237,590 & 2.8 \\
\hline 9 & COPD & 234,552 & 2.8 & Cirrhosis of the liver & 208,861 & 2.5 \\
\hline 10 & Drug use & 222,535 & 2.7 & Cancer colon or rectum & 190,453 & 2.2 \\
\hline \multirow[t]{2}{*}{ Rank } & 65-74 & DALYs & $\%$ of total & $75+$ & DALYs & $\%$ of total \\
\hline & Total & $4,710,335$ & & Total & $4,391,323$ & \\
\hline 1 & Ischaemic heart disease & 820,583 & 17.4 & Ischaemic heart disease & 876,239 & 20.0 \\
\hline 2 & Lung, trachea or bronchial cancer & 448,452 & 9.5 & Dementias & 469,035 & 10.7 \\
\hline 3 & Cerebrovascular disease & 373,629 & 7.9 & Cerebrovascular disease & 420,278 & 48.0 \\
\hline 4 & COPD & 282,397 & 6.0 & Lung, trachea or bronchial cancer & 200,620 & 4.6 \\
\hline 5 & Osteoarthritis & 266,685 & 5.7 & COPD & 186,379 & 4.2 \\
\hline 6 & Dementias & 224,484 & 4.8 & Osteoarthritis & 161,077 & 3.7 \\
\hline 7 & Diabetes mellitus & 168,605 & 3.6 & Lower respiratory infections & $|46,63|$ & 3.3 \\
\hline 8 & Cancer colon or rectum & 138,630 & 2.9 & Cancer colon or rectum & 106,111 & 2.4 \\
\hline 9 & Prostate cancer & 97,033 & 2.1 & Diabetes mellitus & $106,06 \mid$ & 2.4 \\
\hline 10 & Breast cancer & 94,919 & 2.0 & Prostate cancer & 81,456 & 1.9 \\
\hline
\end{tabular}


Table 9: Distribution of burden of disease (DALYs) by age group and sex, US, 1996

\begin{tabular}{|c|c|c|c|c|c|c|}
\hline \multicolumn{3}{|l|}{ Total } & \multicolumn{2}{|l|}{ ales } & \multicolumn{2}{|c|}{ emales } \\
\hline Age Group & DALYs & $\%$ of total & DALYs & $\%$ of total & DALYs & $\%$ of total \\
\hline $0-4$ years & $2,123,767$ & $6.4 \%$ & $1,164,600$ & $6.5 \%$ & 959,167 & $6.3 \%$ \\
\hline $5-14$ years & $1,136,989$ & $3.4 \%$ & 623,416 & $3.5 \%$ & 513,573 & $3.4 \%$ \\
\hline 15-24 years & $3,884,235$ & $11.7 \%$ & $2,279,895$ & $12.8 \%$ & $1,604,340$ & $10.5 \%$ \\
\hline $25-44$ years & $8,364,608$ & $25.3 \%$ & $4,800,710$ & $26.9 \%$ & $3,563,898$ & $23.4 \%$ \\
\hline 45-64 years & $8,478,954$ & $25.6 \%$ & $4,754,166$ & $26.6 \%$ & $3,724,788$ & $24.5 \%$ \\
\hline $65-74$ years & $4,710,335$ & $14.2 \%$ & $2,455,407$ & $13.7 \%$ & $2,254,928$ & $14.8 \%$ \\
\hline 75 years and over & $4,391,323$ & $13.3 \%$ & I,782,198 & $10.0 \%$ & $2,609,125$ & $17.1 \%$ \\
\hline Total & $33,090,212$ & & $17,860,393$ & & $15,229,819$ & \\
\hline
\end{tabular}

in both sexes, confirming findings based on the comparison of YLL rankings (Tables 19 and 20).

The largest differentials between races for males pertained to COPD, cirrhosis of the liver, poisoning, hypertension and hypertensive heart disease. Rankings indicate a higher mortality burden due to COPD and cirrhosis of the liver in American Indians; hypertension and hypertensive heart disease in Blacks; and a lower mortality burden for poisoning in Asians. The largest rank differentials between races were observed in females for HIV/AIDS, self-inflicted injuries, COPD, hypertension and hypertensive heart disease, and cirrhosis of the liver. Rankings for Black females pointed to a higher mortality burden for HIV/AIDS, hypertension and hypertensive heart disease, and a lower mortality burden for self-inflicted injuries and ovarian cancer compared to White, American Indian and Asian females.

\section{Morbidity burden}

Leading causes of YLD

Non-fatal health outcomes resulted in 15 million YLD, which was only slightly less than the mortality burden (17 million YLL). For neuropsychiatric conditions, musculoskeletal conditions, chronic respiratory diseases, YLD contributed more than YLL. Neuropsychiatric conditions were the predominant cause of disability, causing 44 per cent of total YLD, regardless of sex and race (Figure 18). They comprise a wide array of conditions, sub-divided into mental disorders and diseases of the nervous system (DSM IV). Mental disorders include mood disorders (unipolar major depression, bipolar disorders), schizophre-

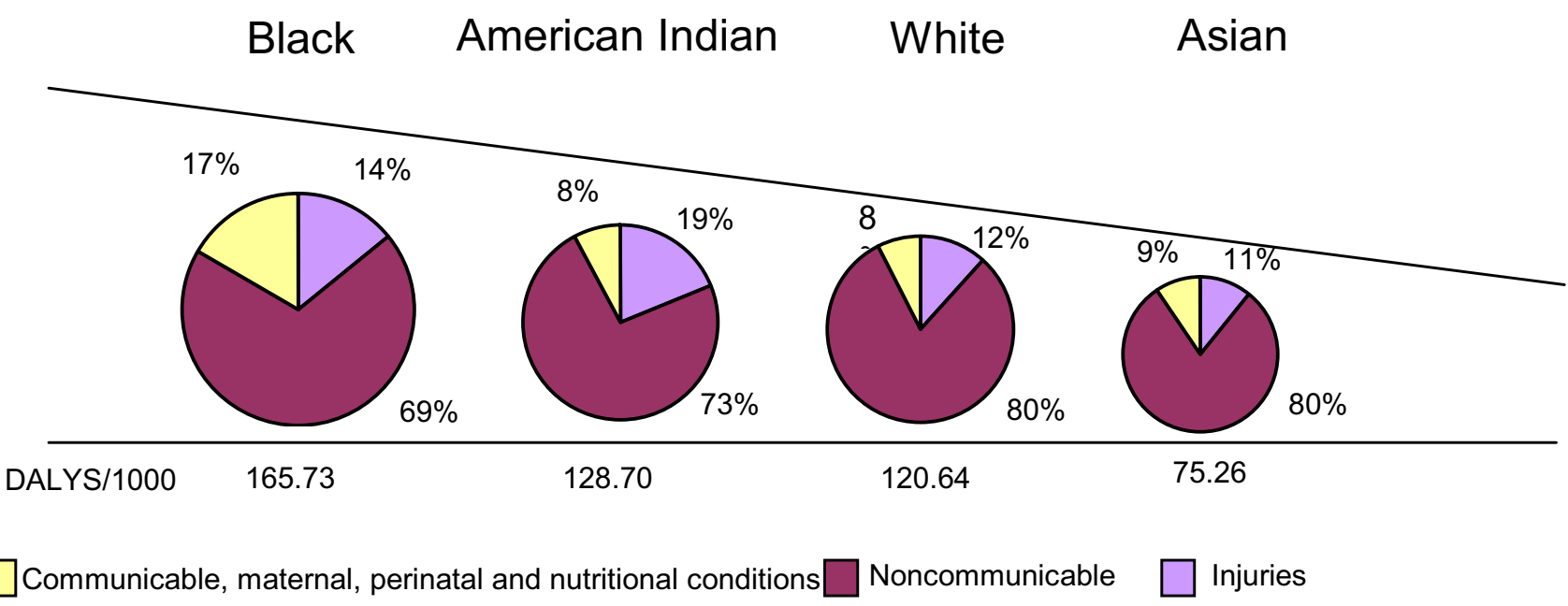

Figure 3

Groups I, II, and III as a percentage of total burden of disease (DALY) by race, US, I 996. 
Table I0: Ten leading causes of DALYs by race, US 1996

\begin{tabular}{|c|c|c|c|c|c|c|c|}
\hline & Whites & DALYs & $\%$ total & & American Indians & DALYs & $\%$ total \\
\hline Rank & Total & $26,510,011$ & & Rank & Total & 294,474 & \\
\hline 1 & Ischaemic heart disease & $2,710,918$ & $10.2 \%$ & I & Alcohol use & 46,419 & $15.8 \%$ \\
\hline 2 & Cerebrovascular Disease & $\mathrm{I}, 20 \mathrm{I}, 246$ & $4.5 \%$ & 2 & Motor vehicle accidents & 23,112 & $7.8 \%$ \\
\hline 3 & Lung trachea or bronchial cancer & $\mathrm{I}, \mathrm{I} 70,492$ & $4.4 \%$ & 3 & Ischaemic heart disease & 14,598 & $5.0 \%$ \\
\hline 4 & Motor vehicle accidents & $\mathrm{I}, \mid \mathrm{4} 8,293$ & $4.3 \%$ & 4 & Unipolar major depression & 11,815 & $4.0 \%$ \\
\hline 5 & Unipolar major depression & $\mathrm{I}, 127,045$ & $4.3 \%$ & 5 & Cirrhosis of the liver & 9,293 & $3.2 \%$ \\
\hline 6 & COPD & $\mathrm{I}, \mathrm{III}, 489$ & $4.2 \%$ & 6 & Diabetes mellitus & 9,070 & $3.1 \%$ \\
\hline 7 & Alcohol use & 857,509 & $3.2 \%$ & 7 & Self-inflicted & 8,336 & $2.8 \%$ \\
\hline 8 & Osteoarthritis & 820,284 & $3.1 \%$ & 8 & Cerebrovascular Disease & 8,241 & $2.8 \%$ \\
\hline 9 & $\begin{array}{l}\text { Dementia and other degenerative and } \\
\text { hereditary CNS disorders }\end{array}$ & 791,780 & $3.0 \%$ & 9 & Homicide and Violence & 7,754 & $2.6 \%$ \\
\hline \multirow[t]{3}{*}{10} & Diabetes mellitus & 727,575 & $2.7 \%$ & 10 & Congenital Abnormalities & 7,489 & $2.5 \%$ \\
\hline & Sub-total & $11,666,630$ & $44.0 \%$ & & sub-total & 146,128 & $49.6 \%$ \\
\hline & Blacks & DALYs & $\%$ total & & Asians & DALYs & $\%$ total \\
\hline Rank & Total & $5,552,448$ & & Rank & Total & 733,279 & \\
\hline 1 & HIVIAIDS & 429,383 & $7.7 \%$ & 1 & Unipolar major depression & 54,264 & $7.4 \%$ \\
\hline 2 & Ischaemic heart disease & 370,170 & $6.7 \%$ & 2 & Ischaemic heart disease & 39,046 & $5.3 \%$ \\
\hline 3 & Homicide and Violence & 336,215 & $6.1 \%$ & 3 & Cerebrovascular Disease & 33,883 & $4.6 \%$ \\
\hline 4 & Cerebrovascular Disease & 266,918 & $4.8 \%$ & 4 & COPD & 29,040 & $4.0 \%$ \\
\hline 5 & Alcohol use & 230,780 & $4.2 \%$ & 5 & Osteoarthritis & 29,027 & $4.0 \%$ \\
\hline 6 & Motor vehicle accidents & 193,159 & $3.5 \%$ & 6 & Motor vehicle accidents & $28,7 \mid 4$ & $3.9 \%$ \\
\hline 7 & Diabetes mellitus & 189,656 & $3.4 \%$ & 7 & Congenital Abnormalities & 28,238 & $3.9 \%$ \\
\hline 8 & Unipolar major depression & 177,162 & $3.2 \%$ & 8 & Asthma & 26,137 & $3.6 \%$ \\
\hline 9 & $\begin{array}{l}\text { Conditions arising during the perinatal } \\
\text { period }\end{array}$ & 174,558 & $3.1 \%$ & 9 & Diabetes mellitus & 19,989 & $2.7 \%$ \\
\hline \multirow[t]{2}{*}{10} & Lung trachea or bronchial cancer & 172,425 & $3.1 \%$ & 10 & $\begin{array}{l}\text { Dementia and other degenerative and } \\
\text { hereditary CNS disorders }\end{array}$ & $|7,83|$ & $2.4 \%$ \\
\hline & sub-total & $2,540,426$ & $45.8 \%$ & & sub-total & 306,170 & $41.8 \%$ \\
\hline
\end{tabular}

nia, anxiety disorders (PTSD, obsessive compulsive disorders, and panic disorders) affecting mostly young adults, and substance related disorders (alcohol and drug use) that increase in older adults. Nervous system disorders include Alzheimer's disease and other degenerative and hereditary CNS disorders, Parkinson's disease, epilepsy, and multiple sclerosis (Figure 19).

Unipolar major depression, alcohol use, osteoarthritis, dementia and other degenerative disorders of the CNS and cerebrovascular diseases were the five leading causes of YLD (Table 21). Unipolar major depression and alcohol use combined (2.4 million YLD) caused 16 per cent of total YLD, which represented almost the same burden as IHD (2.9 million YLL).

Sex and age patterns

Sex differentials were much smaller for YLD than for YLL. The morbidity burden was slightly larger for females (7.7 million YLD) than for males (7.3 million YLD). The five leading causes of YLD were alcohol use, unipolar major depression, osteoarthritis, drug use, and chronic obstructive pulmonary disease (COPD) for males, and unipolar major depression, osteoarthritis, dementia and other degenerative and hereditary CNS disorders, and alcohol use for females (Table 22).

The largest sex differentials pertained to the leading cause of YLD: alcohol use for males and unipolar major depression for females. The burden due to unipolar depression was almost double for females (900 thousand YLD) than it was for males ( 470 thousand YLD), whereas the burden due to alcohol was double for males (651 thousand YLD) than it was for females (386 thousand YLD). Together, alcohol use and unipolar depression caused 15 per cent of total YLD for males, and 17 per cent for females.

The share of total YLD due to neuropsychiatric conditions for males exceeded that for females. Morbidity due to substance abuse (alcohol and drug) in males was not entirely 


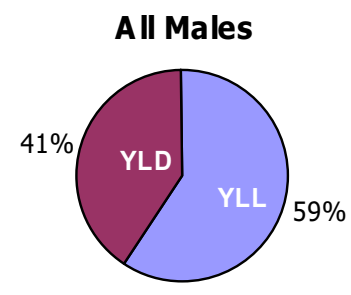

DALYs: $17,860,393$

\section{White males}

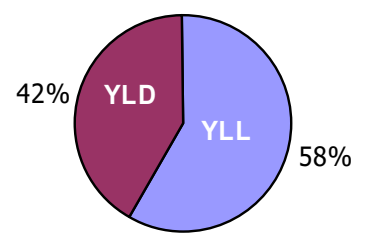

DALYs: $14,257,631$

Black males

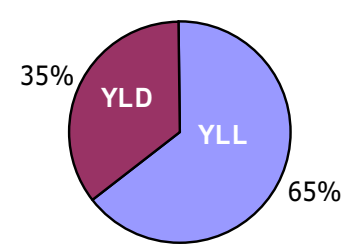

DALYs: $3,065,111$

\section{A merican Indian males}

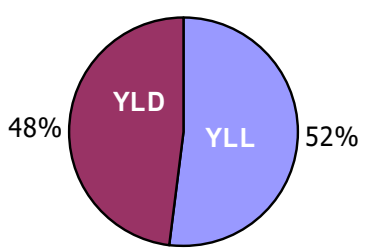

DALYs: 161,221

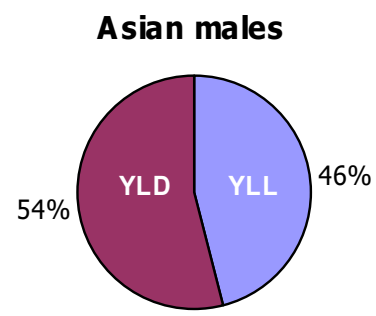

DALYs: 376,430

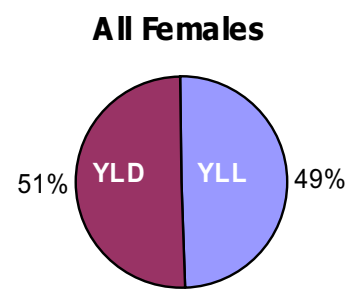

DALYs: $15,229,819$

White females

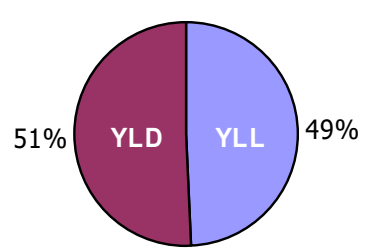

DALYs: $12,252,381$

Black females

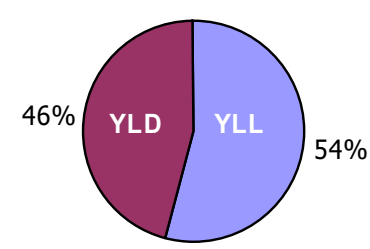

DALYs: $2,487,337$

American Indian females

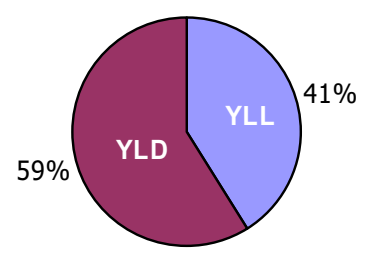

DALYs: 133,254

Asian females

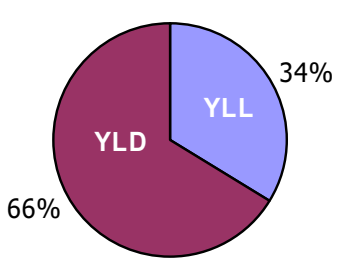

DALYs: 356,848

Figure 4

Distribution of YLL and YLD by sex and race, US, 1996. 

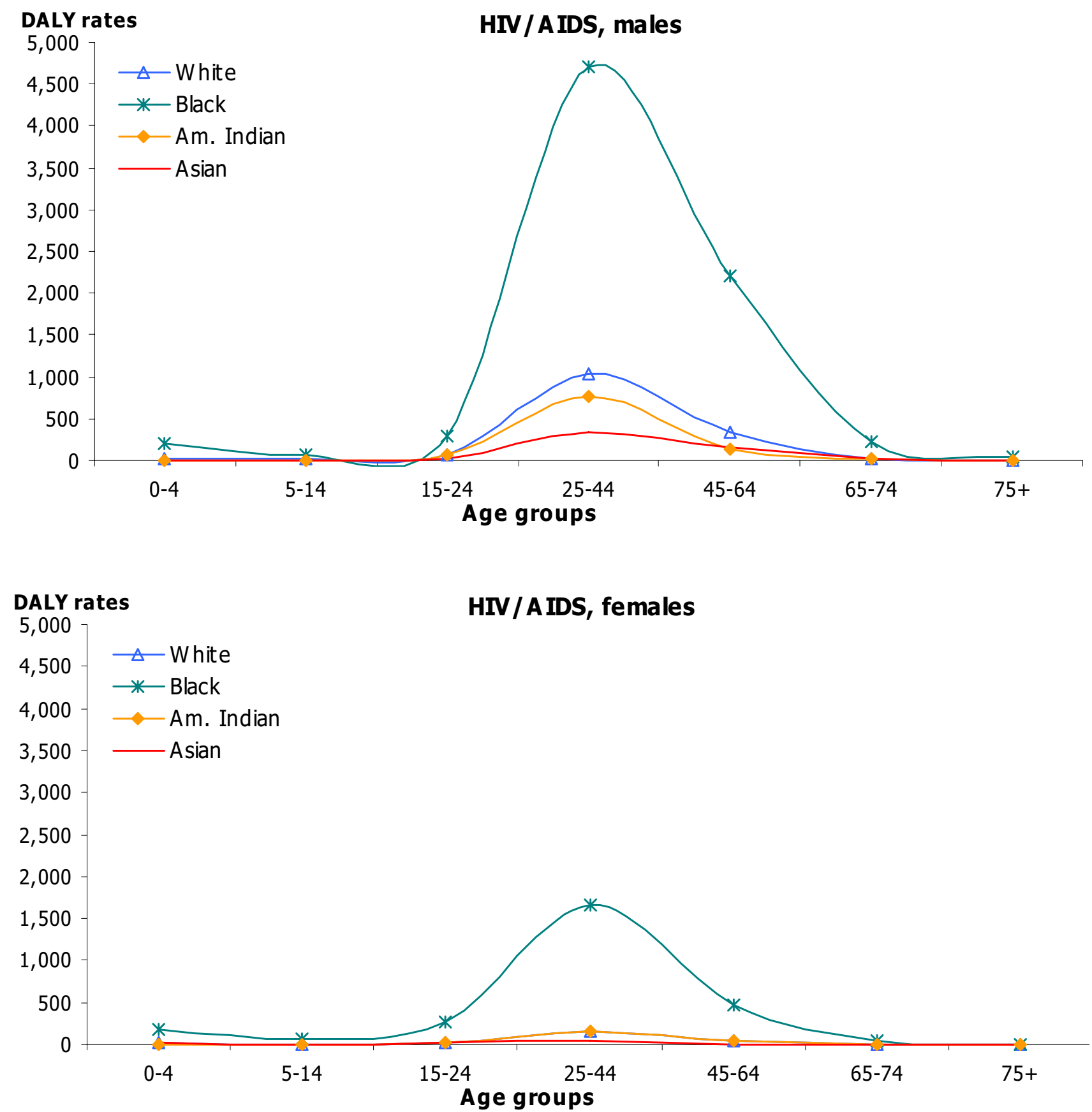

Figure 5

HIV/AIDS: distribution of DALY rates/ I00,000 by age, race and sex, US 1996.

offset by the preponderance of mood and anxiety disorders in females. The slightly higher share of dementia and other degenerative and hereditary CNS disorders in females resulted from their higher life expectancy.
Major causes contributing to the morbidity burden changed with age. Mental disorders and injuries affected mostly young adults, whereas nervous system disorders, musculoskeletal conditions, cardiovascular diseases, and 

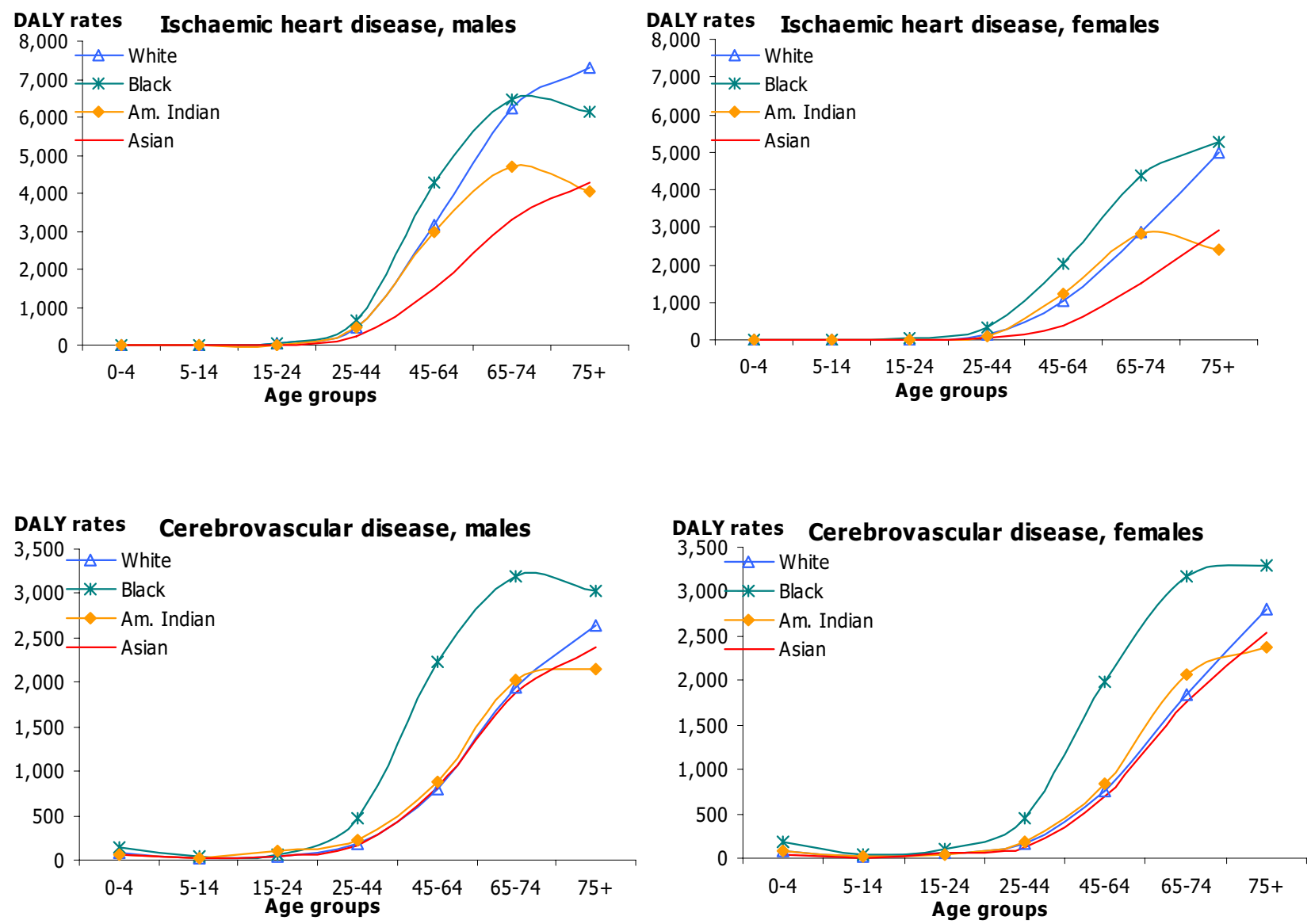

Figure 6

IHD and cerebrovascular diseases: distribution of DALY rates/100,000 by age, race and sex, US 1996 .

diabetes increased with age and were predominant among older adults. Chronic respiratory conditions affected all age groups. Congenital anomalies represented half of the non-fatal burden below age 5 .

\section{Patterns by race}

Alcohol use was the leading cause of YLD for males in all races, with the exception of Asian males for whom unipolar depression was the leading cause. Unipolar major depression was the leading cause for females of all races, with the exception of American Indian females for whom alcohol use was the leading cause (Tables 23, 24, 25, 26).

Differentials in patterns of neuropsychiatric disorders by race were dominated by the large excess morbidity burden caused by substance abuse among American Indians, which accounted for half of total YLD, compared to approximately one third in the other race groups.

The distribution of YLD rates for selected disease groupings by age further illustrate major differences that existed between races. These were particularly prominent for neuropsychiatric conditions in young adults between the ages 15 and 44 years (Figure 20).

\section{Discussion}

Quantifying the burden of disease is not a morally neutral exercise. All summary measures of health include several value choices. A strength of the GBD was to make value choices incorporated in the calculation of DALYs transparent. These include a standard duration of life at each age, an age weighting function, and discounting for time pref- 

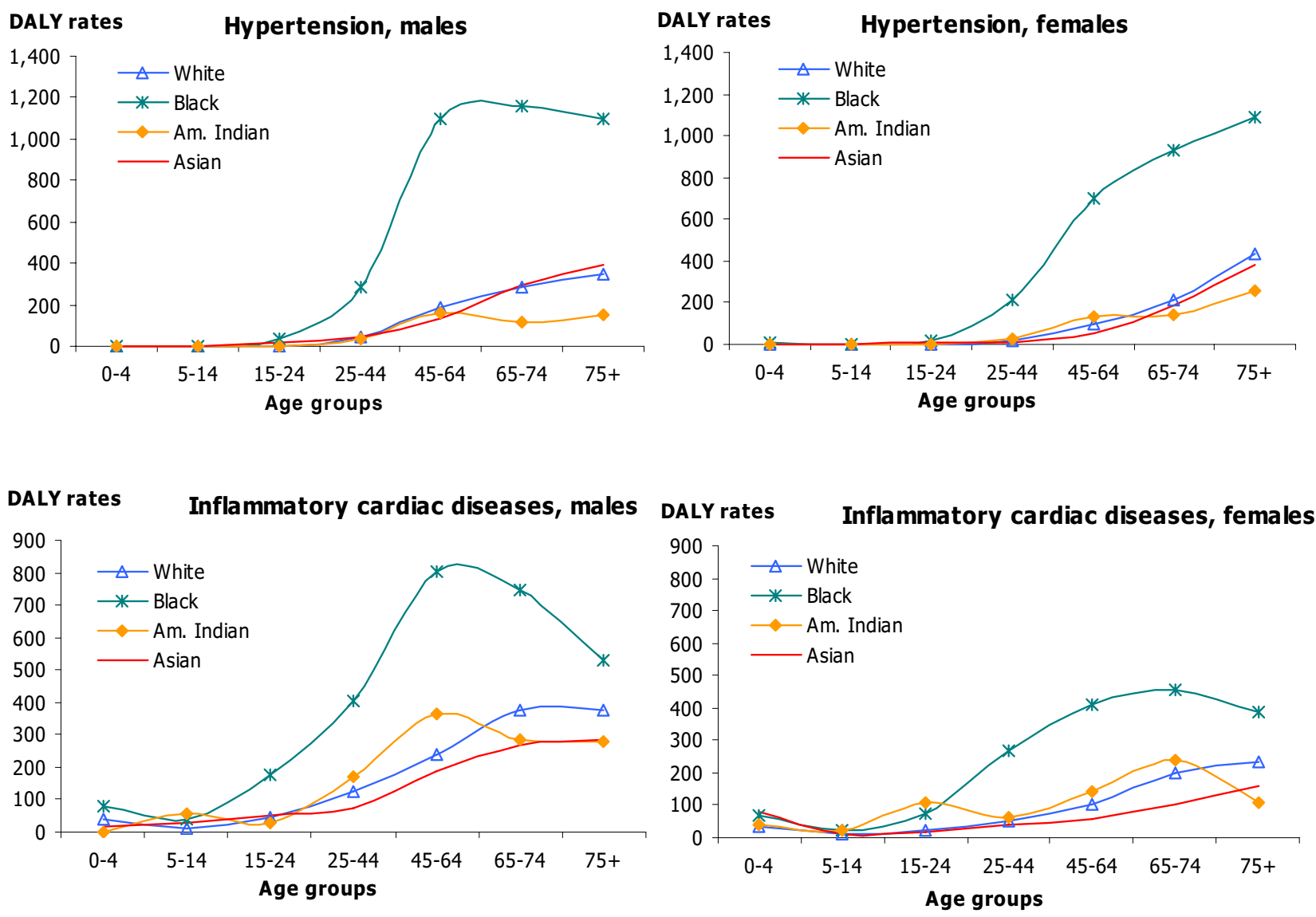

Figure 7

Hypertension and inflammatory cardiac diseases: distribution of DALY rates/I00,000 by age, race and sex, US 1996.

erence. GBD values for these parameters were not changed to ensure the international comparability of the USBODI.

The validation of GBD disability weights in different national contexts is particularly important to enhance the confidence of decision-makers in key findings of national disease burden estimates. The instrument used to derive the disability weights is called the Person Trade-Off (PTO). In the GBD the full PTO was executed for a set of 22 indicator conditions.

In order to assess whether groups of people from the United States might value these indicator conditions substantially differently than the benchmark values developed for the GBD, 35 volunteers that included staff from CDC, state health departments, other US federal agencies such as the National Institutes of Mental Health, as well as members of non-profit groups such as the American Heart Association and the Arthritis Foundation, were recruited to execute a PTO (PTO1 and PTO2) exercise as part of the US study. These participants were placed in 4 small groups of 8-12 members according to the GBD PTO (PTO1 and PTO2) protocol. Consistent with results from other such groups coordinated in a variety of international settings by the Burden of Disease Unit at Harvard, there was evidence of substantial inter-individual variation between the participants for conditions associated with milder disability (Table 4). For example, the median value for vitiligo of the face was 0.00 , and the average disability weight was 0.04. The standard deviation for the disability weight associated with this condition was larger than the actual point estimate. The coefficients of variation (C.V. = standard deviation/point estimate) were much smaller for conditions associated with more severe disability such as 

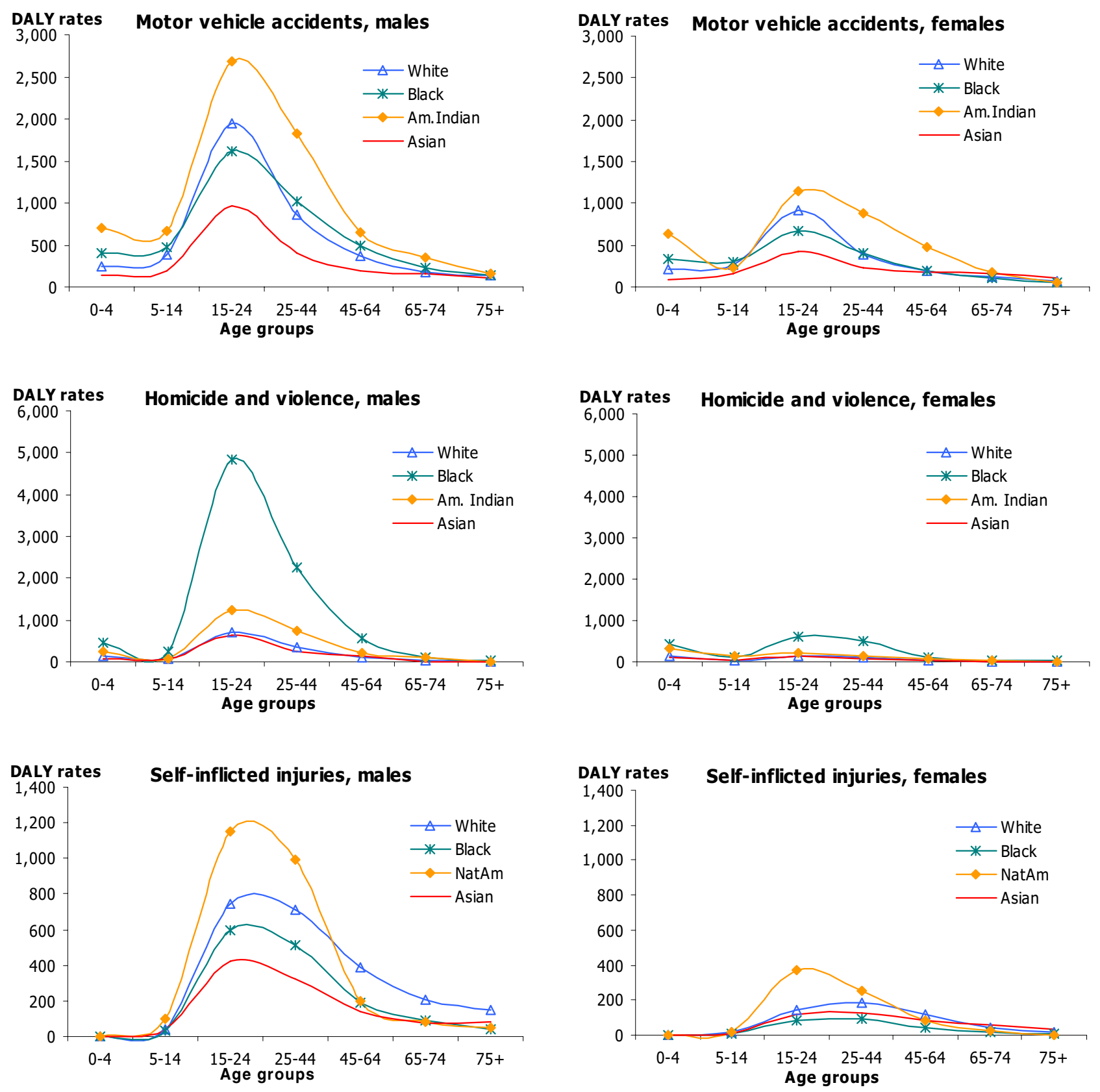

Figure 8

Major causes of injuries: distribution of DALY rates/100,000 by age, race and sex, US 1996.

quadriplegia and severe dementia. However, despite variation between individuals within these groups, the correlation between groups for the disability weight values was very strong. Nineteen conditions were included in every exercise. For each group the median disability weight value for each of these conditions was calculated. The correlations between pairs of groups for the 19 disability weight values were very high (Table 5, Range of Pearson's correlation coefficients $=0.82-0.99$ ).

Based on the above results it seemed reasonable to use the set of disability weights from the GBD study for the US evaluation. In a few instances more detailed data on health conditions were available in the US on the distribu- 

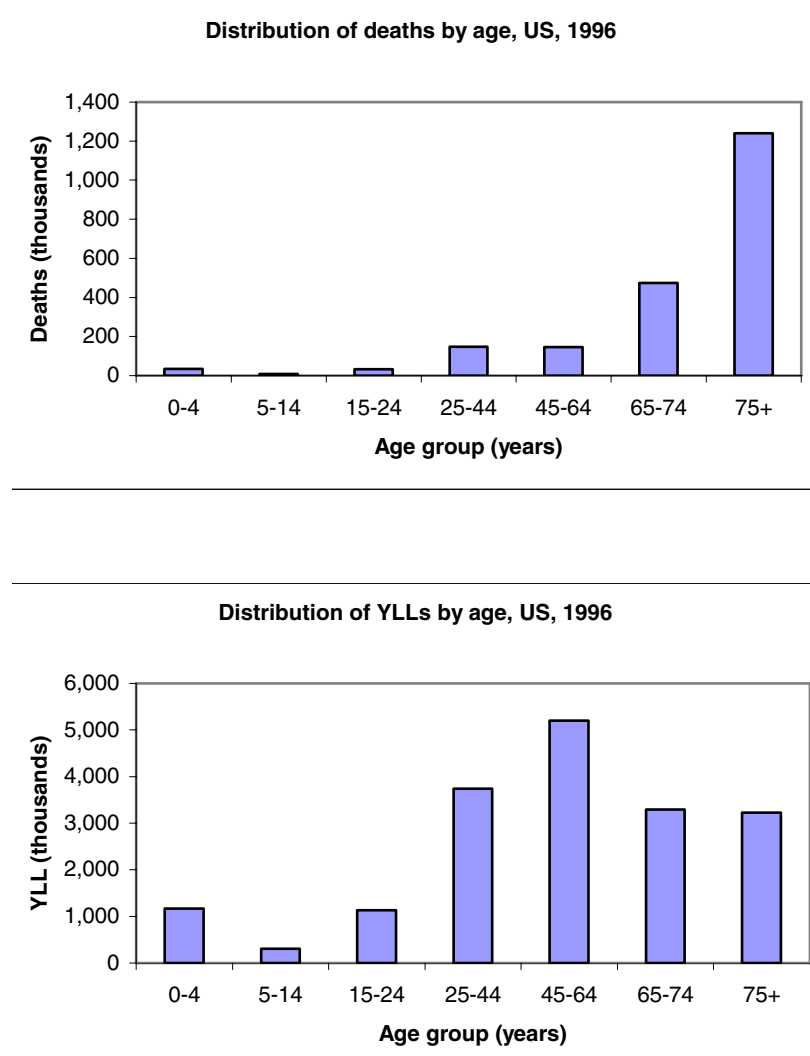

Figure 9

Distribution of deaths and YLL by age, US 1996.

tion of severity for certain health conditions such as depression [see Additional file 2]. Disability weights for severity-specific stages were developed for many of these conditions as part of a burden of disease and injury study implemented in the Netherlands [20]. Therefore, the Dutch weights were used when stage specific information on severity was available.

In the mid-1990s chronic diseases such as cardiovascular diseases, cancers, depression, osteoarthritis, diabetes mellitus, and alcohol use and abuse were the leading causes of death and disability in the United States. In addition, injuries from motor-vehicle accidents and the HIV epidemic exacted a substantial toll on the US population. These findings are consistent with other assessments of disease burden in developed and developing countries. However, the use of DALYs to enumerate the impact of health conditions is notably different from a simple listing of causes of death. This metric captures the importance of mental conditions, such as depression and degenerative musculoskeletal disease that cause major health problems but result in few deaths, as well as the importance of premature deaths among young adults (Tables 27, and 28).

The juxtaposition of the twenty leading causes of death, YLL, YLD and DALYs illustrates the extent to which an assessment of the relative importance of various causes based simply on total number of deaths differs from the assessment of leading causes of YLL, YLD and DALYs. For example, the total number of years lived with a disability resulting from unipolar major depression (1.3 million YLD) was equal to the number of years lost due to premature death from lung cancer (1.3 million YLL); and the burden resulting from osteoarthritis and motor vehicle accidents were similar (940.6 million YLD and 1 billion YLL respectively).

Osteoarthritis of the hip and knee (OA) and rheumatoid arthritis (RA) were the two leading musculoskeletal disorders. OA is an important public health problem that affects mostly older adults causing great pain and disability, and is one of the most rapidly growing causes of disability. The estimated 40 million prevalent cases in 1996 is projected to increase to 60 million cases by 2020 [22].

Substantial differences were found in the relative impact of individual conditions by gender and race. HIV/AIDS, alcohol dependence, as well as violent and unintentional injuries accounted for most of the worse health outcomes observed among Black and American Indian populations compared to White and Asian populations. Blacks fared much worse than the other race groups with regard to pregnancy outcomes. Blacks were the only group for which perinatal conditions ranked among the top ten causes of DALYs. Relatively high perinatal mortality rates persist in this population due to the combined effect of premature delivery and poor perinatal care.

Conditions associated with social issues in younger ages were much more common among Blacks and American Indians. For instance, YLL rates for HIV/AIDS were fivefold larger for Blacks than they were for any of the other races. YLL rates for homicide and violence were seven times higher for American Indians and twice as high for Blacks than they were for Whites and Asians.

One important objective of the study was to place the United States public health situation in a global context. Non-communicable diseases are the leading causes of deaths in all industrialized countries, where child and adult mortality are low. In developing regions, where child and adult mortality are still high, Group I represents a much larger share of the total. The dominance of HIV/ AIDS observed in Blacks in the United States was akin to that in developing regions of the world. It was the third leading cause among black women in the US and the fifth 


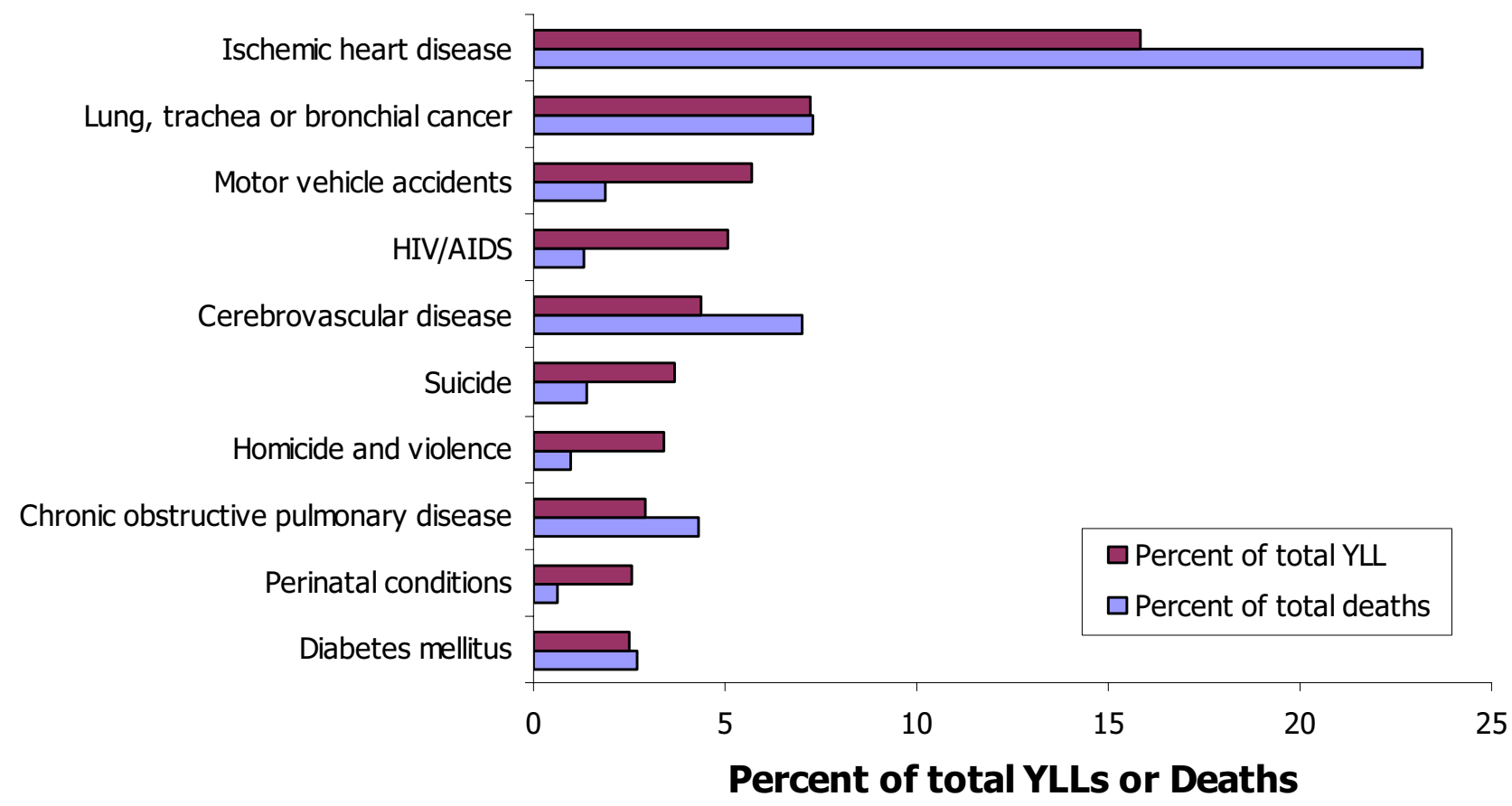

Figure 10

Ten leading causes of mortality burden and death, as per cent of total, both sexes, US 1996.

leading cause among females in developing regions. HIV/ AIDS accounted for a much smaller proportion of DALYs in other races in the US and did not figure among the top ten causes of DALYs in developed countries. Alcohol use for males in most racial subgroups in the United States exacted a high burden. This condition also ranked among the top five in other developed regions. Only Asian males and people living in developing countries did not have a large number of DALYs attributed to alcohol use.

US rankings clearly fell outside of the range observed elsewhere for a few causes: homicide and violence, HIV/AIDS, and perinatal conditions stand out regardless of race and gender. The United States has not been as successful in reducing the mortality burden due to violent injuries and perinatal conditions as were other industrialized countries with comparable levels of development.

In spite of the extensive population-based data available in the United States, there were limitations particularly in estimating disease burden by race due to smaller populations - Asians and American Indians. The major methodological limitations pertained to the different methods used to assign race and ethnicity in the census compared to death certificates; and to the limited population-based information that was available for many conditions for
Asians and American Indians. For these last two groups, ratios of YLL to YLD for the overall US population were generally used to estimate the burden due to non-fatal health conditions. Such assumptions introduce a certain level of uncertainty in the estimates and call for caution in the interpretation of small absolute differences in the number of DALYs between different causes. This study provides a benchmark against which to assess future trends in health differentials in the United States and underscores the importance of further research to improve methods, provide stronger empirical evidence and better understanding of major risk factors for poor health outcomes.

\section{Conclusion}

This study provides a comprehensive picture of conditions that contribute most to poor health outcomes, and yields new evidence to the discussion of racial health inequalities in the United States. The existence of health inequalities is widely acknowledged and lies at the core of public health policy: reducing health inequalities is the major focus of Healthy People 2010 [23]. Previous studies have documented differentials in mortality by cause and have examined socio-economic determinants - income and education - of population health outcomes and health outcomes mediated through the health system: the 
Table I I: Leading causes of death and YLL, both sexes, all races combined

\begin{tabular}{|c|c|c|c|}
\hline & & Deaths & \%total \\
\hline & Total Deaths & $2,314,689$ & \\
\hline 1 & Ischaemic heart disease & 536,314 & $23.2 \%$ \\
\hline 2 & Lung trachea or bronchial cancer & 168,206 & $7.3 \%$ \\
\hline 3 & Cerebrovascular Disease & 161,678 & $7.0 \%$ \\
\hline 4 & COPD & 99,982 & $4.3 \%$ \\
\hline 5 & Lower respiratory infections & 84,319 & $3.6 \%$ \\
\hline 6 & Diabetes mellitus & 62,452 & $2.7 \%$ \\
\hline 7 & Cancer colon or rectum & 61,189 & $2.6 \%$ \\
\hline 8 & Breast cancer & 46,649 & $2.0 \%$ \\
\hline 9 & Motor vehicle accidents & 43,735 & $1.9 \%$ \\
\hline 10 & Dementia and other degenerative and hereditary CNS disorders & 43,190 & $1.9 \%$ \\
\hline II & Hypertension and hypertensive heart disease & 39,589 & $1.7 \%$ \\
\hline 12 & Prostate cancer & 36,667 & $1.6 \%$ \\
\hline 13 & Self-inflicted & 31,725 & $1.4 \%$ \\
\hline 14 & HIV & 31,188 & $1.3 \%$ \\
\hline 15 & Cancer pancreas & 29,494 & $1.3 \%$ \\
\hline 16 & Inflammatory Cardiac & 29,066 & $1.3 \%$ \\
\hline 17 & Lymphomas & 26,443 & $1.1 \%$ \\
\hline 18 & Cirrhosis of the liver & 25,488 & $1.1 \%$ \\
\hline 19 & Nephritis or nephrosis & 24,569 & $1.1 \%$ \\
\hline \multirow[t]{4}{*}{20} & Homicide and Violence & 22,351 & $1.0 \%$ \\
\hline & \multirow[t]{2}{*}{ Sub-total } & $1,604,297$ & $69.3 \%$ \\
\hline & & YLL & $\%$ total \\
\hline & Total YLL & $18,066,099$ & \\
\hline 1 & Ischaemic heart disease & $2,858,744$ & $15.8 \%$ \\
\hline 2 & Lung trachea or bronchial cancer & $1,301,182$ & $7.2 \%$ \\
\hline 3 & Motor vehicle accidents & $1,027,005$ & $5.7 \%$ \\
\hline 4 & Cerebrovascular Disease & 784,443 & $4.3 \%$ \\
\hline 5 & HIV & 718,975 & $4.0 \%$ \\
\hline 6 & Self-inflicted & 660,917 & $3.7 \%$ \\
\hline 7 & Homicide and Violence & 615,332 & $3.4 \%$ \\
\hline 8 & COPD & 526,219 & $2.9 \%$ \\
\hline 9 & Conditions arising during the perinatal period & 464,131 & $2.6 \%$ \\
\hline 10 & Diabetes mellitus & 450,913 & $2.5 \%$ \\
\hline 11 & Breast cancer & 450,327 & $2.5 \%$ \\
\hline 12 & Cancer colon or rectum & 409,534 & $2.3 \%$ \\
\hline 13 & Lower respiratory infections & 388,441 & $2.2 \%$ \\
\hline 14 & Cirrhosis of the liver & 321,588 & $1.8 \%$ \\
\hline 15 & Congenital Abnomalities & 318,948 & $1.8 \%$ \\
\hline 16 & Inflammatory Cardiac & 258,328 & $1.4 \%$ \\
\hline 17 & Hypertension and hypertensive heart disease & 241,073 & $1.3 \%$ \\
\hline 18 & Lymphomas & 233,048 & $1.3 \%$ \\
\hline 19 & Poisoning & 221,906 & $1.2 \%$ \\
\hline \multirow[t]{2}{*}{20} & Cancer pancreas & 205,972 & $1.1 \%$ \\
\hline & Sub-total & $12,457,024$ & $69.0 \%$ \\
\hline
\end{tabular}


Table I2: Leading causes of YLL, by sex, all races combined

\begin{tabular}{|c|c|c|c|}
\hline & Cause list & YLL & $\%$ total \\
\hline & All males & $10,529,540$ & \\
\hline I & Ischaemic heart disease & $1,806,420$ & $17.2 \%$ \\
\hline 2 & Lung trachea or bronchial cancer & 777,726 & $7.4 \%$ \\
\hline 3 & Motor vehicle accidents & 701,111 & $6.7 \%$ \\
\hline 4 & HIV & 575,297 & $5.5 \%$ \\
\hline 5 & Self-inflicted & 533,874 & $5.1 \%$ \\
\hline 6 & Homicide and Violence & 486,129 & $4.6 \%$ \\
\hline 7 & Cerebrovascular Disease & 356,563 & $3.4 \%$ \\
\hline 8 & COPD & 268,774 & $2.6 \%$ \\
\hline 9 & Conditions arising during the perinatal period & 259,581 & $2.5 \%$ \\
\hline 10 & Diabetes mellitus & 220,494 & $2.1 \%$ \\
\hline II & Cirrhosis of the liver & 219,876 & $2.1 \%$ \\
\hline 12 & Cancer colon or rectum & 212,958 & $2.0 \%$ \\
\hline 13 & Lower respiratory infections & 202,668 & $1.9 \%$ \\
\hline 14 & Congenital Abnomalities & 172,399 & $1.6 \%$ \\
\hline 15 & Poisoning & $168,13 \mid$ & $1.6 \%$ \\
\hline 16 & Inflammatory Cardiac & 167,316 & $1.6 \%$ \\
\hline 17 & Prostate cancer & 160,019 & $1.5 \%$ \\
\hline 18 & Lymphomas & 134,145 & $1.3 \%$ \\
\hline 19 & Hypertension and hypertensive heart disease & 127,968 & $1.2 \%$ \\
\hline \multirow[t]{4}{*}{20} & Leukemias & 114,710 & $1.1 \%$ \\
\hline & Sub-total & $7,666,158$ & $72.8 \%$ \\
\hline & Cause list & YLL & $\%$ total \\
\hline & All females & $7,536,559$ & \\
\hline I & Ischaemic heart disease & $1,052,325$ & $14.0 \%$ \\
\hline 2 & Lung trachea or bronchial cancer & 523,456 & $6.9 \%$ \\
\hline 3 & Breast cancer & 450,327 & $6.0 \%$ \\
\hline 4 & Cerebrovascular Disease & 427,881 & $5.7 \%$ \\
\hline 5 & Motor vehicle accidents & 325,894 & $4.3 \%$ \\
\hline 6 & COPD & 257,445 & $3.4 \%$ \\
\hline 7 & Diabetes mellitus & 230,419 & $3.1 \%$ \\
\hline 8 & Conditions arising during the perinatal period & 204,550 & $2.7 \%$ \\
\hline 9 & Cancer colon or rectum & 196,575 & $2.6 \%$ \\
\hline 10 & Lower respiratory infections & 185,774 & $2.5 \%$ \\
\hline 11 & Congenital Abnomalities & $\mid 46,548$ & $1.9 \%$ \\
\hline 12 & HIV & 143,678 & $1.9 \%$ \\
\hline 13 & Homicide and Violence & 129,202 & $1.7 \%$ \\
\hline 14 & Self-inflicted & 127,043 & $1.7 \%$ \\
\hline 15 & Ovarian cancer & 122,350 & $1.6 \%$ \\
\hline 16 & Hypertension and hypertensive heart disease & 113,105 & $1.5 \%$ \\
\hline 17 & Cirrhosis of the liver & 101,712 & $1.3 \%$ \\
\hline 18 & Cancer pancreas & 99,766 & $1.3 \%$ \\
\hline 19 & Lymphomas & 98,902 & $1.3 \%$ \\
\hline \multirow[t]{2}{*}{20} & Inflammatory Cardiac & 91,012 & $1.2 \%$ \\
\hline & Sub-total & $5,027,963$ & $66.7 \%$ \\
\hline
\end{tabular}

utilization of health services, access, and quality of care [24-26].

The main policy message emerging from this study is that cost-effective public health interventions are available to reduce the burden of the three conditions that contributed most to racial inequalities. It adds new evidence that greater investments of public health interventions have a much greater potential to reduce large health inequalities in the United States than do technology driven curative 




\section{Females}

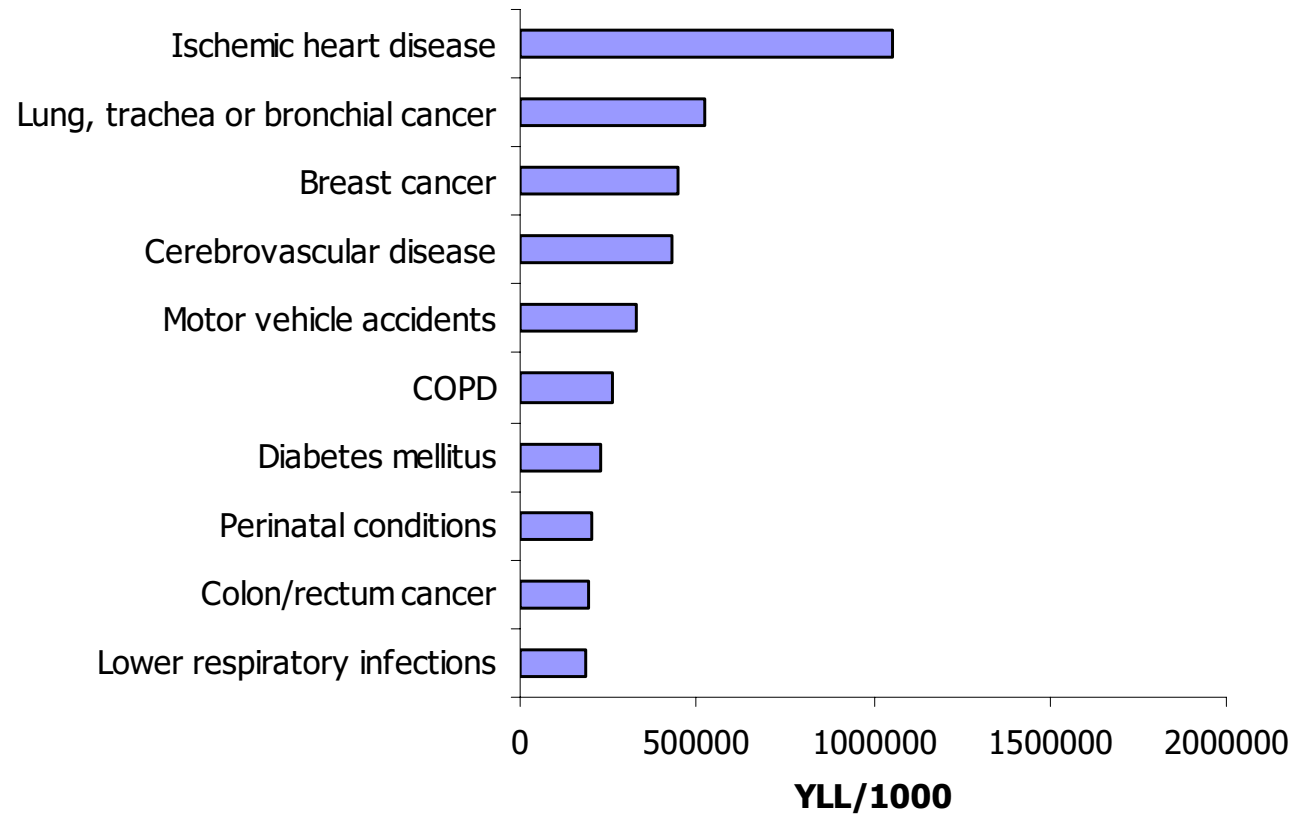

Figure I I

Leading causes of mortality burden (YLL) by sex, US, 1996. 
Table I3: Five leading causes of mortality burden (YLL) by sex and age, US, 1996



interventions. The fact that other countries, which have lower expenditures per capita have achieved better health outcomes than the United States indicates that the major goal of reducing health disparities by 2010 can be achieved.

\section{Competing interests}

The author(s) declare that they have no competing interests.

\section{Authors' contributions}

CJL conceived of the study, participated in its design, and helped to draft the manuscript. CMM, MTM participated in the study's design and coordination, data analysis and helped to draft the manuscript. SB, NT, MM, MTB, EME, JS, JGK, MH contributed to data analysis. ME helped to draft the manuscript. All authors read and approved the final manuscript. 
Table 14: Five leading causes of mortality burden (YLL) by sex and age, US, 1996

\begin{tabular}{|c|c|c|c|c|c|c|}
\hline \multirow[b]{2}{*}{ Rank } & \multicolumn{6}{|l|}{ Females } \\
\hline & All ages & YLL & $\%$ of total & $0-4$ & YLL & $\%$ of total \\
\hline & Total & $7,536,559$ & & Total & 512,861 & \\
\hline I & Ischaemic heart disease & $\mathrm{I}, 052,325$ & $13.96 \%$ & Perinatal conditions & 203,909 & $39.76 \%$ \\
\hline 2 & Lung/Trachea/Bronchial cancer & 523,456 & $6.95 \%$ & Congenital abnormalities & 109,458 & $21.34 \%$ \\
\hline 3 & Breast cancer & 450,327 & $5.98 \%$ & Sudden infant death syndrome & 41,154 & $8.02 \%$ \\
\hline 4 & Cerebrovascular disease & 427,881 & $5.68 \%$ & Motor vehicle accidents & 14,795 & $2.88 \%$ \\
\hline 5 & Motor vehicle accidents & 325,894 & $4.32 \%$ & Homicide and violence & 13,612 & $2.65 \%$ \\
\hline \multirow[t]{2}{*}{ Rank } & $5-14$ & YLL & $\%$ of total & $15-24$ & YLL & $\%$ of total \\
\hline & Total & 123,888 & & Total & 285,089 & \\
\hline I & Motor vehicle accidents & 28,952 & $23.37 \%$ & Motor vehicle accidents & 117,878 & $41.35 \%$ \\
\hline 2 & Homicide and violence & 8,134 & $6.57 \%$ & Homicide and violence & 32,799 & $11.50 \%$ \\
\hline 3 & Congenital abnormalities & 7,226 & $5.83 \%$ & Suicide & 22,517 & $7.90 \%$ \\
\hline 4 & Leukemias & 6,120 & $4.94 \%$ & Leukemias & 6,726 & $2.36 \%$ \\
\hline 5 & Brain cancer & 5,611 & $4.53 \%$ & HIVIAIDS & 5,830 & $2.05 \%$ \\
\hline \multirow[t]{2}{*}{ Rank } & $25-44$ & YLL & $\%$ of total & $45-64$ & YLL & $\%$ of total \\
\hline & Total & $1,192,947$ & & Total & $2,053,395$ & \\
\hline I & Motor vehicle accidents & 117,878 & $9.88 \%$ & Ischaemic heart disease & 524,172 & $25.53 \%$ \\
\hline 2 & HIVIAIDS & 109,310 & $9.16 \%$ & Lung/Trachea/Bronchial cancer & 234,241 & $11.41 \%$ \\
\hline 3 & Breast cancer & 95,818 & $8.03 \%$ & Breast cancer & 220,350 & $10.73 \%$ \\
\hline 4 & Suicide & 67,035 & $5.62 \%$ & Cerebrovascular disease & 99,565 & $4.85 \%$ \\
\hline 5 & Homicide and violence & 60,074 & $5.04 \%$ & Diabetes mellitus & 81,366 & $3.96 \%$ \\
\hline \multirow[t]{2}{*}{ Rank } & $65-74$ & YLL & $\%$ of total & $75+$ & YLL & $\%$ of total \\
\hline & Total & $\mathrm{I}, 503,549$ & & Total & $1,864,830$ & \\
\hline 1 & Ischaemic heart disease & 277,053 & $18.43 \%$ & Ischaemic heart disease & 459,396 & $24.63 \%$ \\
\hline 2 & Lung/Trachea/Bronchial cancer & 172,116 & $11.45 \%$ & Cerebrovascular disease & 186,468 & $10.00 \%$ \\
\hline 3 & Chronic obstructive pulmonary disease & 97,759 & $6.50 \%$ & Chronic obstructive pulmonary disease & 88,838 & $4.76 \%$ \\
\hline 4 & Cerebrovascular disease & 90,698 & $6.03 \%$ & Lung/Trachea/Bronchial cancer & 84,492 & $4.53 \%$ \\
\hline 5 & Breast cancer & 82,227 & $5.47 \%$ & Lower respiratory infections & 83,467 & $4.48 \%$ \\
\hline
\end{tabular}


Table 15: Leading causes of YLL by sex and race - Whites

\begin{tabular}{|c|c|c|c|}
\hline & Cause list & YLL & $\%$ total \\
\hline & Total White males & $8,293,920$ & \\
\hline I & Ischaemic heart disease & $1,584,087$ & $19.1 \%$ \\
\hline 2 & Lung trachea or bronchial cancer & 656,850 & $7.9 \%$ \\
\hline 3 & Road Traffic Accidents & 573,953 & $6.9 \%$ \\
\hline 4 & Self-inflicted & 469,430 & $5.7 \%$ \\
\hline 5 & HIV & 334,425 & $4.0 \%$ \\
\hline 6 & Cerebrovascular Disease & 276,544 & $3.3 \%$ \\
\hline 7 & COPD & 244,401 & $2.9 \%$ \\
\hline 8 & Homicide and Violence & 221,000 & $2.7 \%$ \\
\hline 9 & Cirrhosis of the liver & 183,600 & $2.2 \%$ \\
\hline 10 & Cancer colon or rectum & 180,184 & $2.2 \%$ \\
\hline 11 & Diabetes mellitus & 173,405 & $2.1 \%$ \\
\hline 12 & Conditions arising during the perinatal period & 158,462 & $1.9 \%$ \\
\hline 13 & Lower respiratory infections & $|58,23|$ & $1.9 \%$ \\
\hline 14 & Congenital Abnomalities & 135,970 & $1.6 \%$ \\
\hline 15 & Poisoning & 134,929 & $1.6 \%$ \\
\hline 16 & Prostate cancer & 128,058 & $1.5 \%$ \\
\hline 17 & Inflammatory Cardiac & 121,438 & $1.5 \%$ \\
\hline 18 & Lymphomas & 116,804 & $1.4 \%$ \\
\hline 19 & Leukemias & 99,137 & $1.2 \%$ \\
\hline \multirow[t]{4}{*}{20} & Cancer pancreas & 89,780 & $1.1 \%$ \\
\hline & \multirow[t]{2}{*}{ Sub-total } & $6,040,688$ & $72.8 \%$ \\
\hline & & YLL & $\%$ total \\
\hline & Total White females & $6,018,361$ & \\
\hline I & Ischaemic heart disease & 895,819 & $14.9 \%$ \\
\hline 2 & Lung trachea or bronchial cancer & 460,651 & $7.7 \%$ \\
\hline 3 & Breast cancer & 370,855 & $6.2 \%$ \\
\hline 4 & Cerebrovascular Disease & 342,620 & $5.7 \%$ \\
\hline 5 & Road Traffic Accidents & 268,996 & $4.5 \%$ \\
\hline 6 & COPD & 240,803 & $4.0 \%$ \\
\hline 7 & Diabetes mellitus & 169,449 & $2.8 \%$ \\
\hline 8 & Cancer colon or rectum & 163,068 & $2.7 \%$ \\
\hline 9 & Lower respiratory infections & 153,465 & $2.5 \%$ \\
\hline 10 & Conditions arising during the perinatal period & 124,599 & $2.1 \%$ \\
\hline 11 & Congenital Abnomalities & 112,925 & $1.9 \%$ \\
\hline 12 & Self-inflicted & || $2,62 \mid$ & $1.9 \%$ \\
\hline 13 & Ovarian cancer & 108,262 & $1.8 \%$ \\
\hline 14 & Lymphomas & 87,677 & $1.5 \%$ \\
\hline 15 & Cancer pancreas & 83,238 & $1.4 \%$ \\
\hline 16 & Cirrhosis of the liver & 81,843 & $1.4 \%$ \\
\hline 17 & Dementia and other degenerative and hereditary CNS disorders & 76,867 & $1.3 \%$ \\
\hline 18 & Leukemias & 74,069 & $1.2 \%$ \\
\hline 19 & Homicide and Violence & 72,469 & $1.2 \%$ \\
\hline \multirow[t]{2}{*}{20} & Hypertension and hypertensive heart disease & 72,258 & $1.2 \%$ \\
\hline & Sub-total & $4,072,553$ & $67.7 \%$ \\
\hline
\end{tabular}


Table 16: Leading causes of YLL by sex and race - Blacks

\begin{tabular}{|c|c|c|c|}
\hline & Cause list & YLL & $\%$ total \\
\hline & Total Black males & $1,978,704$ & \\
\hline I & Homicide and Violence & 250,257 & $12.6 \%$ \\
\hline 2 & HIV & 234,400 & $11.8 \%$ \\
\hline 3 & Ischaemic heart disease & $|89,03|$ & $9.6 \%$ \\
\hline 4 & Lung trachea or bronchial cancer & 109,191 & $5.5 \%$ \\
\hline 5 & Motor vehicle accidents & 99,734 & $5.0 \%$ \\
\hline 6 & Conditions arising during the perinatal period & 92,854 & $4.7 \%$ \\
\hline 7 & Cerebrovascular Disease & 69,225 & $3.5 \%$ \\
\hline 8 & Self-inflicted & 47,940 & $2.4 \%$ \\
\hline 9 & Hypertension and hypertensive heart disease & 44,841 & $2.3 \%$ \\
\hline 10 & Inflammatory Cardiac & 41,409 & $2.1 \%$ \\
\hline 11 & Diabetes mellitus & 40,795 & $2.1 \%$ \\
\hline 12 & Lower respiratory infections & 38,675 & $2.0 \%$ \\
\hline 13 & Congenital Abnomalities & 30,182 & $1.5 \%$ \\
\hline 14 & Cirrhosis of the liver & 30,182 & $1.5 \%$ \\
\hline 15 & Poisoning & 30,101 & $1.5 \%$ \\
\hline 16 & Prostate cancer & 30,075 & $1.5 \%$ \\
\hline 17 & Cancer colon or rectum & 28,380 & $1.4 \%$ \\
\hline 18 & COPD & 21,382 & $1.1 \%$ \\
\hline 19 & Sudden Infant Death Syndrome & 19,017 & $1.0 \%$ \\
\hline \multirow[t]{4}{*}{20} & Nephritis or nephrosis & 17,092 & $0.9 \%$ \\
\hline & Sub-total & $1,464,762$ & $74.0 \%$ \\
\hline & Cause list & YLL & $\%$ total \\
\hline & Total Black females & $1,342,205$ & \\
\hline I & Ischaemic heart disease & $|4|, 305$ & $10.5 \%$ \\
\hline 2 & HIV & 89,973 & $6.7 \%$ \\
\hline 3 & Cerebrovascular Disease & 74,323 & $5.5 \%$ \\
\hline 4 & Conditions arising during the perinatal period & 73,969 & $5.5 \%$ \\
\hline 5 & Breast cancer & 70,421 & $5.2 \%$ \\
\hline 6 & Lung trachea or bronchial cancer & 55,561 & $4.1 \%$ \\
\hline 7 & Diabetes mellitus & 54,669 & $4.1 \%$ \\
\hline 8 & Homicide and Violence & 52,280 & $3.9 \%$ \\
\hline 9 & Motor vehicle accidents & 42,499 & $3.2 \%$ \\
\hline 10 & Hypertension and hypertensive heart disease & 39,005 & $2.9 \%$ \\
\hline 11 & Cancer colon or rectum & 28,896 & $2.2 \%$ \\
\hline 12 & Congenital Abnomalities & 28,218 & $2.1 \%$ \\
\hline 13 & Lower respiratory infections & 28,108 & $2.1 \%$ \\
\hline 14 & Inflammatory Cardiac & 25,707 & $1.9 \%$ \\
\hline 15 & Nephritis or nephrosis & $|5,8| \mid$ & $1.2 \%$ \\
\hline 16 & Cirrhosis of the liver & $|5,70|$ & $1.2 \%$ \\
\hline 17 & COPD & 14,858 & $1.1 \%$ \\
\hline 18 & Cancer pancreas & 14,132 & $1.1 \%$ \\
\hline 19 & Sudden Infant Death Syndrome & $|3,84|$ & $1.0 \%$ \\
\hline \multirow[t]{2}{*}{20} & Cancer cervix & 13,786 & $1.0 \%$ \\
\hline & Sub-total & 893,064 & $66.5 \%$ \\
\hline
\end{tabular}


Table 17: Leading causes of YLL by sex and race - American Indians

\begin{tabular}{|c|c|c|c|}
\hline & Cause list & YLL & $\%$ total \\
\hline & Total American Indian males & 83,713 & \\
\hline 1 & Motor vehicle accidents & 13,665 & $16.3 \%$ \\
\hline 2 & Ischaemic heart disease & 8,804 & $10.5 \%$ \\
\hline 3 & Self-inflicted & 6,472 & $7.7 \%$ \\
\hline 4 & Homicide and Violence & 5,287 & $6.3 \%$ \\
\hline 5 & Cirrhosis of the liver & 3,982 & $4.8 \%$ \\
\hline 6 & Alcohol use & 2,849 & $3.4 \%$ \\
\hline 7 & Lung trachea or bronchial cancer & 2,792 & $3.3 \%$ \\
\hline 8 & Diabetes mellitus & 2,610 & $3.1 \%$ \\
\hline 9 & Lower respiratory infections & 2,168 & $2.6 \%$ \\
\hline 10 & Conditions arising during the perinatal period & 2,078 & $2.5 \%$ \\
\hline 11 & Poisoning & 2,009 & $2.4 \%$ \\
\hline 12 & HIV & 1,952 & $2.3 \%$ \\
\hline 13 & Cerebrovascular Disease & 1,919 & $2.3 \%$ \\
\hline 14 & Congenital Abnomalities & 1,658 & $2.0 \%$ \\
\hline 15 & Drowning & 1,489 & $1.8 \%$ \\
\hline 16 & Sudden Infant Death Syndrome & 1,239 & $1.5 \%$ \\
\hline 17 & Inflammatory Cardiac & 1,193 & $1.4 \%$ \\
\hline 18 & Cancer colon or rectum & 816 & $1.0 \%$ \\
\hline 19 & Falls & 755 & $0.9 \%$ \\
\hline \multirow[t]{4}{*}{20} & COPD & 719 & $0.9 \%$ \\
\hline & Sub-total & 64,456 & $77.0 \%$ \\
\hline & Cause list & YLL & $\%$ total \\
\hline & Total Amerian Indian females & 54,732 & \\
\hline 1 & Motor vehicle accidents & 6,429 & $11.7 \%$ \\
\hline 2 & Ischaemic heart disease & 4,247 & $7.8 \%$ \\
\hline 3 & Cirrhosis of the liver & 3,311 & $6.0 \%$ \\
\hline 4 & Diabetes mellitus & 2,970 & $5.4 \%$ \\
\hline 5 & Cerebrovascular Disease & 2,057 & $3.8 \%$ \\
\hline 6 & Breast cancer & 1,901 & $3.5 \%$ \\
\hline 7 & Lung trachea or bronchial cancer & 1,788 & $3.3 \%$ \\
\hline 8 & Self-inflicted & I,786 & $3.3 \%$ \\
\hline 9 & Homicide and Violence & 1,534 & $2.8 \%$ \\
\hline 10 & Conditions arising during the perinatal period & $|, 53|$ & $2.8 \%$ \\
\hline 11 & Lower respiratory infections & 1,523 & $2.8 \%$ \\
\hline 12 & Congenital Abnomalities & 1,182 & $2.2 \%$ \\
\hline 13 & Alcohol use & 1,156 & $2.1 \%$ \\
\hline 14 & Sudden Infant Death Syndrome & 907 & $1.7 \%$ \\
\hline 15 & Cancer colon or rectum & 851 & $1.6 \%$ \\
\hline 16 & Poisoning & 809 & $1.5 \%$ \\
\hline 17 & COPD & 731 & $1.3 \%$ \\
\hline 18 & Ovarian cancer & 678 & $1.2 \%$ \\
\hline 19 & Inflammatory Cardiac & 651 & $1.2 \%$ \\
\hline \multirow[t]{2}{*}{20} & Drowning & 633 & $1.2 \%$ \\
\hline & Sub-total & 36,675 & $67.0 \%$ \\
\hline
\end{tabular}


Table 18: Leading causes of YLL by sex and race - Asians

\begin{tabular}{|c|c|c|c|}
\hline & Cause list & YLL & $\%$ total \\
\hline & Total Asian males & $|73,20|$ & \\
\hline $\mathrm{I}$ & Ischaemic heart disease & 24,497 & $14.1 \%$ \\
\hline 2 & Motor vehicle accidents & 13,759 & $7.9 \%$ \\
\hline 3 & Self-inflicted & 10,032 & $5.8 \%$ \\
\hline 4 & Homicide and Violence & 9,584 & $5.5 \%$ \\
\hline 5 & Lung trachea or bronchial cancer & 8,892 & $5.1 \%$ \\
\hline 6 & Cerebrovascular Disease & 8,875 & $5.1 \%$ \\
\hline 7 & Cancer liver & 6,330 & $3.7 \%$ \\
\hline 8 & Conditions arising during the perinatal period & 6,188 & $3.6 \%$ \\
\hline 9 & Congenital Abnomalities & 4,590 & $2.7 \%$ \\
\hline 10 & HIV & 4,520 & $2.6 \%$ \\
\hline 11 & Diabetes mellitus & 3,684 & $2.1 \%$ \\
\hline 12 & Lower respiratory infections & 3,593 & $2.1 \%$ \\
\hline 13 & Cancer colon or rectum & 3,578 & $2.1 \%$ \\
\hline 14 & Inflammatory Cardiac & 3,276 & $1.9 \%$ \\
\hline 15 & Drowning & 3,256 & $1.9 \%$ \\
\hline 16 & Cancer stomach & 2,935 & $1.7 \%$ \\
\hline 17 & Leukemias & 2,601 & $1.5 \%$ \\
\hline 18 & Hypertension and hypertensive heart disease & 2,365 & $1.4 \%$ \\
\hline 19 & COPD & 2,272 & $1.3 \%$ \\
\hline \multirow[t]{4}{*}{20} & Cirrhosis of the liver & 2,113 & $1.2 \%$ \\
\hline & Sub-total & $|26,94|$ & $73.3 \%$ \\
\hline & Cause list & YLL & $\%$ total \\
\hline & Total Asian females & $|2|, 26 \mid$ & \\
\hline 1 & Ischaemic heart disease & 10,953 & $9.0 \%$ \\
\hline 2 & Cerebrovascular Disease & 8,881 & $7.3 \%$ \\
\hline 3 & Road Traffic Accidents & 7,970 & $6.6 \%$ \\
\hline 4 & Breast cancer & 7,150 & $5.9 \%$ \\
\hline 5 & Lung trachea or bronchial cancer & 5,455 & $4.5 \%$ \\
\hline 6 & Conditions arising during the perinatal period & 4,451 & $3.7 \%$ \\
\hline 7 & Congenital Abnomalities & 4,223 & $3.5 \%$ \\
\hline 8 & Self-inflicted & 4,112 & $3.4 \%$ \\
\hline 9 & Cancer colon or rectum & 3,761 & $3.1 \%$ \\
\hline 10 & Diabetes mellitus & 3,331 & $2.7 \%$ \\
\hline 11 & Homicide and Violence & 2,920 & $2.4 \%$ \\
\hline 12 & Cancer stomach & 2,873 & $2.4 \%$ \\
\hline 13 & Ovarian cancer & 2,776 & $2.3 \%$ \\
\hline 14 & Lower respiratory infections & 2,677 & $2.2 \%$ \\
\hline 15 & Cancer liver & 2,210 & $1.8 \%$ \\
\hline 16 & Leukemias & 2,126 & $1.8 \%$ \\
\hline 17 & Cancer cervix & 1,892 & $1.6 \%$ \\
\hline 18 & Cancer pancreas & $\mathrm{I}, 888$ & $1.6 \%$ \\
\hline 19 & Inflammatory Cardiac & 1,602 & $1.3 \%$ \\
\hline \multirow[t]{2}{*}{20} & Lymphomas & 1,479 & $1.2 \%$ \\
\hline & Sub-total & 82,729 & $68.2 \%$ \\
\hline
\end{tabular}




\section{Whites}

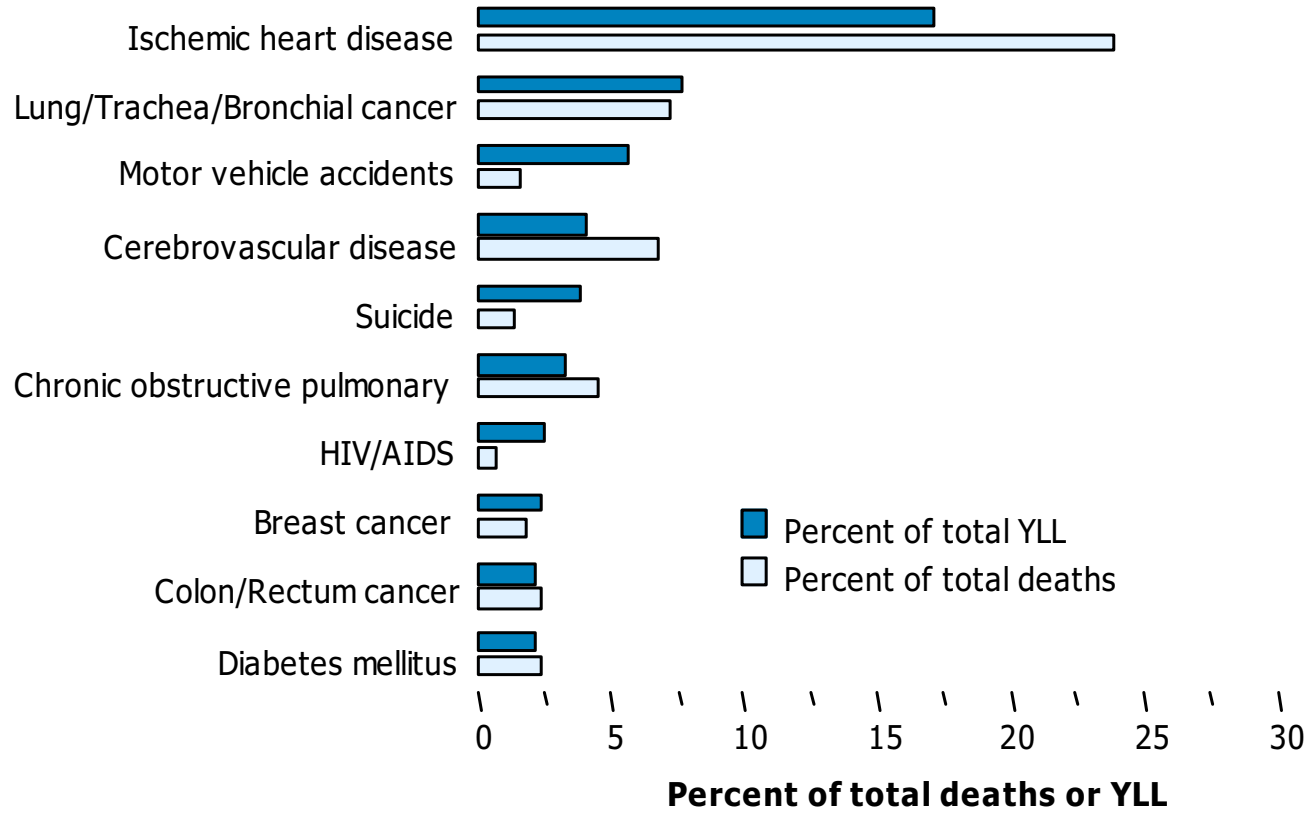

\section{Blacks}

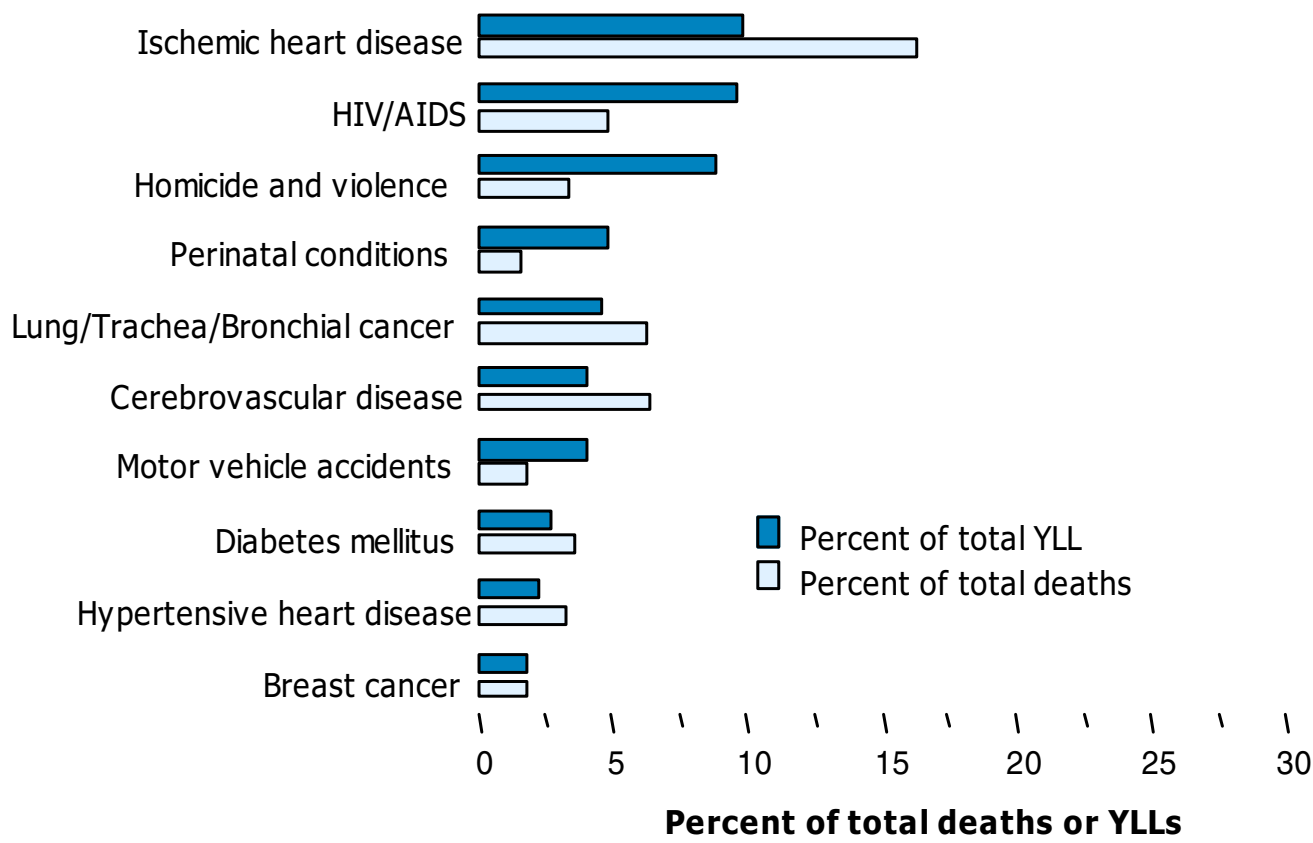

Figure 12

Ten leading causes of mortality burden (YLL) and death, as a per cent of total, by race, US, 1996. 


\section{American Indian}

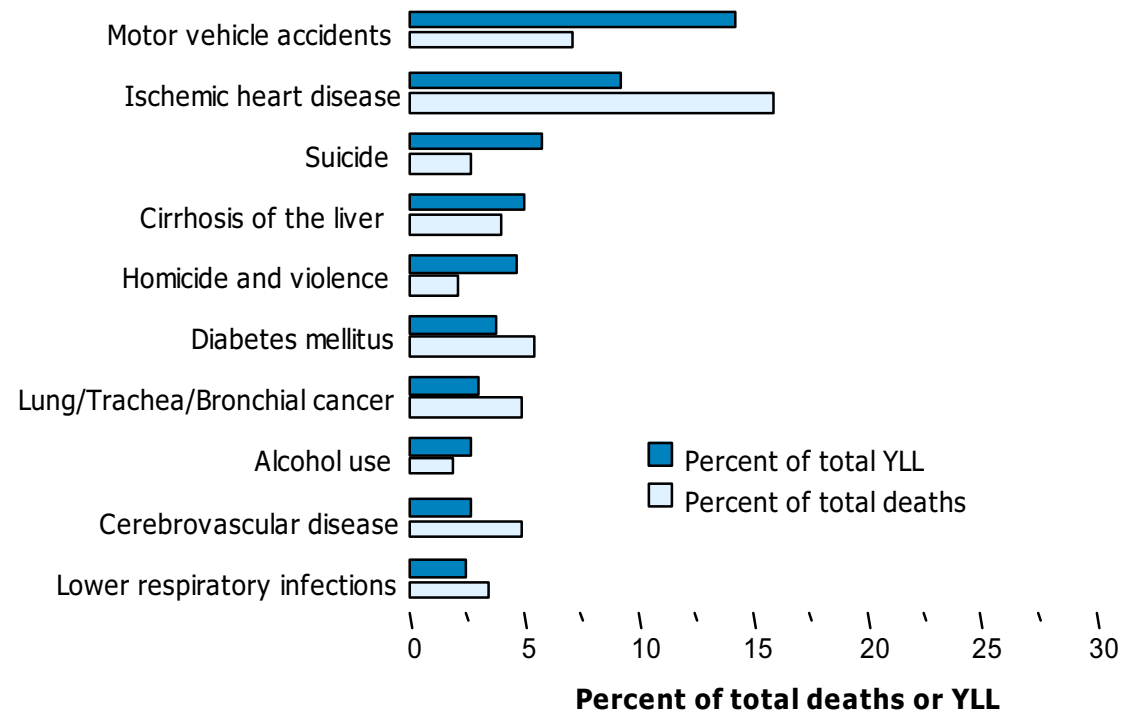

\section{Asians}

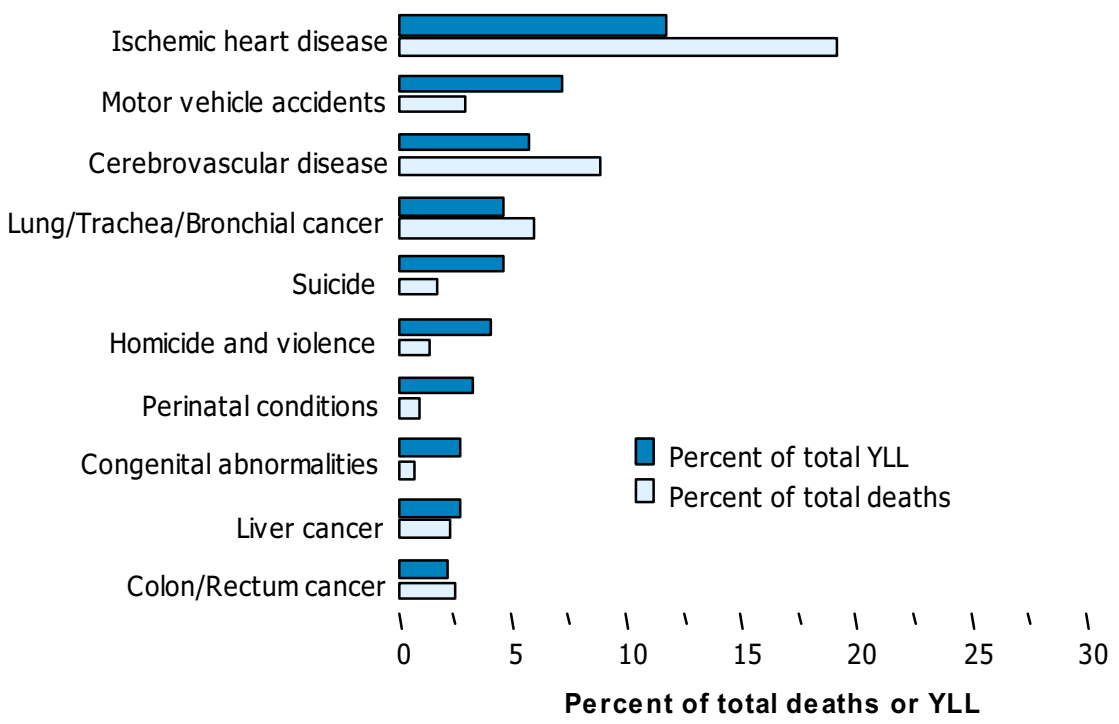

Figure 13

Ten leading causes of mortality burden (YLL) and death, as a per cent of total, by race, US, 1996. 


\section{Male Ranking}

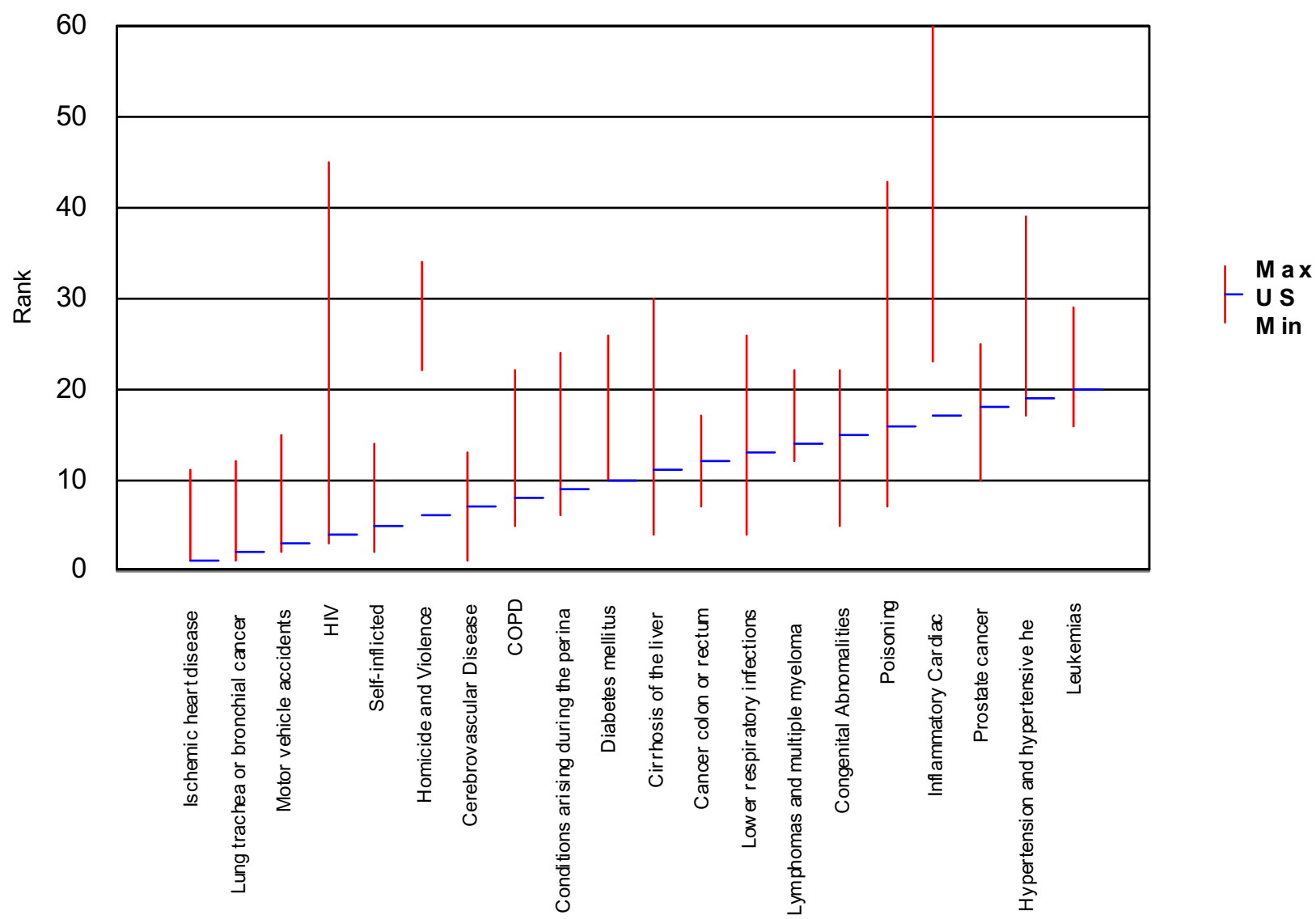

Figure 14

Comparative rankings for the twenty leading causes of YLL for males, US compared with selected non-US OECD countries. Note: Vertical red bars indicate the range between minimum and maximum rankings observed in the selected OECD countries (excluding the US). Blue horizontal lines indicate rankings for the US. The ten selected non-US OECD countries are: Australia, Canada, France, Germany, Greece, Italy, Japan, Netherlands, Spain and the United Kingdom. 
Fe male Ranking

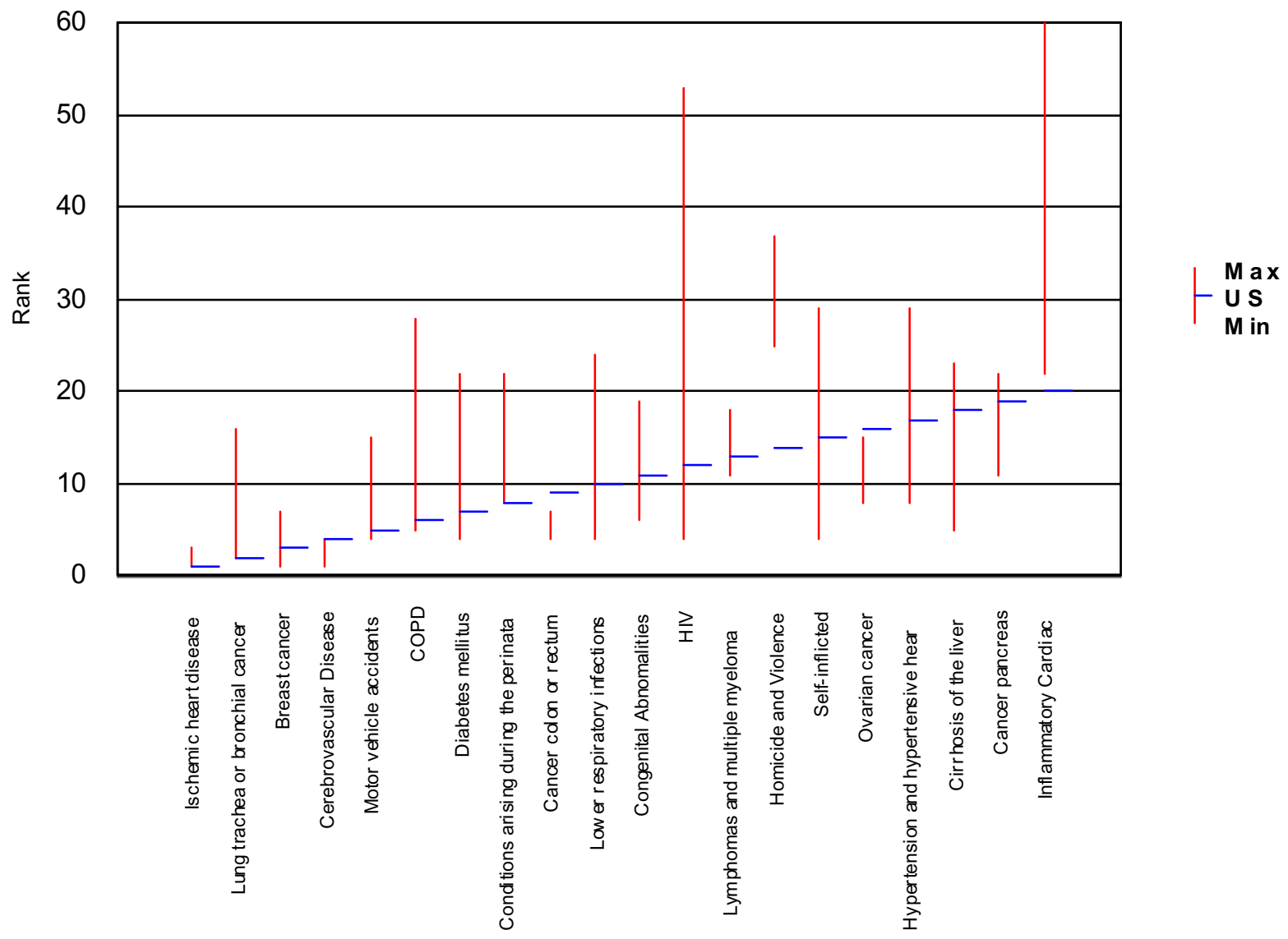

Figure 15

Comparative rankings for the twenty leading causes of YLL for females, US compared with selected non-US OECD countries. Note: Vertical red bars indicate the range between minimum and maximum rankings observed in the selected OECD countries (excluding the US). Blue horizontal lines indicate rankings for the US. The ten selected OECD countries are: Australia, Canada, France, Germany, Greece, Italy, Japan, Netherlands, Spain and the United Kingdom. 


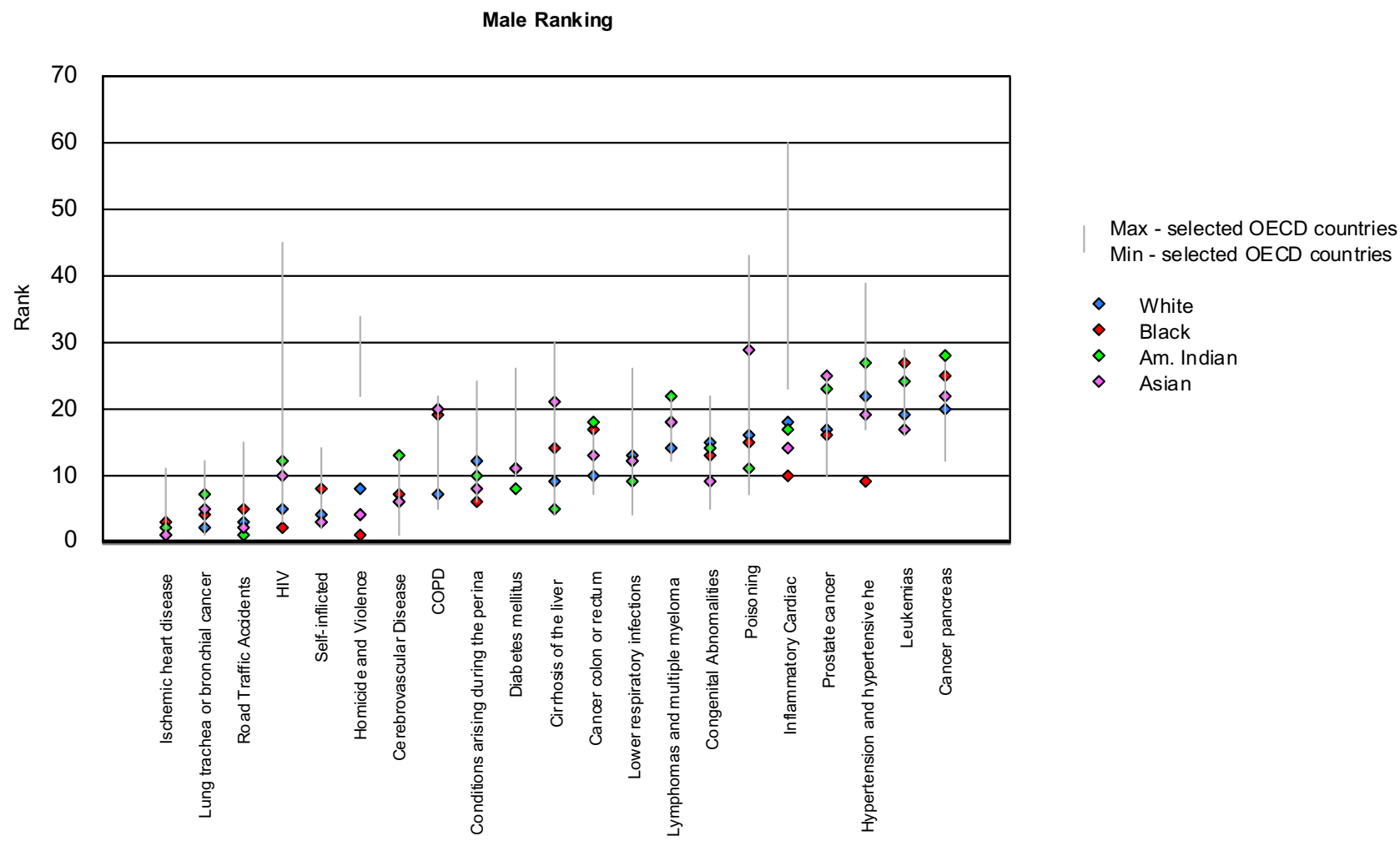

Figure 16

YLL rankings by race in the US compared with selected non-US OECD countries, males. Note: Vertical red bars indicate the range between minimum and maximum rankings observed in the selected OECD countries (excluding the US).

Blue horizontal lines indicate rankings for the US. The ten selected OECD countries are: Australia, Canada, France, Germany, Greece, Italy, Japan, Netherlands, Spain and the United Kingdom 


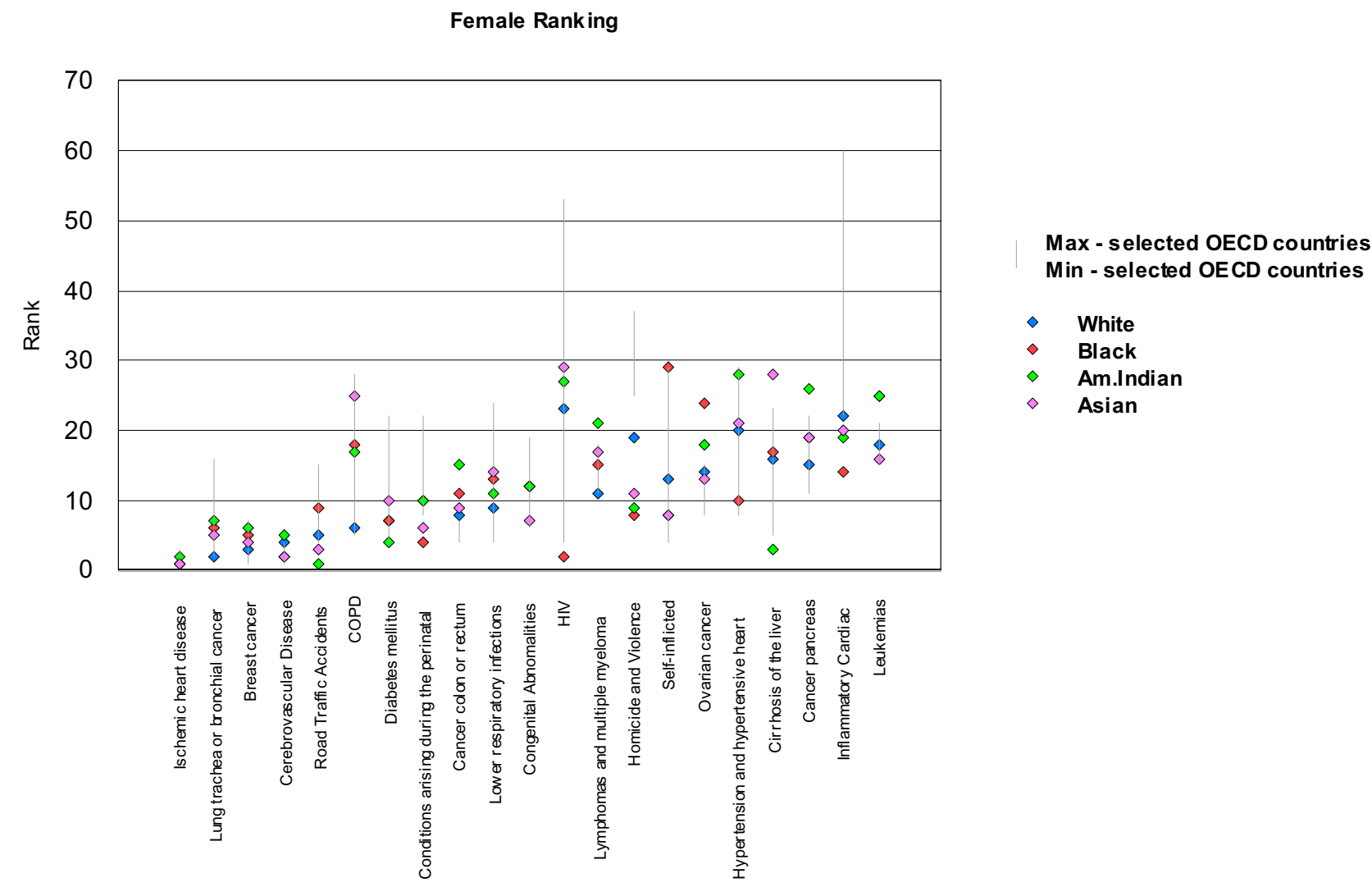

Figure 17

YLL rankings by race in the US compared with non-US OECD countries, females. Note: Vertical red bars indicate the range between minimum and maximum rankings observed in the selected OECD countries (excluding the US). Blue horizontal lines indicate rankings for the US. The ten selected OECD countries are: Australia, Canada, France, Germany, Greece, Italy, Japan, Netherlands, Spain and the United Kingdom 
Table 19: Twenty leading causes of YLL in the United States: comparison of YLL rates per 100,000 between the United States and selected countries - Male

\begin{tabular}{|c|c|c|c|c|c|c|c|c|c|c|c|}
\hline $\begin{array}{l}\text { Twenty leading causes of YLL in } \\
\text { the United States }\end{array}$ & United States & Australia & Canada & France & Germany & Greece & Italy & Japan & Netherlands & Spain & United Kingdom \\
\hline IHD & 1,392 & 269 & 950 & 578 & 1,249 & 1,337 & 974 & 504 & 942 & 826 & 2,154 \\
\hline Trachea, bronchus, lung cancer & 599 & 105 & 469 & 666 & 611 & 756 & 683 & 387 & 595 & 638 & 714 \\
\hline MVA & 547 & 106 & 292 & 515 & 325 & 690 & 438 & 242 & 233 & 550 & 350 \\
\hline HIVIAIDS & 443 & 9 & 62 & 60 & 26 & 11 & 67 & I & 31 & 176 & 18 \\
\hline Self-inflicted & 411 & 140 & 414 & 459 & 367 & 101 & 184 & 582 & 221 & 218 & 410 \\
\hline homicide and violence & 375 & 15 & 57 & 21 & 19 & 37 & 38 & 14 & 38 & 35 & 55 \\
\hline Cerebroavascular disease & 275 & 72 & 205 & 307 & 377 & 723 & 421 & 546 & 319 & 356 & 566 \\
\hline COPD & 207 & 51 & 145 & 142 & 182 & 88 & 168 & 57 & 234 & 247 & 371 \\
\hline Perinatal conditions & 200 & 43 & 115 & 120 & 87 & 115 & 90 & 39 & 116 & 78 & 215 \\
\hline Diabetes & 170 & 33 & 146 & 97 & 125 & 54 & 144 & 76 & 120 & 93 & 99 \\
\hline Cirrhosis of the liver & 169 & 25 & 104 & 281 & 372 & 85 & 228 & 161 & 85 & 195 & 258 \\
\hline Colon and rectum & 164 & 68 & 187 & 213 & 267 & 160 & 225 & 231 & 220 & 235 & 338 \\
\hline Lower respiratory infections & 156 & 19 & 66 & 134 & 99 & 49 & 80 & 281 & 152 & 97 & 524 \\
\hline Congenital anomalies & 133 & 33 & 95 & 101 & 78 & 104 & 78 & 66 & 113 & 86 & 125 \\
\hline poisonings & 130 & 51 & 87 & 12 & 28 & 104 & II & 12 & 30 & 71 & 111 \\
\hline Inflammatory heart disease & 129 & 21 & 52 & 68 & 116 & 3 & 67 & 45 & 65 & 87 & 84 \\
\hline Prostate & 123 & 41 & 118 & 145 & 142 & 119 & 110 & 50 & 151 & 121 & 241 \\
\hline Lymphoma and multiple myeloma & 103 & 36 & 125 & 114 & 108 & 92 & 130 & 77 & 128 & 106 & 176 \\
\hline Hypertesive heart disease & 99 & 7 & 21 & 51 & 77 & 48 & 117 & 15 & 24 & 38 & 54 \\
\hline Leukemia & 88 & 25 & 82 & 91 & 87 & 105 & 100 & 70 & 78 & 86 & 115 \\
\hline
\end{tabular}


Table 20: Twenty leading causes of YLL in the United States: comparison of YLL rates per 100,000 between the United States and selected countries - Female

\begin{tabular}{|c|c|c|c|c|c|c|c|c|c|c|c|}
\hline $\begin{array}{c}\text { Twenty leading causes of YLL in } \\
\text { the United States }\end{array}$ & United States & Australia & Canada & France & Germany & Greece & Italy & Japan & Netherlands & Spain & United Kingdom \\
\hline IHD & 777 & 462 & 475 & 228 & 753 & 570 & 491 & 562 & 466 & 383 & 868 \\
\hline Trachea, bronchus, lung cancer & 386 & 186 & 354 & 140 & 201 & 125 & 154 & 328 & 288 & 86 & 357 \\
\hline Breast cancer & 332 & 285 & 326 & 389 & 404 & 313 & 363 & 396 & 457 & 288 & 492 \\
\hline Cerebroavascular disease & 316 & 253 & 213 & 253 & 405 & 826 & 426 & 943 & 378 & 362 & 510 \\
\hline MVA & 241 & 125 & 124 & 157 & 105 & 178 & 117 & 167 & 71 & $15 \mid$ & 73 \\
\hline COPD & 190 & 108 & 114 & 67 & 90 & 41 & 66 & 39 & 152 & 57 & 227 \\
\hline Diabetes & 170 & 80 & 109 & 76 & 123 & 55 & $|5|$ & 102 & 115 & 108 & 66 \\
\hline Perinatal conditions & $15 \mid$ & 108 & 87 & 89 & 64 & 75 & 70 & 70 & 94 & 63 & 115 \\
\hline Colon and rectum & 145 & 164 & 145 & 155 & 217 & 153 & 171 & 381 & 189 & 174 & 201 \\
\hline Lower respiratory infections & 137 & 50 & 56 & 91 & 79 & 34 & 61 & 418 & 147 & 71 & 412 \\
\hline Congenital anomalies & 108 & 89 & 73 & 71 & 64 & 76 & 59 & 136 & 100 & 73 & 84 \\
\hline HIV/AIDS & 106 & 2 & 13 & 16 & 6 & 2 & 17 & 0 & 8 & 43 & 4 \\
\hline homicide and violence & 95 & 32 & 21 & 12 & 16 & 11 & 11 & 25 & 19 & 13 & 20 \\
\hline sel-inflicted & 94 & 120 & 119 & 155 & 106 & 27 & 55 & 473 & 107 & 63 & 90 \\
\hline Ovarian cancer & 90 & 69 & 79 & 90 & 114 & 82 & 88 & 148 & 99 & 74 & 144 \\
\hline Hypertesive heart disease & 83 & 27 & 21 & 50 & 94 & 50 & 137 & 34 & 27 & 53 & 32 \\
\hline Cirrhosis of the liver & 75 & 32 & 45 & 113 & 156 & 28 & 115 & 99 & 44 & 71 & 113 \\
\hline Cancer pancreas & 74 & 56 & 67 & 66 & 94 & 73 & 85 & 187 & 78 & 62 & 84 \\
\hline Lymphoma and multiple myeloma & 73 & 88 & 97 & 80 & 83 & 71 & 103 & 126 & 90 & 84 & 110 \\
\hline Inflammatory heart disease & 67 & 31 & 29 & 24 & 44 & 3 & 30 & 53 & 42 & 45 & 32 \\
\hline
\end{tabular}




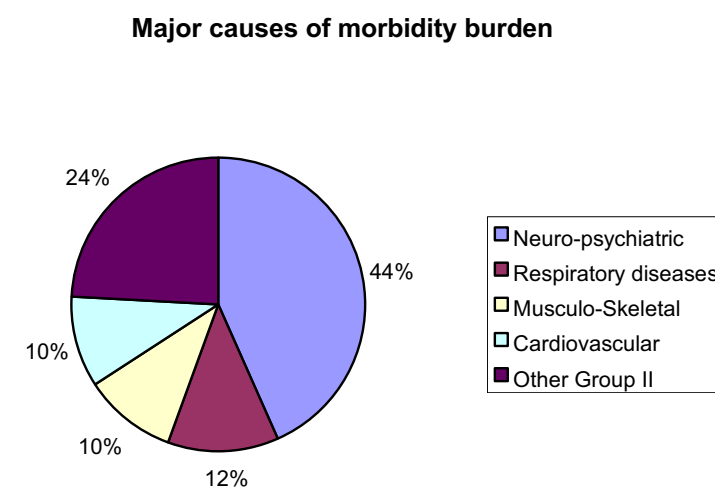

Figure 18

Distribution of YLD for non-communicable cause groupings.

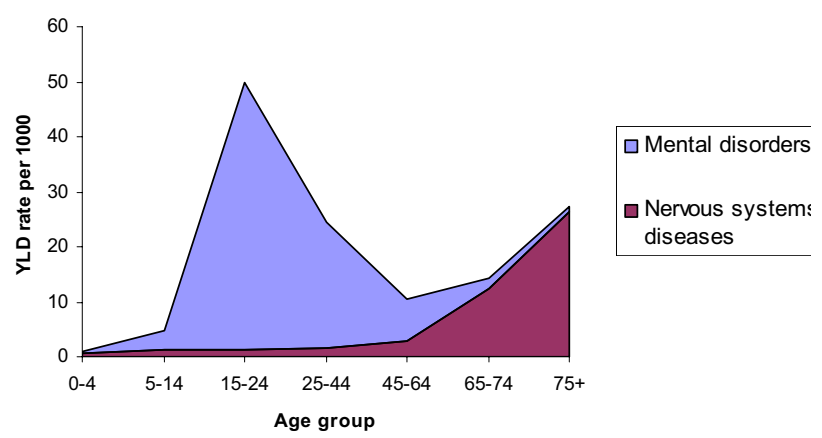

Figure 19

Age patterns of mental disorders and diseases of the nervous system. 
Table 21: Twenty leading causes of YLD, both sexes and all races combined

\begin{tabular}{|c|c|c|c|}
\hline Rank & & YLD & $\%$ of total \\
\hline & Total & $15,024,113$ & \\
\hline I & Unipolar major depression & $1,370,070$ & $9.1 \%$ \\
\hline 2 & Alcohol use & $1,037,529$ & $6.9 \%$ \\
\hline 3 & Osteoarthritis & 940,612 & $6.3 \%$ \\
\hline 4 & Dementia and other degenerative and hereditary CNS disorders & 755,925 & $5.0 \%$ \\
\hline 5 & COPD & 727,272 & $4.8 \%$ \\
\hline 6 & Cerebrovascular Disease & 725,844 & $4.8 \%$ \\
\hline 7 & Asthma & 593,233 & $3.9 \%$ \\
\hline 8 & Drug use & 504,718 & $3.4 \%$ \\
\hline 9 & Diabetes mellitus & 495,377 & $3.3 \%$ \\
\hline 10 & Congenital Abnomalities & 443,004 & $2.9 \%$ \\
\hline 11 & Motor vehicle accidents & 366,273 & $2.4 \%$ \\
\hline 12 & Bipolar disorder & 363,298 & $2.4 \%$ \\
\hline 13 & Schizophrenia & 315,720 & $2.1 \%$ \\
\hline 14 & Ischaemic heart disease & 275,988 & $1.8 \%$ \\
\hline 15 & PTSD & 260,337 & $1.7 \%$ \\
\hline 16 & Panic disorder & 259,904 & $1.7 \%$ \\
\hline 17 & HIV & 237,443 & $1.6 \%$ \\
\hline 18 & Falls & 221,036 & $1.5 \%$ \\
\hline 19 & Rheumatoid arthritis & $|89,42|$ & $1.3 \%$ \\
\hline \multirow[t]{2}{*}{20} & Obsessive-compulsive disorders & 169,067 & $1.1 \%$ \\
\hline & Sub-total & $10,252,070$ & $68.2 \%$ \\
\hline
\end{tabular}


Table 22: Twenty leading causes of YLD by sex, US 1996

\begin{tabular}{|c|c|c|c|}
\hline & MALES & & \\
\hline \multirow[t]{2}{*}{ Rank } & & YLD & $\%$ total YLD \\
\hline & Total & $7,330,853$ & \\
\hline I & Alcohol use & 651,223 & $8.9 \%$ \\
\hline 2 & Unipolar major depression & 469,861 & $6.4 \%$ \\
\hline 3 & Osteoarthritis & 434,200 & $5.9 \%$ \\
\hline 4 & Drug use & 384,319 & $5.2 \%$ \\
\hline 5 & COPD & 372,927 & $5.1 \%$ \\
\hline 6 & Dementia and other degenerative and hereditary CNS disorders & 332,046 & $4.5 \%$ \\
\hline 7 & Cerebrovascular Disease & 317,366 & $4.3 \%$ \\
\hline 8 & Asthma & 272,898 & $3.7 \%$ \\
\hline 9 & Congenital Abnomalities & 237,988 & $3.2 \%$ \\
\hline 10 & Motor vehicle accidents & 232,687 & $3.2 \%$ \\
\hline 11 & Diabetes mellitus & 221,557 & $3.0 \%$ \\
\hline 12 & Bipolar disorder & 198,308 & $2.7 \%$ \\
\hline 13 & HIV & 188,519 & $2.6 \%$ \\
\hline 14 & Schizophrenia & 166,988 & $2.3 \%$ \\
\hline 15 & Ischaemic heart disease & $15 \mid, 764$ & $2.1 \%$ \\
\hline 16 & Falls & 132,485 & $1.8 \%$ \\
\hline 17 & Obsessive-compulsive disorders & 88,623 & $1.2 \%$ \\
\hline 18 & Homicide and Violence & 81,588 & $1.1 \%$ \\
\hline 19 & Prostate cancer & 78,870 & $1.1 \%$ \\
\hline \multirow[t]{3}{*}{20} & Panic disorder & 77,701 & $1.1 \%$ \\
\hline & sub-total & $5,091,918$ & $69.5 \%$ \\
\hline & FEMALES & & \\
\hline \multirow[t]{2}{*}{ Rank } & & YLD & $\%$ total YLD \\
\hline & Total & $7,693,260$ & \\
\hline I & Unipolar major depression & 900,209 & $11.7 \%$ \\
\hline 2 & Osteoarthritis & 506,412 & $6.6 \%$ \\
\hline 3 & Dementia and other degenerative and hereditary CNS disorders & 423,878 & $5.5 \%$ \\
\hline 4 & Cerebrovascular Disease & 408,478 & $5.3 \%$ \\
\hline 5 & Alcohol use & 386,306 & $5.0 \%$ \\
\hline 6 & COPD & 354,345 & $4.6 \%$ \\
\hline 7 & Asthma & 320,336 & $4.2 \%$ \\
\hline 8 & Diabetes mellitus & 273,821 & $3.6 \%$ \\
\hline 9 & Congenital Abnomalities & 205,015 & $2.7 \%$ \\
\hline 10 & PTSD & 193,533 & $2.5 \%$ \\
\hline 11 & Panic disorder & 182,203 & $2.4 \%$ \\
\hline 12 & Bipolar disorder & 164,990 & $2.1 \%$ \\
\hline 13 & Schizophrenia & 148,732 & $1.9 \%$ \\
\hline 14 & Motor vehicle accidents & 133,586 & $1.7 \%$ \\
\hline 15 & Rheumatoid arthritis & $|3|, 758$ & $1.7 \%$ \\
\hline 16 & STD's excluding HIV & $125,4 \mid 8$ & $1.6 \%$ \\
\hline 17 & Ischaemic heart disease & 124,224 & $1.6 \%$ \\
\hline 18 & Drug use & 120,399 & $1.6 \%$ \\
\hline 19 & Maternal Conditions & 105,155 & $1.4 \%$ \\
\hline \multirow[t]{2}{*}{20} & Falls & 88,551 & $1.2 \%$ \\
\hline & sub-total & $5,297,349$ & $68.9 \%$ \\
\hline
\end{tabular}


Table 23: Leading causes of YLD - Whites

\begin{tabular}{|c|c|c|c|}
\hline & WHITE MALES & & \\
\hline \multirow[t]{2}{*}{ Rank } & Cause list & YLD & $\%$ total YLD \\
\hline & Total YLD & $5,963,710$ & \\
\hline I & Alcohol use & 488,341 & $8.2 \%$ \\
\hline 2 & Unipolar major depression & 390,121 & $6.5 \%$ \\
\hline 3 & Osteoarthritis & 378,589 & $6.3 \%$ \\
\hline 4 & Drug use & 324,878 & $5.4 \%$ \\
\hline 5 & COPD & 319,049 & $5.3 \%$ \\
\hline 6 & Dementia and other degenerative and hereditary CNS disorders & 293,857 & $4.9 \%$ \\
\hline 7 & Cerebrovascular Disease & 258,909 & $4.3 \%$ \\
\hline 8 & Asthma & 216,831 & $3.6 \%$ \\
\hline 9 & Motor vehicle accidents & 195,590 & $3.3 \%$ \\
\hline 10 & Congenital Abnomalities & 189,083 & $3.2 \%$ \\
\hline 11 & Diabetes mellitus & 174,663 & $2.9 \%$ \\
\hline 12 & Bipolar disorder & 161,700 & $2.7 \%$ \\
\hline 13 & Schizophrenia & 134,190 & $2.3 \%$ \\
\hline 14 & Ischaemic heart disease & 130,502 & $2.2 \%$ \\
\hline 15 & Falls & 113,345 & $1.9 \%$ \\
\hline 16 & HIV & III,533 & $1.9 \%$ \\
\hline 17 & Obsessive-compulsive disorders & 71,313 & $1.2 \%$ \\
\hline 18 & Prostate cancer & 68,023 & $1.1 \%$ \\
\hline 19 & Panic disorder & 63,735 & $1.1 \%$ \\
\hline \multirow[t]{3}{*}{20} & PTSD & 55,968 & $0.9 \%$ \\
\hline & sub-total & $4,140,220$ & $69.4 \%$ \\
\hline & WHITE FEMALES & & \\
\hline \multirow[t]{2}{*}{ Rank } & Cause list & YLD & \% total YLD \\
\hline & Total YLD & $6,234,020$ & \\
\hline I & Unipolar major depression & 736,746 & $11.8 \%$ \\
\hline 2 & Osteoarthritis & 439,876 & $7.1 \%$ \\
\hline 3 & Dementia and other degenerative and hereditary CNS disorders & 375,458 & $6.0 \%$ \\
\hline 4 & Cerebrovascular Disease & 323,173 & $5.2 \%$ \\
\hline 5 & COPD & 307,237 & $4.9 \%$ \\
\hline 6 & Alcohol use & 291,334 & $4.7 \%$ \\
\hline 7 & Asthma & 253,904 & $4.1 \%$ \\
\hline 8 & Diabetes mellitus & 210,058 & $3.4 \%$ \\
\hline 9 & Congenital Abnomalities & 162,162 & $2.6 \%$ \\
\hline 10 & PTSD & 159,120 & $2.6 \%$ \\
\hline 11 & Panic disorder & 145,888 & $2.3 \%$ \\
\hline 12 & Bipolar disorder & 131,835 & $2.1 \%$ \\
\hline 13 & Schizophrenia & 118,134 & $1.9 \%$ \\
\hline 14 & Rheumatoid arthritis & 110,674 & $1.8 \%$ \\
\hline 15 & Motor vehicle accidents & 109,754 & $1.8 \%$ \\
\hline 16 & STD's excluding HIV & 101,298 & $1.6 \%$ \\
\hline 17 & Ischaemic heart disease & 100,510 & $1.6 \%$ \\
\hline 18 & Drug use & 98,319 & $1.6 \%$ \\
\hline 19 & Maternal Conditions & 82,750 & $1.3 \%$ \\
\hline \multirow[t]{2}{*}{20} & Falls & 76,404 & $1.2 \%$ \\
\hline & Sub-total & $4,334,635$ & $69.5 \%$ \\
\hline
\end{tabular}


Table 24: Leading causes of YLD - Blacks

\begin{tabular}{|c|c|c|c|}
\hline & BLACK MALES & & \\
\hline \multirow[t]{2}{*}{ Rank } & Simple cause list & YLD & $\%$ total YLD \\
\hline & Total YLD & $1,086,407$ & \\
\hline 1 & Alcohol use & 135,346 & $12.5 \%$ \\
\hline 2 & HIV & 73,292 & $6.7 \%$ \\
\hline 3 & Unipolar major depression & 57,653 & $5.3 \%$ \\
\hline 4 & Cerebrovascular Disease & 49,191 & $4.5 \%$ \\
\hline 5 & Drug use & 44,504 & $4.1 \%$ \\
\hline 6 & Asthma & 42,295 & $3.9 \%$ \\
\hline 7 & Diabetes mellitus & 39,783 & $3.7 \%$ \\
\hline 8 & COPD & 38,739 & $3.6 \%$ \\
\hline 9 & Osteoarthritis & 38,641 & $3.6 \%$ \\
\hline 10 & Congenital Abnomalities & 36,030 & $3.3 \%$ \\
\hline 11 & Road Traffic Accidents & 31,173 & $2.9 \%$ \\
\hline 12 & Dementia and other degenerative and hereditary CNS disorders & 28,292 & $2.6 \%$ \\
\hline 13 & Homicide and Violence & 26,846 & $2.5 \%$ \\
\hline 14 & Bipolar disorder & 26,799 & $2.5 \%$ \\
\hline 15 & Schizophrenia & 24,323 & $2.2 \%$ \\
\hline 16 & Ischaemic heart disease & 18,148 & $1.7 \%$ \\
\hline 17 & Falls & 15,894 & $1.5 \%$ \\
\hline 18 & Diarrhoeal diseases & 15,602 & $1.4 \%$ \\
\hline 19 & Inflammatory Cardiac & 13,178 & $1.2 \%$ \\
\hline \multirow[t]{2}{*}{20} & Obsessive-compulsive disorders & 12,818 & $1.2 \%$ \\
\hline & sub-total & 768,546 & $70.7 \%$ \\
\hline
\end{tabular}

\section{BLACK FEMALES}

\begin{tabular}{|c|c|c|c|}
\hline Rank & Simple cause list & YLD & $\%$ total YLD \\
\hline & Total YLD & $|| 45,,|3|$ & \\
\hline I & Unipolar major depression & || $9,47 \mid$ & $10.4 \%$ \\
\hline 2 & Alcohol use & 74,248 & $6.5 \%$ \\
\hline 3 & Cerebrovascular Disease & 74,179 & $6.5 \%$ \\
\hline 4 & Diabetes mellitus & 54,409 & $4.8 \%$ \\
\hline 5 & Asthma & 50,869 & $4.4 \%$ \\
\hline 6 & Osteoarthritis & 48,521 & $4.2 \%$ \\
\hline 7 & Dementia and other degenerative and hereditary CNS disorders & 37,519 & $3.3 \%$ \\
\hline 8 & HIV & 31,719 & $2.8 \%$ \\
\hline 9 & Congenital Abnomalities & 31,654 & $2.8 \%$ \\
\hline 10 & COPD & 31,132 & $2.7 \%$ \\
\hline 11 & PTSD & 27,508 & $2.4 \%$ \\
\hline 12 & Panic disorder & 26,916 & $2.4 \%$ \\
\hline 13 & Bipolar disorder & 24,649 & $2.2 \%$ \\
\hline 14 & Schizophrenia & 22,823 & $2.0 \%$ \\
\hline 15 & Ischaemic heart disease & 21,685 & $1.9 \%$ \\
\hline 16 & Road Traffic Accidents & 19,754 & $1.7 \%$ \\
\hline 17 & STD's excluding HIV & 17,688 & $1.5 \%$ \\
\hline 18 & Drug use & 17,686 & $1.5 \%$ \\
\hline 19 & Maternal Conditions & 16,770 & $1.5 \%$ \\
\hline 20 & Rheumatoid arthritis & $|5,52|$ & $1.4 \%$ \\
\hline & sub-total & 764,722 & $66.8 \%$ \\
\hline
\end{tabular}


Table 25: Leading causes of YLD - American Indians

\begin{tabular}{|c|c|c|c|}
\hline & AMERICAN INDIAN MALES & & \\
\hline \multirow[t]{2}{*}{ Rank } & Simple cause list & YLD & $\%$ total YLD \\
\hline & Total YLD & 77,508 & \\
\hline I & Alcohol use & 22,997 & $29.7 \%$ \\
\hline 2 & Unipolar major depression & 4,160 & $5.4 \%$ \\
\hline 3 & Drug use & 3,042 & $3.9 \%$ \\
\hline 4 & Osteoarthritis & 2,940 & $3.8 \%$ \\
\hline 5 & Asthma & 2,745 & $3.5 \%$ \\
\hline 6 & COPD & 2,708 & $3.5 \%$ \\
\hline 7 & Congenital Abnomalities & 2,467 & $3.2 \%$ \\
\hline 8 & Cerebrovascular Disease & 2,014 & $2.6 \%$ \\
\hline 9 & Bipolar disorder & 1,948 & $2.5 \%$ \\
\hline 10 & Road Traffic Accidents & 1,902 & $2.5 \%$ \\
\hline 11 & Schizophrenia & 1,796 & $2.3 \%$ \\
\hline 12 & Dementia and other degenerative and hereditary CNS disorders & $\mathrm{I}, 775$ & $2.3 \%$ \\
\hline 13 & Diabetes mellitus & 1,595 & $2.1 \%$ \\
\hline 14 & HIV & 1,190 & $1.5 \%$ \\
\hline 15 & Cirrhosis of the liver & 1,082 & $1.4 \%$ \\
\hline 16 & Fires & 1,027 & $1.3 \%$ \\
\hline 17 & Obsessive-compulsive disorders & 940 & $1.2 \%$ \\
\hline 18 & Falls & 921 & $1.2 \%$ \\
\hline 19 & Ischaemic heart disease & 881 & $1.1 \%$ \\
\hline \multirow[t]{2}{*}{20} & Panic disorder & 743 & $1.0 \%$ \\
\hline & sub-total & 58,874 & $76.0 \%$ \\
\hline
\end{tabular}

\section{AMERICAN INDIAN FEMALES}

\begin{tabular}{|c|c|c|c|}
\hline Rank & Simple cause list & $\begin{array}{l}\text { YLD } \\
\mathbf{7 8 , 5 2 2}\end{array}$ & $\%$ total YLD \\
\hline I & Alcohol use & 19,417 & $24.7 \%$ \\
\hline 2 & Unipolar major depression & 7,655 & $9.7 \%$ \\
\hline 3 & Asthma & 3,233 & $4.1 \%$ \\
\hline 4 & Osteoarthritis & 3,020 & $3.8 \%$ \\
\hline 5 & COPD & 2,692 & $3.4 \%$ \\
\hline 6 & Cerebrovascular Disease & 2,251 & $2.9 \%$ \\
\hline 7 & Congenital Abnomalities & 2,182 & $2.8 \%$ \\
\hline 8 & Dementia and other degenerative and hereditary CNS disorders & 2,006 & $2.6 \%$ \\
\hline 9 & Diabetes mellitus & 1,895 & $2.4 \%$ \\
\hline 10 & Panic disorder & $|, 85|$ & $2.4 \%$ \\
\hline 11 & Bipolar disorder & 1,717 & $2.2 \%$ \\
\hline 12 & Schizophrenia & 1,625 & $2.1 \%$ \\
\hline 13 & PTSD & $\mathrm{I}, 25 \mathrm{I}$ & $1.6 \%$ \\
\hline 14 & Maternal Conditions & $\mathrm{I}, 178$ & $1.5 \%$ \\
\hline 15 & STD's excluding HIV & $\mathrm{I}, 157$ & $1.5 \%$ \\
\hline 16 & Road Traffic Accidents & 1,115 & $1.4 \%$ \\
\hline 17 & Rheumatoid arthritis & 958 & $1.2 \%$ \\
\hline 18 & Drug use & 925 & $1.2 \%$ \\
\hline 19 & Cirrhosis of the liver & 918 & $1.2 \%$ \\
\hline \multirow[t]{2}{*}{20} & Obsessive-compulsive disorders & 865 & $1.1 \%$ \\
\hline & Sub-total & 57,910 & $73.8 \%$ \\
\hline
\end{tabular}


Table 26: Leading causes of YLD - Asians

\begin{tabular}{|c|c|c|c|}
\hline & ASIAN MALES & & \\
\hline \multirow[t]{2}{*}{ Rank } & Simple cause list & YLD & $\%$ total YLD \\
\hline & Total YLD & 203,229 & \\
\hline I & Unipolar major depression & 17,926 & $8.8 \%$ \\
\hline 2 & Osteoarthritis & 14,029 & $6.9 \%$ \\
\hline 3 & COPD & $|2,43|$ & $6.1 \%$ \\
\hline 4 & Drug use & 11,895 & $5.9 \%$ \\
\hline 5 & Asthma & 11,027 & $5.4 \%$ \\
\hline 6 & Congenital Abnomalities & 10,408 & $5.1 \%$ \\
\hline 7 & Dementia and other degenerative and hereditary CNS disorders & 8,122 & $4.0 \%$ \\
\hline 8 & Bipolar disorder & 7,862 & $3.9 \%$ \\
\hline 9 & Cerebrovascular Disease & 7,251 & $3.6 \%$ \\
\hline 10 & Schizophrenia & 6,679 & $3.3 \%$ \\
\hline II & Diabetes mellitus & 5,516 & $2.7 \%$ \\
\hline 12 & Alcohol use & 4,539 & $2.2 \%$ \\
\hline 13 & Road Traffic Accidents & 4,022 & $2.0 \%$ \\
\hline 14 & Obsessive-compulsive disorders & 3,552 & $1.7 \%$ \\
\hline 15 & Panic disorder & 2,994 & $1.5 \%$ \\
\hline 16 & HIV & 2,505 & $1.2 \%$ \\
\hline 17 & Epilepsy & 2,470 & $1.2 \%$ \\
\hline 18 & Falls & 2,325 & $1.1 \%$ \\
\hline 19 & Ischaemic heart disease & 2,234 & $1.1 \%$ \\
\hline \multirow[t]{2}{*}{20} & Diarrhoeal diseases & 2,057 & $1.0 \%$ \\
\hline & Sub-total & 139,843 & $68.8 \%$ \\
\hline
\end{tabular}

\section{ASIAN FEMALES}

\begin{tabular}{|c|c|c|c|}
\hline Rank & Simple cause list & YLD & $\%$ total YLD \\
\hline & Total YLD & 235,588 & \\
\hline I & Unipolar major depression & 36,337 & $15.4 \%$ \\
\hline 2 & Osteoarthritis & 14,995 & $6.4 \%$ \\
\hline 3 & COPD & 13,285 & $5.6 \%$ \\
\hline 4 & Asthma & 12,329 & $5.2 \%$ \\
\hline 5 & Congenital Abnomalities & 9,018 & $3.8 \%$ \\
\hline 6 & Dementia and other degenerative and hereditary CNS disorders & 8,896 & $3.8 \%$ \\
\hline 7 & Cerebrovascular Disease & 8,876 & $3.8 \%$ \\
\hline 8 & Panic disorder & 7,548 & $3.2 \%$ \\
\hline 9 & Diabetes mellitus & 7,458 & $3.2 \%$ \\
\hline 10 & Bipolar disorder & 6,788 & $2.9 \%$ \\
\hline II & Schizophrenia & 6,150 & $2.6 \%$ \\
\hline 12 & PTSD & 5,654 & $2.4 \%$ \\
\hline 13 & STD's excluding HIV & 5,275 & $2.2 \%$ \\
\hline 14 & Rheumatoid arthritis & 4,605 & $2.0 \%$ \\
\hline 15 & Maternal Conditions & 4,456 & $1.9 \%$ \\
\hline 16 & Drug use & 3,469 & $1.5 \%$ \\
\hline 17 & Obsessive-compulsive disorders & 3,347 & $1.4 \%$ \\
\hline 18 & Road Traffic Accidents & 2,963 & $1.3 \%$ \\
\hline 19 & Epilepsy & 2,222 & $0.9 \%$ \\
\hline \multirow[t]{2}{*}{20} & Diarrhoeal diseases & $\mathrm{I}, 745$ & $0.7 \%$ \\
\hline & Sub-total & 165,417 & $70.2 \%$ \\
\hline
\end{tabular}




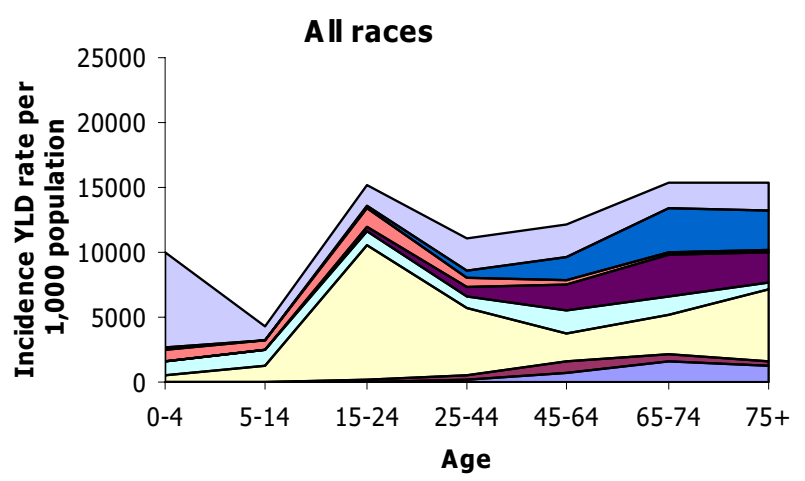

\section{$\square$ Other}

$\square$ Cardiovascular

$\square$ Injuries

Musculo-Skeletal

$\square$ Chronic Respiratory

$\square$ Neuro-psychiatric

$\square$ Diabetes Mellitus

$\square$ Cancer
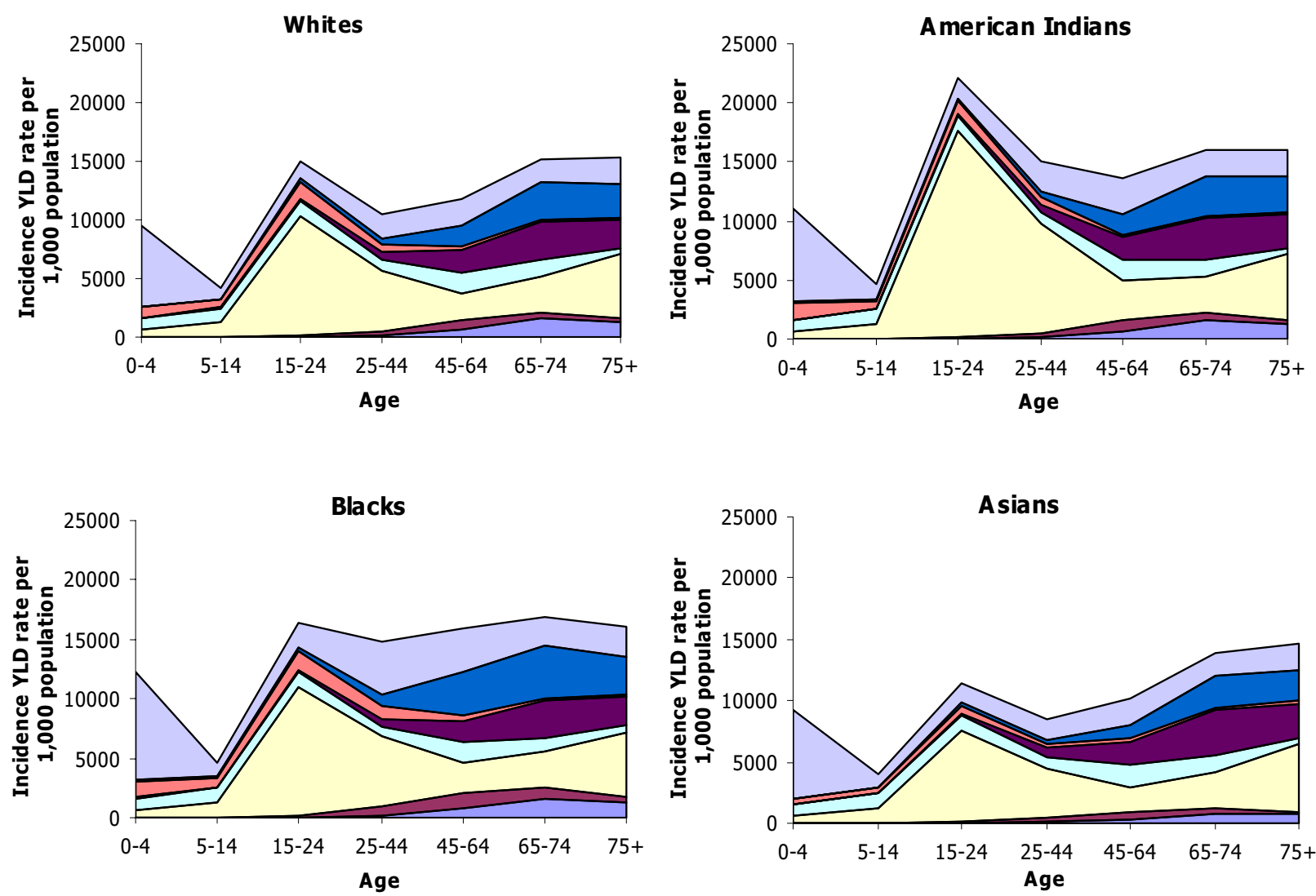

Figure 20

Patterns of YLD by age and race, US 1996. 
Table 27: Top twenty leading causes of Disability Adjusted Life Years (DALY), Years Lost to Disability (YLD), Years of Life Lost (YLL) and Deaths for Males - US 1996*

\begin{tabular}{|c|c|c|c|c|c|}
\hline & Cause & DALY (\%) & YLD (\%) & YLL (\%) & Death (\%) \\
\hline I & Ischaemic heart disease & $1,958(11.0)$ & $152(2.1)$ & $1,806(17.2)$ & $287(24.7)$ \\
\hline 2 & Road traffic accidents & $934(5.2)$ & $233(3.2)$ & $701(6.7)$ & $29(2.5)$ \\
\hline 3 & Lung trachea or bronchial cancer & $813(4.6)$ & $35(0.5)$ & 778 (7.4) & $102(8.8)$ \\
\hline 4 & HIVIAIDS & $764(4.3)$ & $189(2.6)$ & $575(5.5)$ & $25(2.2)$ \\
\hline 5 & Alcohol use & $732(4.1)$ & $651(8.9)$ & $81(0.8)$ & $5(0.4)$ \\
\hline 6 & Cerebrovascular Disease & $674(3.8)$ & $317(4.3)$ & $357(3.4)$ & $63(5.4)$ \\
\hline 7 & COPD & $642(3.6)$ & $373(5.1)$ & $269(2.6)$ & $52(4.5)$ \\
\hline 8 & Homicide and Violence & $568(3.2)$ & $82(1.1)$ & $486(4.6)$ & $17(1.5)$ \\
\hline 9 & Self-inflicted injuries & $541(3.0)$ & $8(0.1)$ & $534(5.1)$ & $26(2.2)$ \\
\hline 10 & Unipolar major depression & $470(2.6)$ & $470(6.4)$ & $0(0.0)$ & $0(0)$ \\
\hline 11 & Diabetes mellitus & $442(2.5)$ & $222(3.0)$ & $220(2.1)$ & $28(2.4)$ \\
\hline 12 & Osteoarthritis & $435(2.4)$ & $434(5.9)$ & $\mathrm{I}(0.0)$ & $0(0)$ \\
\hline 13 & Drug use & $412(2.3)$ & $384(5.2)$ & $27(0.3)$ & $\mathrm{I}(0.1)$ \\
\hline 14 & Congenital Abnormalities & $410(2.3)$ & $238(3.2)$ & $172(1.6)$ & $6(0.5)$ \\
\hline 15 & Dementia and other degenerative and hereditary CNS disorders & $382(2.1)$ & $332(4.5)$ & $50(0.5)$ & $14(1.2)$ \\
\hline 16 & Asthma & $303(1.7)$ & $273(3.7)$ & $30(0.3)$ & $2(0.2)$ \\
\hline 17 & Cirrhosis of the liver & $281(1.6)$ & $61(0.8)$ & $220(2.1)$ & $17(1.4)$ \\
\hline 18 & Conditions arising during the perinatal period & $274(1.5)$ & $14(0.2)$ & $260(2.5)$ & $8(0.7)$ \\
\hline 19 & Cancer colon or rectum & $249(1.4)$ & $37(0.5)$ & $213(2.0)$ & $30(2.6)$ \\
\hline 20 & Prostate cancer & $239(1.3)$ & $79(1.1)$ & $160(1.5)$ & $37(3.2)$ \\
\hline- & Total number for each measure in the top 20 causes & II,523 (64.5) & $4,584(62.5)$ & $6,940(65.9)$ & $749(64.5)$ \\
\hline- & Total number for each measure & $17,861(100)$ & $7,331(100)$ & $10,530(100)$ & $1,164(100)$ \\
\hline
\end{tabular}

*All counts for DALYs, Deaths, YLDs, and YLLs are in 1000's.

Table 28: Top twenty leading causes of Disability Adjusted Life Years (DALY), Years Lost to Disability (YLD), Years of Life Lost (YLL) and Deaths for Females - US 1996*

\begin{tabular}{|c|c|c|c|c|c|}
\hline & Cause & DALY (\%) & YLD (\%) & YLL (\%) & Death (\%) \\
\hline I & Ischaemic heart disease & $\mathrm{I}, 177(7.7)$ & $124(1.6)$ & $1,052(14.0)$ & $249(2 \mid .7)$ \\
\hline 2 & Unipolar major depression & $900(5.9)$ & $900(11.7)$ & $0(0.0)$ & $0(0.0)$ \\
\hline 3 & Cerebrovascular disease & $836(5.5)$ & $408(5.3)$ & $428(5.7)$ & $99(8.6)$ \\
\hline 4 & COPD & $612(4.0)$ & $354(4.6)$ & $257(3.4)$ & $48(4.1)$ \\
\hline 5 & Lung trachea or bronchial cancer & $550(3.6)$ & $26(0.3)$ & $523(6.9)$ & $66(5.7)$ \\
\hline 6 & Breast cancer & $515(3.4)$ & $64(0.8)$ & $450(6.0)$ & $47(4.1)$ \\
\hline 7 & Osteoarthritis & $508(3.3)$ & $506(6.6)$ & $\mathrm{I}(0.0)$ & $\mathrm{I}(0.0)$ \\
\hline 8 & Dementia and other degenerative and hereditary CNS disorders & $507(3.3)$ & $424(5.5)$ & $83(1.1)$ & $29(2.5)$ \\
\hline 9 & Diabetes mellitus & $504(3.3)$ & $274(3.6)$ & $230(3.1)$ & $34(3.0)$ \\
\hline 10 & Road traffic accidents & $459(3.0)$ & $134(1.7)$ & $326(4.3)$ & $15(1.3)$ \\
\hline 11 & Alcohol use & $409(2.7)$ & $386(5.0)$ & $23(0.3)$ & $\mathrm{I}(0.1)$ \\
\hline 12 & Asthma & $362(2.4)$ & $320(4.2)$ & $42(0.6)$ & $4(0.3)$ \\
\hline 13 & Congenital abnormalities & $352(2.3)$ & $205(2.7)$ & 147 ( 1.9$)$ & $6(0.5)$ \\
\hline 14 & Cancer colon or rectum & $234(1.5)$ & $38(0.5)$ & $197(2.6)$ & $31(2.7)$ \\
\hline 15 & Conditions arising during the perinatal period & $220(1.4)$ & $16(0.2)$ & $205(2.7)$ & $6(0.5)$ \\
\hline 16 & Lower respiratory infections & $195(1.3)$ & $10(0.1)$ & $186(2.5)$ & $46(4.0)$ \\
\hline 17 & PTSD & $194(1.3)$ & $194(2.5)$ & $0(0.0)$ & $0(0.0)$ \\
\hline 18 & HIVIAIDS & $193(1.3)$ & $49(0.6)$ & 144 (1.9) & $6(0.5)$ \\
\hline 19 & Panic disorder & $182(1.2)$ & $182(2.4)$ & $0(0.0)$ & $0(0.0)$ \\
\hline 20 & Bipolar disorder & $165(1.1)$ & $165(2.1)$ & $0(0.0)$ & $0(0.0)$ \\
\hline \multicolumn{2}{|r|}{ Total number for each measure in the top 20 causes } & $9,074(59.6)$ & $4,779(62.1)$ & $4,294(57.0)$ & $688(59.7)$ \\
\hline \multicolumn{2}{|c|}{ Total number for each measure } & $15,230(100)$ & $7,693(100)$ & $7,537(100)$ & $1,151(100)$ \\
\hline
\end{tabular}

*All counts for DALYs, Deaths, YLDs, and YLLs are in 1000's 


\section{Additional material}

\section{Additional File 1}

Global burden of disease methodology: summary overview. A summary overview of GBD methods.

Click here for file

[http://www.biomedcentral.com/content/supplementary/14787954-4-11-S1.doc]

\section{Additional File 2}

Data sources and methods for developing estimates for the incidence, mortality, prevalence, and duration of selected conditions for estimation of YLD in the United States. A detailed presentation of analytic methods, data sources, and data sets used to develop estimates for major causes of diseases and injuries.

Click here for file

[http://www.biomedcentral.com/content/supplementary/14787954-4-11-S2.doc]

\section{Additional File 3}

US burden of disease study classification system for diseases and injuries The detailed list of causes selected for the USBODI.

Click here for file

[http://www.biomedcentral.com/content/supplementary/14787954-4-11-S3.doc]

\section{Additional File 4}

US burden of disease - Detailed tabulations of deaths, YLL, YLD and DALYs. Detailed tabulations of deaths, YLL, YLD and DALYs for the 73 causes included in the USBODI by age, gender and race.

Click here for file

[http://www.biomedcentral.com/content/supplementary/14787954-4-11-S4.ppt]

\section{Additional File 5}

Epidemiological estimates. Detailed incidence by age, sex and race by disease and sequelae, included in the USBODI.

Click here for file

[http://www.biomedcentral.com/content/supplementary/14787954-4-11-S5.xls]

\section{Acknowledgements}

We wish to acknowledge:

James S. Marks for initiating the study and for his support throughout the study; Lee Anneston, George Cauthen and Ted Thompson who developed estimates for selected causes; William Eaton, Charles Helmick, Ronald Kessler, Alan Lopez, Colin Mathers, Wayne Rosamond, Richard Seelik and Bedirhan Ustun who contributed invaluable technical guidance and critically reviewed estimates; Yuliya Popova and J.A. Kurichety who contributed to the preparation of the final document; Emmanuela Gakidou and Stanislava Nikolova who edited the final document.

Disclaimer: "The views and opinions in this report represent those of the authors and not the Centers for Disease Control and Prevention."

This study was funded by an Association of Schools of Public Health; ASPH/ Centers for Disease Control and Prevention (CDC)/Agency for Toxic Substances and Disease Registry (ATSDR) Cooperative Agreement. The fund- ing source had no role in study design; in the collection, analysis, and interpretation of data; in the writing of the manuscript; and in the decision to submit the manuscript for publication.

\section{References}

I. Murray CJL, Lopez A: The Global Burden of Disease: a comprehensive assessment of mortality and disability from diseases, injuries, and risk factors in 1990 and projected to 2020 Ist edition. Cambridge, Harvard University Press; 1996.

2. Bank W: World Development Report 1993: Investing in Health New York, NY, Oxford University Press; 1993.

3. Field MJ, Gold MR: Summarizing Population Health: Directions for the development and application of population metrics Washington, D.C. National Academy Press; 1998.

4. McGinnis JM, Foege WH: Actual causes of death in the United States. JAMA 1993, 270:2207-2212.

5. Olshansky SJ, Carnes BA, Cassel C: In search of Methuselah: estimating the upper limits to human longevity. Science 1990, 250:634-640.

6. Fries JF, Koop CE, Sokolov J, Beadle CE, Wright D: Beyond health promotion: reducing need and demand for medical care. Health Aff (Millwood) 1998, I 7:70-84.

7. Pollock AM, Rice DP: Monitoring health care in the United States--a challenging task. Public Health Rep 1997, I I 2: I08-I I3.

8. Tengs TO, Adams ME, Pliskin JS, Safran DG, Siegel JE, Weinstein MC, Graham JD: Five-hundred life-saving interventions and their cost-effectiveness. Risk Anal 1995, I 5:369-390.

9. Murray CJ, Salomon JA, Mathers C: A critical examination of summary measures of population health. Bull World Health Organ 2000, 78:981-994.

10. Des J D.C., Jones A: Small world, big challenges: a report from the 9th International Congress of the World Federation of Public Health Associations. Am J Public Health 200I, 9 I: |4- I5.

II. Foege WH: The growing brown plague. JAMA 1990, 264: 1580.

12. Shortt SE: Can Alberta buck stampede of health-care globalisation? Lancet 2000, 356:1291-1292.

13. Talbot EA, Moore M, McCray E, Binkin NJ: Tuberculosis among foreign-born persons in the United States, I993-1998. JAMA 2000, 284:2894-2900.

14. Murray CJL, Michaud CM, McKenna MT, Marks JS: U.S. Patterns of Mortality by Country and Race: 1965-1994 Cambridge, MA, Harvard Center for Population and Development Studies; 1998.

15. National Center for Health Statistics CDCP: Detailed Mortality File. Hyattsville, MD, US Department of Health and Human Services; 1996.

16. Rosenberg HM, Maurer JD, Sorlie PD, Johnson NJ, MacDorman MF Hoyert DL, Spitler JF, Scott C: Quality of death rates by race and Hispanic origin: a summary of current research, 1999. Vital Health Stat 2 1999: I-I3.

17. Organization WH: International Statistical Classification of Disease and Related Health Problems 9th edition. Geneva, Switzerland, World Health Organization; 1997.

18. Peto R, Lopez AD, Boreham J, Thun M, Heath C Jr.: Mortality from tobacco in developed countries: indirect estimation from national vital statistics. Lancet 1992, 339: I268-I278.

19. Murray CJ, Kulkarni SC, Ezzati M: Understanding the coronary heart disease versus total cardiovascular mortality paradox: a method to enhance the comparability of cardiovascular death statistics in the United States. Circulation 2006, I | 3:207|-208|.

20. Mathers CD, Vos ET, Stevenson CE, Begg SJ: The burden of disease and injury in Australia. Bull World Health Organ 200I, 79:1076-1084.

21. Melse JM, Essink-Bot ML, Kramers PG, Hoeymans N: A national burden of disease calculation: Dutch disability-adjusted lifeyears. Dutch Burden of Disease Group. Am J Public Health 2000, 90: $124 \mid-1247$.

22. Lawrence RC, Helmick CG, Arnett FC, Deyo RA, Felson DT, Giannini EH, Heyse SP, Hirsch R, Hochberg MC, Hunder GG, Liang MH, Pillemer SR, Steen VD, Wolfe F: Estimates of the prevalence of arthritis and selected musculoskeletal disorders in the United States. Arthritis Rheum 1998, 41:778-799.

23. U.S. Department of Health and Human Services: Office of Disease Prevention and Health Promotion--Healthy People 2010. Nasnewsletter 2000, I 5:3. 
24. Lavizzo-Mourey R, Knickman JR: Racial disparities--the need for research and action. N EnglJ Med 2003, 349:1379-I380.

25. Wong MD, Shapiro MF, Boscardin WJ, Ettner SL: Contribution of major diseases to disparities in mortality. N Engl J Med 2002, 347:1585- 1592.

26. Woolf SH, Johnson RE, Fryer GE Jr., Rust G, Satcher D: The health impact of resolving racial disparities: an analysis of US mortality data. Am J Public Health 2004, 94:2078-2081.

Publish with Biomed Central and every scientist can read your work free of charge

"BioMed Central will be the most significant development for disseminating the results of biomedical research in our lifetime. " Sir Paul Nurse, Cancer Research UK

Your research papers will be:

- available free of charge to the entire biomedical community

- peer reviewed and published immediately upon acceptance

- cited in PubMed and archived on PubMed Central

- yours - you keep the copyright

Submit your manuscript here:

http://www.biomedcentral.com/info/publishing_adv.asp 